\title{
Mitigation of Magnetohydrodynamic Electromagnetic Pulse (MHD-EMP) Effects from Commercial Electric Power Systems
}

\author{
P.R. Barnes \\ Energy Division \\ Oak Ridge National Laboratory \\ Oak Ridge, Tennessee \\ F.M. Tesche \\ Consultant \\ Dallas, Texas \\ E.F. Vance \\ Consultant \\ Fort Worth, Texas
}

ORNL -6709

DE92. 018547

March 1992

Research Jointly Sponsored by

Defense Nuclear Agency

Washington, DC 20585

\author{
Department of Energy \\ Office of Energy Management \\ Washington, DC 20585
}

Under Interagency Agreement No. 0046.C156-Al

\author{
Prepared by the \\ OAK RIDGE NATIONAL LABORATORY \\ Oak Ridge, Tennessee 37831.6285 \\ managed by \\ MARTIN MARIETTA ENERGY SYSTEMS, INC. \\ for thie \\ U.S. DEPARTMENT OF ENERGY \\ under contract DE-ACOS-840R21400
}

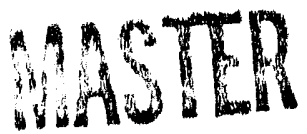

UISTRIGUTION al THIS ROCUMTN IS IINLIMITEA 
TABLE OF CONTENTS

Section Page

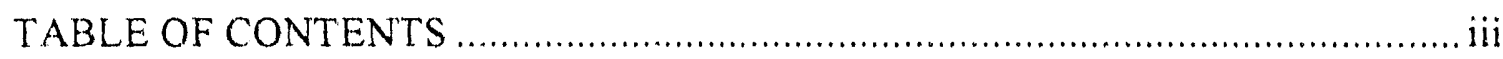

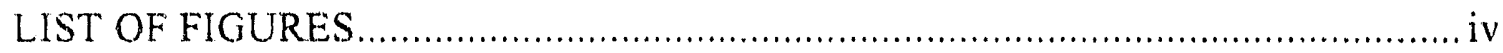

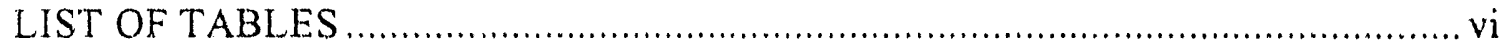

LIST OF ACRONYMS, ABBREVIATIONS AND SYMBOLS …........................ vii

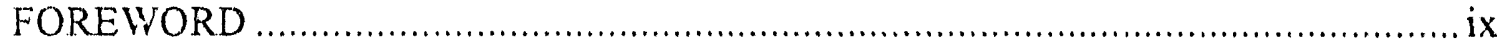

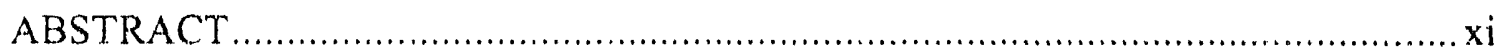

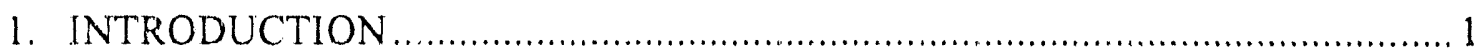

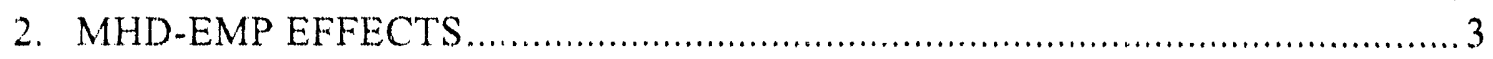

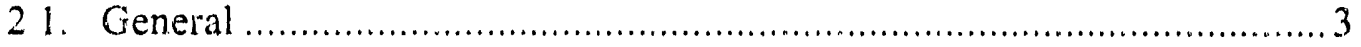

2.2. MHD-EMP Effects on Commercial Power.......................................... 3

2.3. Impacts on Critical Facilities .......................................................... 5

3. MHD-EMP MITIGATION MEASURES …............................................. 11

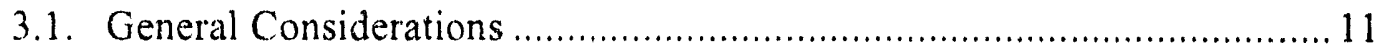

3.2. Definition of the $\mathrm{E}_{3}$ Protective Barrier ............................................... 11

3.3. Treatment of Commercial Power.................................................... 14

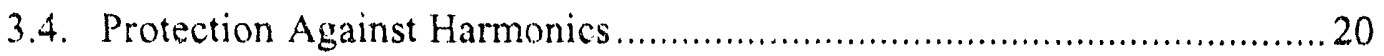

3.5. Non-Power Line Conductors ............................................................ 20

3.6. Summary of Recommended Design Practices......................................... 24

3.7. Emergency Operating Procedures ........................................................24

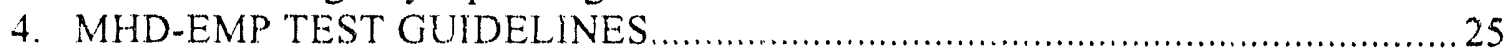

4.1. The General Simulation Concept ......................................................25

4.2. Overall Test Objectives and Procedures .............................................22

4.3. Recommended Test Configurations ................................................29

4.3.1. Long, Non-Power-System Conductors ...................................29

4.3.2. Power System Testing - Three-Phase Systems Without A Neutral Conductor ............................................................ 31

4.3.3. Power System Testing - Three-Phase Systems With A Neutral Conductor ............................................................. 35

4.3.4. Power System Testing - Three-Phase Systems With Periodically Grounded Neutral Conductors .............................37

4.3.5. Testing of a Protected Pnwer System ......................................39

4.3.6. Isolation Gap Evaluation...................................................... 40

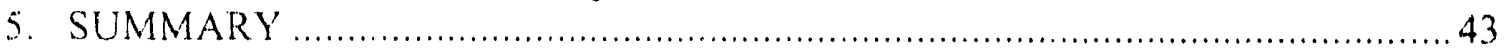

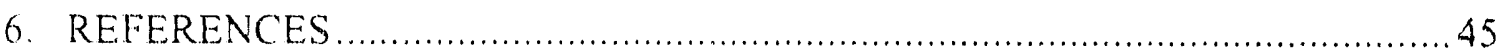

APPENDIX: THE THEORETICAL BASIS FOR MHD-EMP CURRENT INJECTION

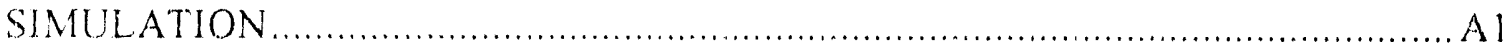




\section{LIST OF FIGURES}

Figure

Fig. 2.1. A typical power system involving transmission, subtransmission and distribution components. (a) Long transmission lines with grounded transformers, (b) Typical electrical power transmission and distribution system.

Fig. 2.2. A typical power system feeding a critical facility. (a) Large facility load served by a subtransmission line, (b) Facility load served by a distribution line. 6

Fig. 2.3. Exciting-current harmonic sequence components. 7

Fig. 2.4. Example of MHD-EMP currents entering the facility via the neutral conductor. (a) MHD-EMP currents from a neutral conductor, (b) dc circuit for example shown in part a.

Fig. 3.1. Hypothetical ground systern with alternate $\mathrm{E}_{3}$ shielding topologies.

Fig. 3.2. Recommended three-phase power service to critical facilities, (a) Delta/grounded wye coifiguration. (b) delta/grounded delta configuration.

Fig. 3.3. Recommended power system design practice. (a) Primary distribution power line configuration, (b) facility power transformers. 16

Fig. 3.4. Recommended power service configurations for large and small facility ioads. (a) Large facility served by a loop subtransmission system, (b) single phase load served by two phases of a three-phase system

Fig. 3.5. Protection of a power system using a rotary isolator

Fig. 3.6. Protection against harmonics. (a) Harmonic filter protection,

(b) harmonic detection and switching.

Fig. 3.7. Recommended design practice for non-power line conductors. 22

Fig. 3.8. Mitigation methods for an electro-optic converter on an audio/data cable

(a) Commercial power feed, (b) power feed from the facility.

Fig. 4.1. A simple simulation of the MHD-EMP excitation of a long line. (a) Physical line configuration, (b) line replaced by a Thevenin equivalent MHD-EMP pulser. 
Fig. 4.2. Simulation Configurations for a Long, Isolated Line. (a) $E_{3}$ pulser in series (recommended), (b) $E_{3}$ pulser shunted across line (not recommended).

Fig. 4.3. $E_{3}$ pulser excitation of a three-phase distribution line. (a) Pulser located in the transformer neutral (recommended), (b) pulsers located in the phase conductors (not recommended).

Fig. 4.4. Three-phase line excited by shunt sources (not recommended).

(a) Three $E_{3}$ pulsers, (b) one $E_{3}$ pulser feeding with a three-phase winding.

Fig. 4.5. $E_{3}$ simulation for a three-phase line with neutral conductor. 36

Fig. 4.6. $\mathrm{E}_{3}$ simulation for a three phase line with neutral conductor and an ungrounded delta load.

Fig. 4.7. $E_{3}$ simulation for three-phase systems with a periodically grounded neutral. 38

Fig. 4.7. $E_{3}$ simulation for three-phase systems with a periodically grounded neutral. 38

Fig. 4.9. E E $_{3}$ pulser configuration for testing a protected facility. 40

Fig. 4.10. E E $_{3}$ testing of buried facilities. 


\section{LIST OF TABLES}

Table

Page

Table 2.1. Limited survey of commercial-electric power characteristics at sample facilities... 


\section{LIST OF ACRONYMS, ABBREVIATIONS AND SYMBOLS}

$\begin{array}{ll}\text { A } & \text { amperes } \\ \text { AC } & \text { alternating current } \\ \text { D } & \text { largest facility dimension } \\ \text { DC } & \text { direct current } \\ \text { DoD } & \text { U.S. department of defense } \\ \text { EMP } & \text { electromagnetic pulse } \\ \text { ESP } & \text { earth-surface potential } \\ E_{1} & \text { the early-time HEMP environment } \\ E_{2} & \text { the intermediate-time HEMP environment } \\ E_{3} & \text { the MHD-EMP late-time HEMP } \\ \text { GIC } & \text { geomagnetically induced current } \\ \text { GMD } & \text { geomagnetic disturbance } \\ \text { HEMP } & \text { high-altitude electromagnetic pulse } \\ \text { Hz } & \text { hertz } \\ \text { I } & \text { current } \\ l_{\text {exc }} & \text { transformer excitation current } \\ \text { kV } & \text { kilovolts } \\ \text { kVA } & \text { kilovolts times amperes } \\ \text { L } & \text { line length } \\ \text { m } & \text { meter } \\ \text { MHD-EMP } & \text { magnetohydrodynamic electromagnetic pulse } \\ \text { MOV } & \text { metal oxide varistor } \\ \text { POE } & \text { points of entry } \\ \text { PVC } & \text { polyvinyl chloride } \\ R_{\mathrm{S}} & \text { pulser resistance } \\ \text { UPS } & \text { uninterruptable power supply } \\ V_{S} & \text { pulser voltage } \\ \Omega & \text { ohms } \\ & \end{array}$


(Blank) 


\section{FOREWORD}

This work was sponsored by the Defense Nuclear Agency (DNA) under Interagency Agreement No. 0046-C156-Al with the U.S. Department of Energy (DOE) and was conducted under DOE Contract No. DE-AC05-840R21400 with Martin Marietta Energy Systems, Inc., manager of the Oak Ridge National Laboratory. Assistance in this effort was provided by two subcontractors to Martin Marietta Energy Systems: F.M. Tesche and E.F. Vance, Consultants. 
(Blank) 


\begin{abstract}
A large nuclear detonation at altitudes of several hundred kilometers above the earth distorts the earth's magnetic field and produces a strong magnetohydrodynamic electromagnetic pulse (MHD-EMP). This can adversely affect electrical power systems. In this report, the effects of this nuclear environment on critical facilities connected to the commercial power system are considered. Methods of mitigating the MHD-EMP impacts are investigated, and recommended protection schemes are presented. Guidelines for testing facilities to determine the effects of MHD-EMP and to validate the mitigation methods also are discussed.
\end{abstract}


(Blank) 


\section{INTRODUCTION}

A large nuclear detonation at altitudes of several hundred kilometers above the earth will distort the earth's magnetic field, resulting in a strong magnetohydrodynamic electromagnetic pulse (MHD-EMP) ${ }^{1}$. This electromagnetic $(E M)$ environment is also referred to as $E_{3}$, since it is the third EM field component--occurring at late times - that characterizes the high-altitude elertromagnetic pulse (HEMP) produced by an exoatmospheric nuclear burst. MHD-EMP is similar to the environment produced by a solar geomagnetic storm, in that it is global in extent and low in frequency (less than $1 \mathrm{~Hz}$ ); however, the $\mathrm{E}_{3}$ pulse is much more intense, with a far shorter duration, than the environment produced by a geomagnetic storm.

It has been known for over 30 years that geomagnetic storms have the potential to damage or operationally impair communications and electric power systems. From an engineering perspective, the interaction between the impressed magnetic signal and the earth can give rise to a tangential electric field in the earth. Over a finite distance, an earth-surface potential (ESP), or voltage, is induced. For power lines or other long conductors that are grounded at both ends, the ESP stimulus results in a circulating current in the line, with the earth serving as a return path. This very low frequency "quasi-dc" current is referred to as a geomagnetically induced current (GIC). The geomagnetic disturbance (GMD) associated with $\mathrm{E}_{3}$ could induce GICs that are significantly more intense than those caused by solar storms, with a duration from a few seconds to hundreds of seconds. Due to its high intensity, MHD-EMP can interact with power transmission and distribution lines that are normally not affected by solar storms. This interaction can adversely impact Department of Defense (DoD) critical facilities.

In this report, the possible $E_{3}$ effects on critical facilities connected to the commercial power system are considered. Methods of mitigating the MHD-EMP impacts are investigated, and recommended protection is presented. Guidelines for testing facilities to determine the effects of $E_{3}$ and to validate the mitigation methods also are discussed. 
(Blank) 


\section{MHD-EMP EFFECTS}

\subsection{GENERAL}

Many of the effects of the $E_{3}$ environment can be inferred from the effects of geomagnetic storms on electrical systems. On March 13, 1989, a geomagnetic storm caused a widespread power outage in the Hydro-Quebec electrical system. This particular event has been studied extensively ${ }^{2}$, and has led to a deeper understanding of the effects of GICs on power systems. It must be remembered, however, that there are several important differences between the geomagnetic storm environments and those produced by a HEMP:

- The $E_{3}$ excitation of a system occurs after it has been struck by the $50-k$ Vim $E_{1}$ HEMP excitation and by the less-intense $E_{2}$ fields. Consequently, the overall state of the power system may not be the same as in the case of excitation by a quasi-dc GMD.

- The $E_{3}$ excitation typically lasts for a much shorter periud of time than does the geomagnetic storm excitation.

- The estimated $E_{3}$ GIC induced in the system can be much larger that those for a naturallyoccurring GMD.

Past experience with geomagnetic storms has provided insight into probable effects of MHD.EMP on the electrical power system and on the critical facilities it feeds. These are discussed in the subsections that follow.

\subsection{MHD-EMP EFFECTS ON COMMERCIAL POWER.}

Long transmission lines with grounded wye transformers (Fig. 2.1 a) will have quasi-dc currents induced by MHD-EMP. A typical electric power transmission, subtransmission, and distribution system is shown in Fig. 2.1b. The auto transformer in this figure permits some of the de current induced in the 500-kV system to flow into the $161-\mathrm{kV}$ line. In a stud: of an actual utility system, an MHD-EMP environment with a peak of $24 \mathrm{~V} / \mathrm{km}$ resulted in dc currents up to several hundred amperes $(A)^{3,4}$. This caused transformers to saturate and resulted in harmonic generation and large reactive power demands. Such disturbances can cause relay trips and major power blackouts. Severe voltage swings or voltage depression can also occur and may precede blackout: such voltage swings and or brownout conditions can damage customer equipment. 


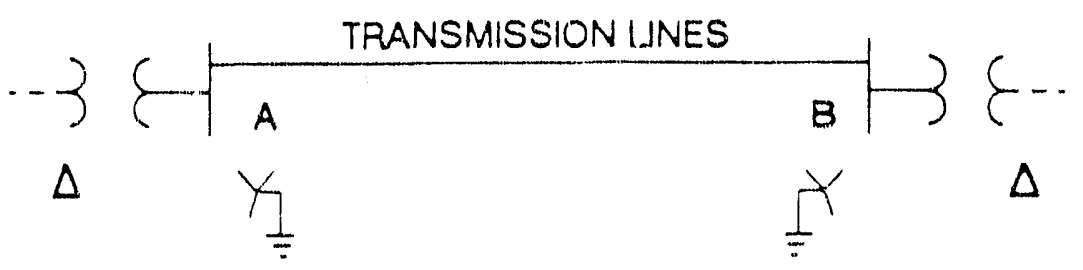

(a)

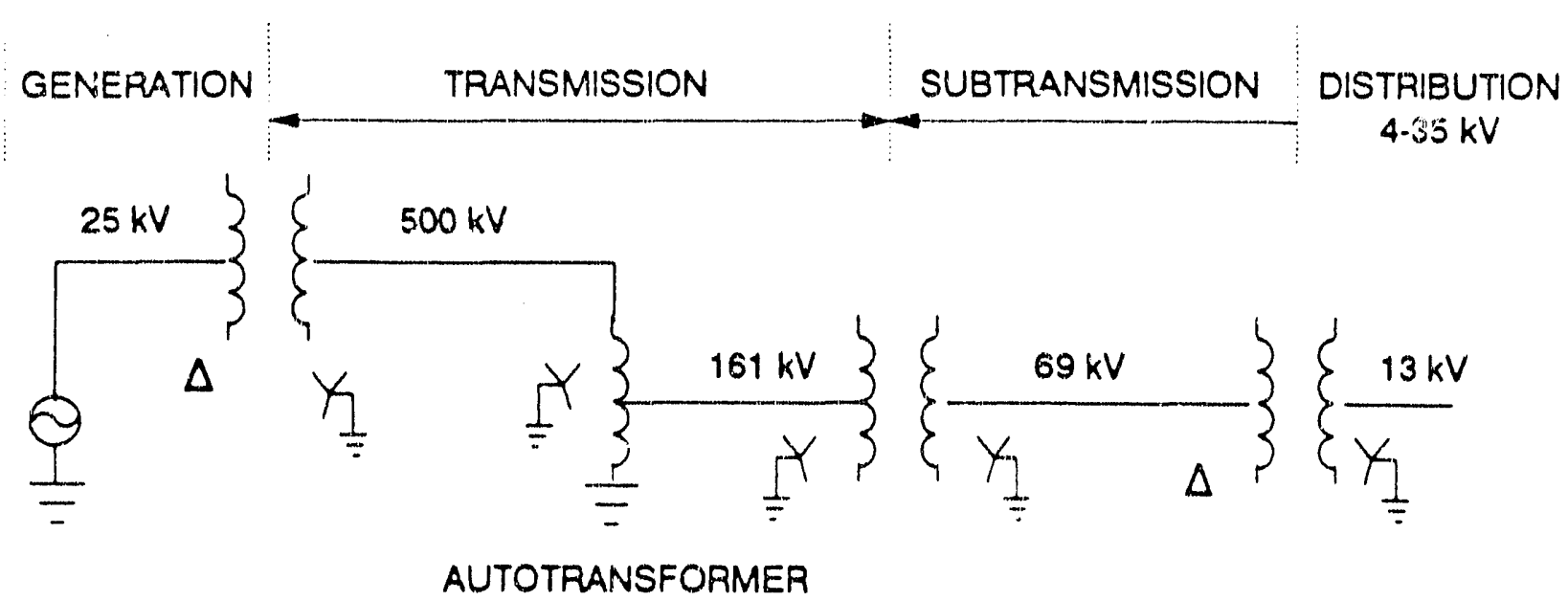

(b)

Fig. 2.1. A typical power system involving transmission, subtransmission and distribution components. (a) Long transmissiun lines with grounded transformers, (b) Typical electrical power transmission and distribution system. 
$E_{3}$ can also affect subtransmission and distribution systems by causing harmonic distortion and voltage depression. The voltage regulators at the substation will attempt to correct for low voltage levels on distribution circuits. This attempt can result in overvoltages when the $E_{3}$ stimulus decays to a low value if a blackout has not occurred.

\subsection{IMPACTS ON CRITICAL FACILITIES}

Critical facilities with large loads are served by subtransmission lines. Facilities with smaller loads are generally served by a distribution line. Both of these cases are illustrated in Fig. 2.2, and a limited survey of the characteristics of commercial power at five typical facilities is shown in Table 2.1. Although most facilities use three-phase power, small facilities may be served by single-phase power.

Table 2.1. Limited survey of commercial-electric power characteristics at sample facilities*

\begin{tabular}{cccc}
\hline Facility & Voltage(kV) & kVA & Primary/sec. \\
A & $34.5 / 4.16$ & 5000 & Delta/wye \\
B & $69 / 4.16$ & 5000 & Delta/wye \\
C & $115 / 4.16$ & 7000 & Delta/wye \\
D & $3.2 / 0.480$ & 2000 & Delta/wye \\
E & $22.9 / 4.16$ & 7500 & W'ye/wye \\
\hline
\end{tabular}

- Source: Air Force Space Command.

A disturbance in the electric power system caused by MHD-EMP can result in harmonic distortion and large voltage swings or voltage suppression. An example of harmonic components generated by saturated transformers is shown in Fig. 2.3, taken from ref. 6 . The response of a facility to such an abnormal power waveform may be difficult to predict exactly, but possible responses can be hypothesized. 


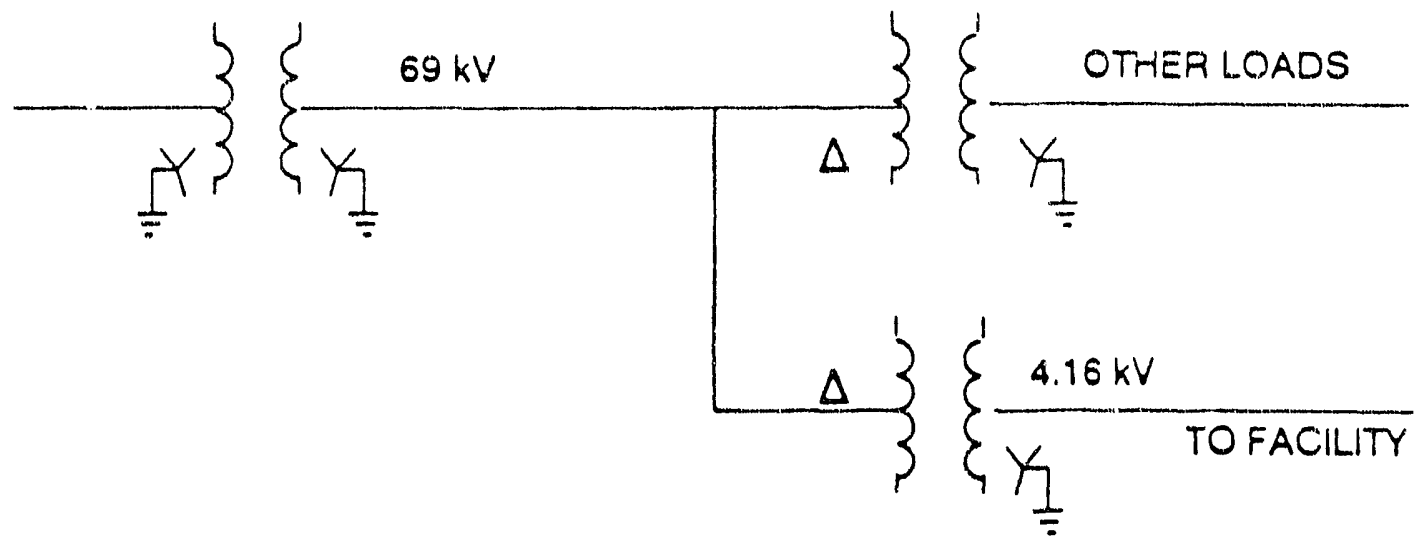

(a)

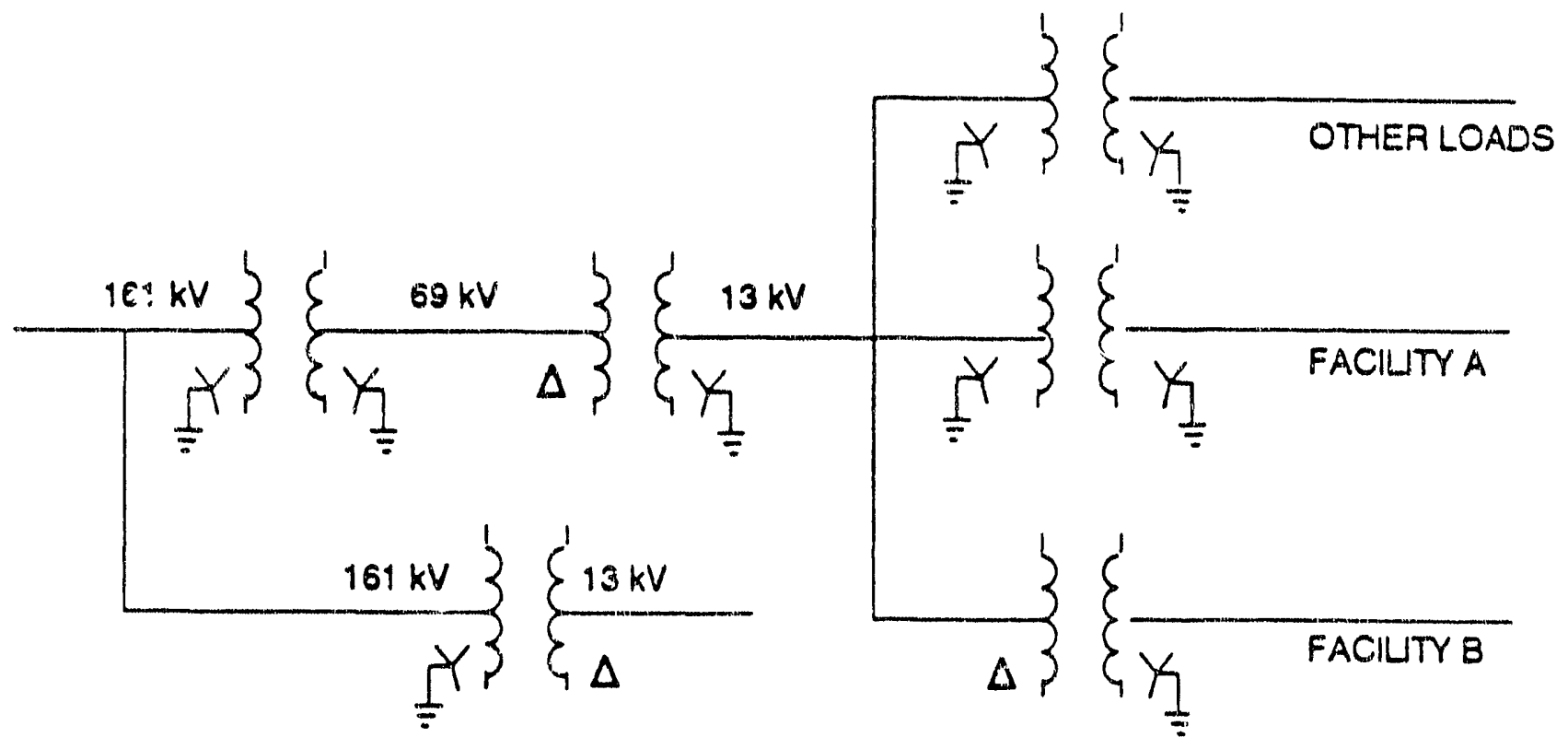

(b)

Fig. 2.2. A typical power system feeding a critical facility. (a) Large facility load served by a subtransmission line, (b) Facility load served by a distribution line. 

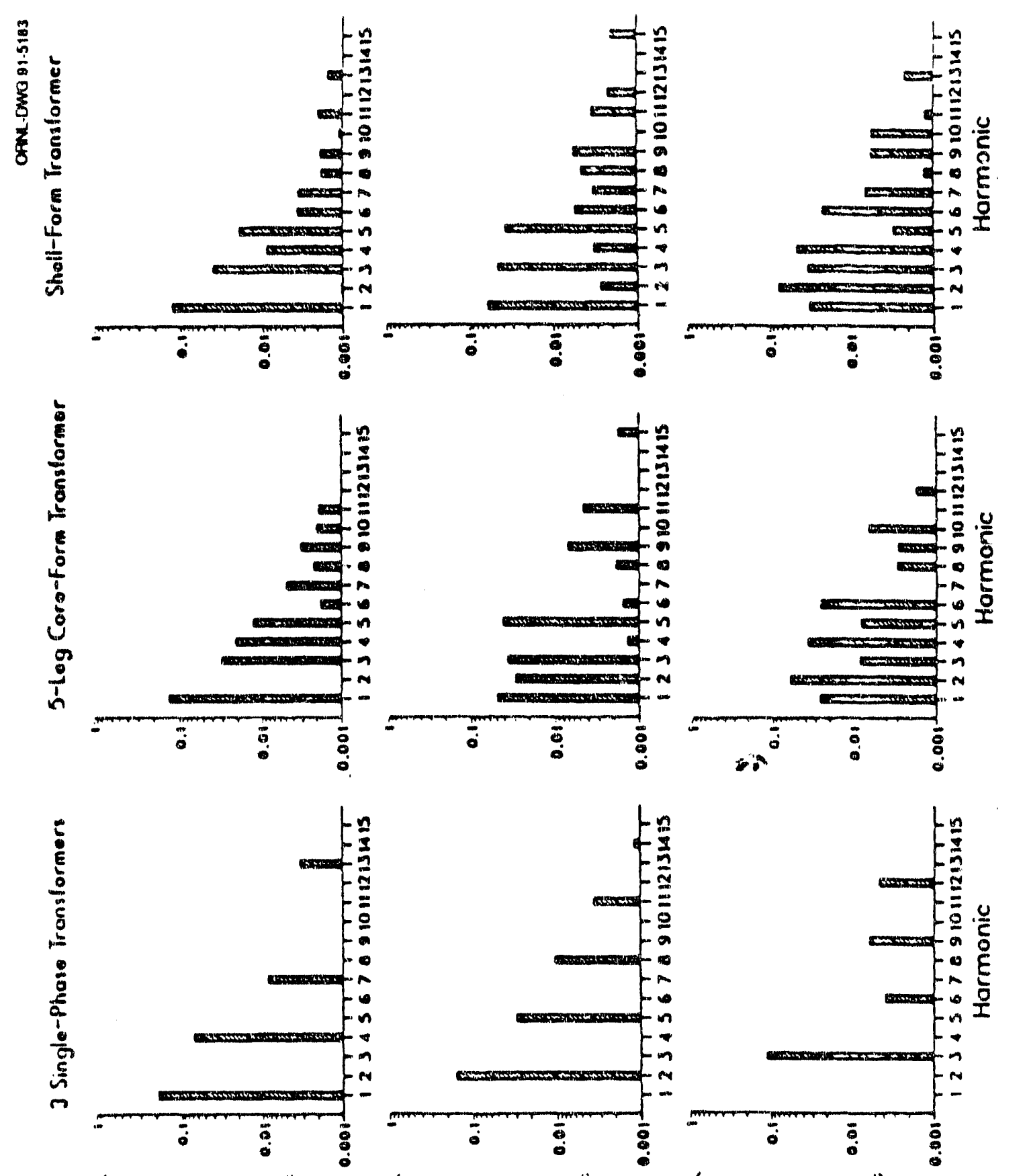

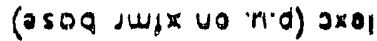

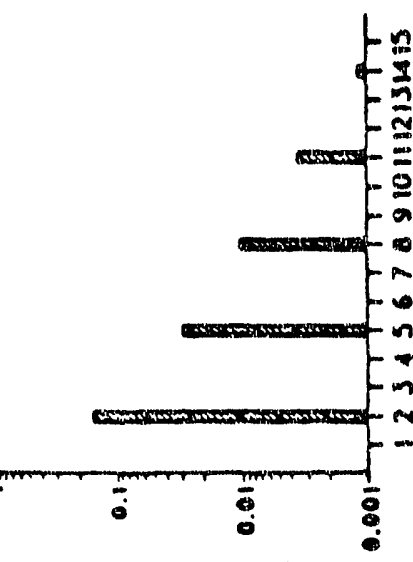

(asog dw/k vo ndd) $2 \times$.

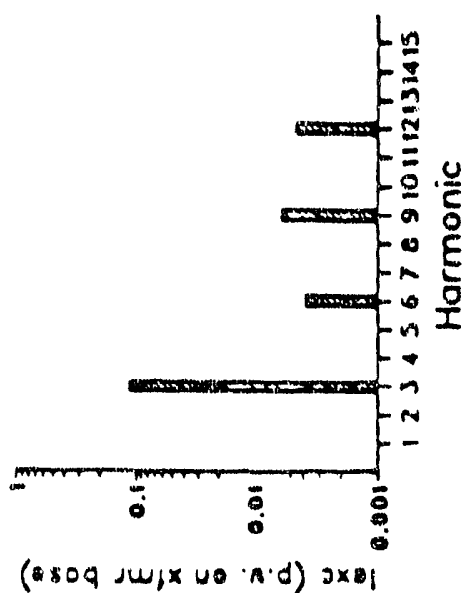


Abnormal power voltage levels can cause transfer switches to trip and disconnect the facility from the commercial power line. Conversely, the harmonic distortion in the $60-\mathrm{Hz}$ waveform may inhibit the operation of logic circuits within the transfer switch from responding, resulting in consequential equipment damage. Harmonic voltages and currents may interact with the uninterruptable power supply (UPS) and damage the system. Harmonic currents may also rrip breakers, blow fuses, and damage motors within the facility, thereby disrupting operations during a critical time period ${ }^{7}$. Harmonic voltages and currents can also interfere with communications and electronic control ${ }^{8}$. Large facilities connected to radial subtransmission transformers at distribution substations will have far less problems with harmonics, since no $\mathrm{E}_{3}$ currents will be induced in the subtransmission lines.

Any other conductor connected to the facility, such as telephone lines, water pipes, or the power neutral wire, may have significant $E_{3}$ currents induced in them. An example of MHDEMP currents entering a facility via the power neutral is shown in Fig. 2.4. These currents may also cause transformers within the facility to saturate and generate harmonics, interfere with motor operation, and cause problems with the UPS. The problems that harmonics can cause for computers and other electronic equipment, as well as the facility power distribution system, are discussed further in ref. 8. Currents on other long conductors, such as water pipes and phone lines, could cause similar problems, since such conductors are all connected to the facility ground system. Resonances in the power system and the facility can cause high crest voltages and consequential component failures. 


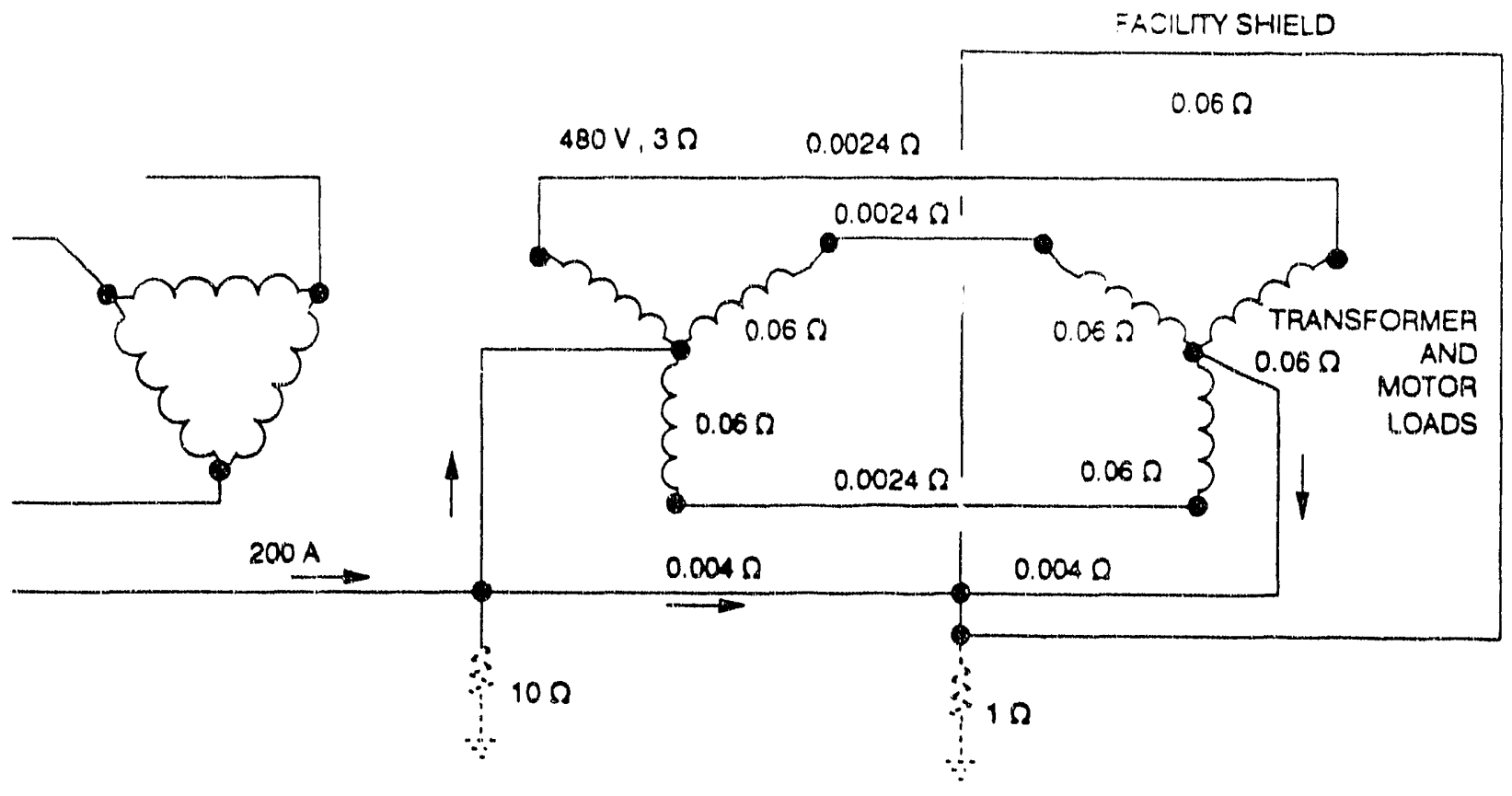

(a)

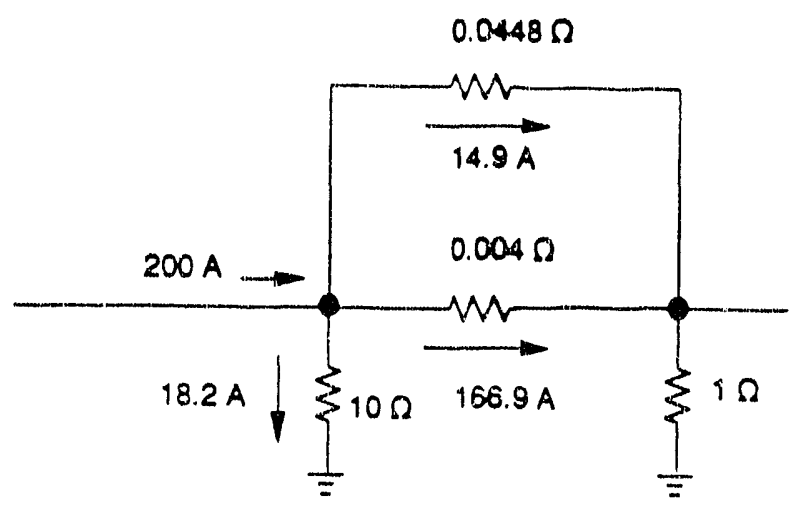

(b)

Fig. 2.4. Example of MHD-EMP currents entering the facility via the neutral conductor. (a) MHD-EMP currents from a neutral conductor, (b) de circuit for example shown in part a. 
(Blank) 


\section{MHD-EMP MITIGATION MEASURES}

\subsection{GENERAL CONSIDERATIONS}

Because the MHD-EMP is induced by potential gradients of a few tens of volts per $\mathrm{km}$, · distribution lines have open-circuit voltages of only a few thousand volts induced on them. Sizable currents can flow only if the circuit resistance is small (i.e., a few ohms). Therefore it is easy to control the MHD-EMP currents by interrupting the circuit with a high impedance or gap that will withstand the modest open-circuit voltages. On the other hand, it is difficult to control the quasi-dc currents if they are allowed to flow onto the facility shield, since the shield and lowpass filters are transparent to these currents (i.e., some of the currents will flow through any interior paths that may exist).

Note that this is quite different from the $E_{1}$ problem, in which the $E_{1}$ field induces very large open-circuit voltages on conductors with characteristic impedances of a few hundred ohms. The use of current interruption techniques for $E_{1}$ is discouraged because of the very large opencircuit voltages (up to $1 \mathrm{MV}$ ) t'lat the interrupters must withstand. On the other hand, it is quite easy to divert the $E_{1}$ current through low-impedance surge arresters and filters to the outside of the facility shield, where they remain excluded from the facility interior.

To mitigate the effects of MHD.EMP on a facility, attempts must be made to isolate long conductors from the building enclosure. In addition, the generation of $60-\mathrm{Hz}$ harmonics and large voltage swings in the commercial power system must be eliminated. The power system transfer switch at the facility power entrance should respond to the voltage fluctuations as long as the harmonics have not interfered with the switch control circuitry. The major sources of MHD-EMP-induced currents are the commercial power lines and neutral; the neutral current indirect coupling to the facility power or ground system via the metal fence, powered gate, parking lights, etc.; metal water pipes; phone lines; and other long conductors that enter or approach the facility. The major source of harmonics is the commercial power system.

\subsection{DEFINITION OF THE E 3 PROTECTIVE BARRIER}

For understanding and designing EMP protection for electrical systems, the concept of electromagnetic topology has been introduced 9,10 . This theory suggests that well-protected sys- 
tems can be viewed as having one or more nested shields, or EM barriers, which impede the passage of the EMP energy from the outside to the interior of the sy'stem. It is required that all openings, or points of entry (POEs), of the barrier be either closed, or suitably protected with an electrical device to reduce or eliminate the EMP stress entering the system.

This topological shielding concept (sometimes referred to as zoning) has been most frequently applied to protection of systems against the $E_{1}$ component of HEMP. For this earlytime EM environment, the conducting enclosure of a system is usually viewed as comprising the first, or primary, barrier. Thus, for a ground-based facility, the conducting walls of an outer steel liner enclosing the building would be considered as the primary shielding element in the first barrier. All other $E_{1}$ protection devices are located at penetration points on this barrier.

With this topological theory, protecting a system from an external EMP environment becomes simple to understand: either the coupling of the external environment to lines leading to the system is controlled and reduced, the propagation of the coupled energy to the system enclo. sure is interrupted, or the penetration of the EMP energy into the facility at the barrier is controlled. Of these three techniques, the controlling of the penetration of unwanted signals through the barrier is the most commonly applied protection measure .

As discussed in ref. 10, the definition of the shielding topology of a system is not unique. It can change depending on the nature of the protection devices installed and on the frequency of the EM environment. For example, a permanently installed (i.e., welded) door cover may be thought of as effectively sealing a door aperture, thereby modifying the system topology. Similarly, a conducting facility shield might be very effective at preventing high-frequency signals from entering, but the quasi-dc currents from MHD-EMP can easily pass through the facility shield. This is because the facility behaves as a resistive network at low frequencies.

This ambiguity of the topological shield at low frequencies poses a problem for MHDEMP protection of a facility. Fig. 3.1 illustrates a hypothetical ground-based facility that is fed by the commercial power network through a transformer mounted outside the facility. For the $E_{1}$ environment, the facility enclosure is usually considered to be the primary barrier. This is labeled as barrier 1 in the figure. For this case the transformer is located outside the barrier and does not constitute part of the $\mathrm{E}_{1}$ HEMP protection.

For $E_{3}$, however, the situation can be quite different. Because of the ill-defined nature of the shielding surface at low frequencies, barrier 2 in the figure is just as valid a choice as is barrier 1. In this case, the transformer becomes a hardening element in the protection scheme. As has been noted previously, delta-wye transformers can be very effective in interrupting the MHD-EMP-induced currents on a power systern, and the possibility of considering the 
transformer as a protection element is consistent with the topological concepts of ref. 10 .

The choice of the barrier geometry and the definition of the hardening elements can be important in a practical sense. MIL-STD-188-125 (ref. 11) requires that pulse injection testing at the facility barrier be conducteo with a standard $E_{3}$ pulse that is derived from long-line coupling calculations. If the facility barrier for the quasi-dc environment were chosen to include the transformer, as is the case with barrier 2 in Fig. 3.1, the pulser should be located at point B. Because there is no attenuation between the long line and the barrier entry point to reduce the incoming $E_{3}$ pulse, testing with the defined threat level of ref. 11 is reasonable at this location. However, if the topological shield is chosen to be barrier 1, the required testing should be conducted at point $A$. The actual $E_{3}$ stress at this point, however, will be reduced considerably by the presence of the transformer. The required test levels of MIL-STD-188-125 do not take this additional attenuation into account. Testing at this location with the requirements of ref. 11 will provide responses of the system that are too large, and may lead to unwanted damage within the facility.

In the discussions of $\mathrm{E}_{3}$ protective measures for the power system that follow in this section, the isolation offered by a transformer plays a crucial role. We will view the transformer as being a protective element in the $E_{3}$ shielding topology, if it is located close (say within 25 meteis) to the facility, and if it provides attenuation of the $E_{3}$ pulse. However, if the transformer is located far from the facility and is able to affect the $E_{3}$ surge levels experienced by the facility, we view the device as part of the $E_{3}$ coupling and propagation process, and recognize that it will modify the MHD-EMP current level at the facility from that specified in MIL-STD-188-125.

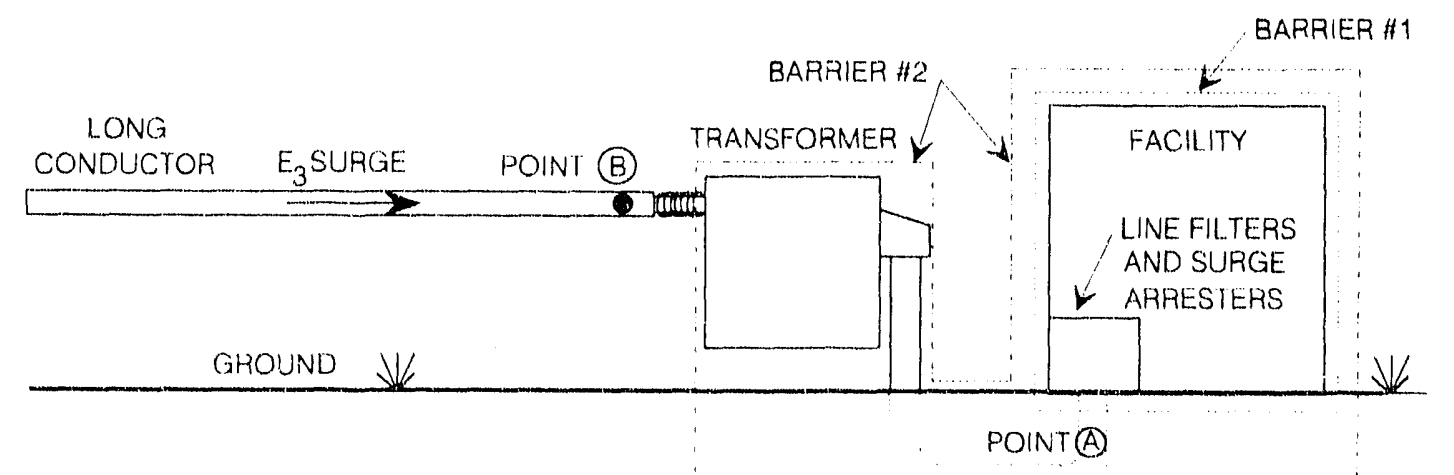

Fig. 3.1. Hypothetical ground system with alternate $\mathrm{E}_{3}$ shielding topologies. 


\subsection{TREATMENT OF COMMERCIAL POWER}

A distribution transformer can serve as a protective element in a barrier against the quasido MHD-EMP-induced power line currents when a primary delta winding is used (Fig. 3.2). As seen from an examination of the dc current paths, the $E_{3}$ current flows only in the neutral circuit of the primary, since the primary delta winding of the transformer is open-circuited. The delta winding will also provide some protection against harmonic distortion, since it will not pass zero-sequence harm nics.

Fig. 3.3a shows a more realistic configuration for a facility, having an incoming 3-phase power line with underground service to the transformer and the facility. In this case, the $E_{3}$ shielding topology of the facility is taken to be barrier 2 of Fig. 3.1. For $E_{3}$ protection, the primary neutral conductor from the power line should be terminated a distance of at least twice the greatest facility dimension to reduce neutral current coupling to the facility. The recommended grounding scheme for the facility and power system is also illustrated in the figure.

The primary circuit of the transformer should be protected against surges at the last pole by surge arresters connected to a multiple-rod ground to reduce the grounding resistance. The facility transformer should be protected by surge arresters and fast-blow fuses or fast responding circuit breakers (Fig. 3.3b). In the event of a fault in the primary winding to ground or the secondary winding, the primary fuses will blow and disconnect the transformer from the primary circuit in less than a second. No $E_{3}$ currents will enter the facility due to a fault on the highvoltage side of the transformer, since the line will be disconnected before the quasi-de currents can develop.

The quasi-dc $E_{3}$ currents flowing through the delta winding of the facility transformer will be zero for a balanced system. However, slight imbalances in the resistance to ground among the three-phase $s$ will allow some $E_{3}$ currents in the delta winding. To assure a reasonably balanced quasi-dc circuit, each phase should have an equal number of similar size grounded transformers in the same vicinity along the line. Smaller single-phase transformers may be disconnected from the line during an MHD-EMP event, since power fuses with ratings up to $15 \mathrm{~A}$ will open in a few tenths of a second for de currents on the order of a $100 \mathrm{~A}$. Therefore, it is important to balance the circuit by using equal-sized transformers with similar fuse sizes along the line. 


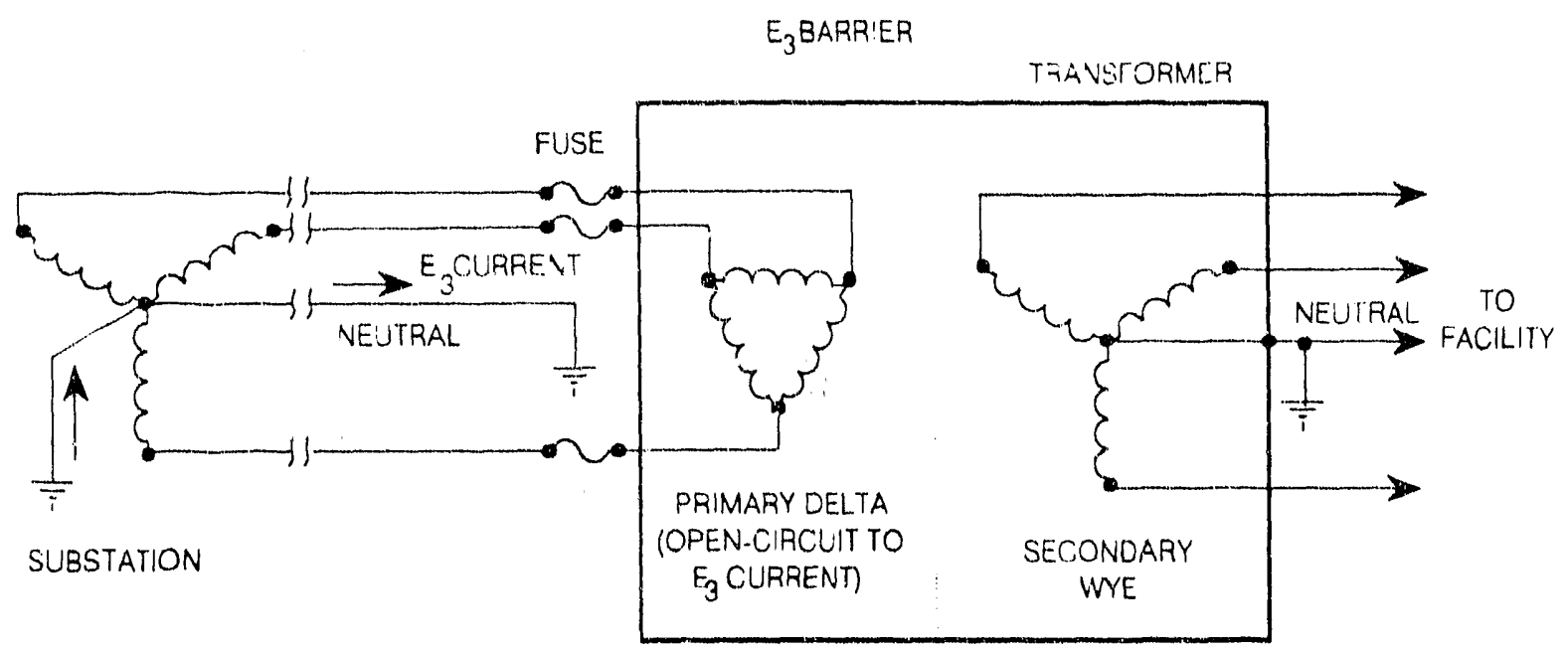

(a)

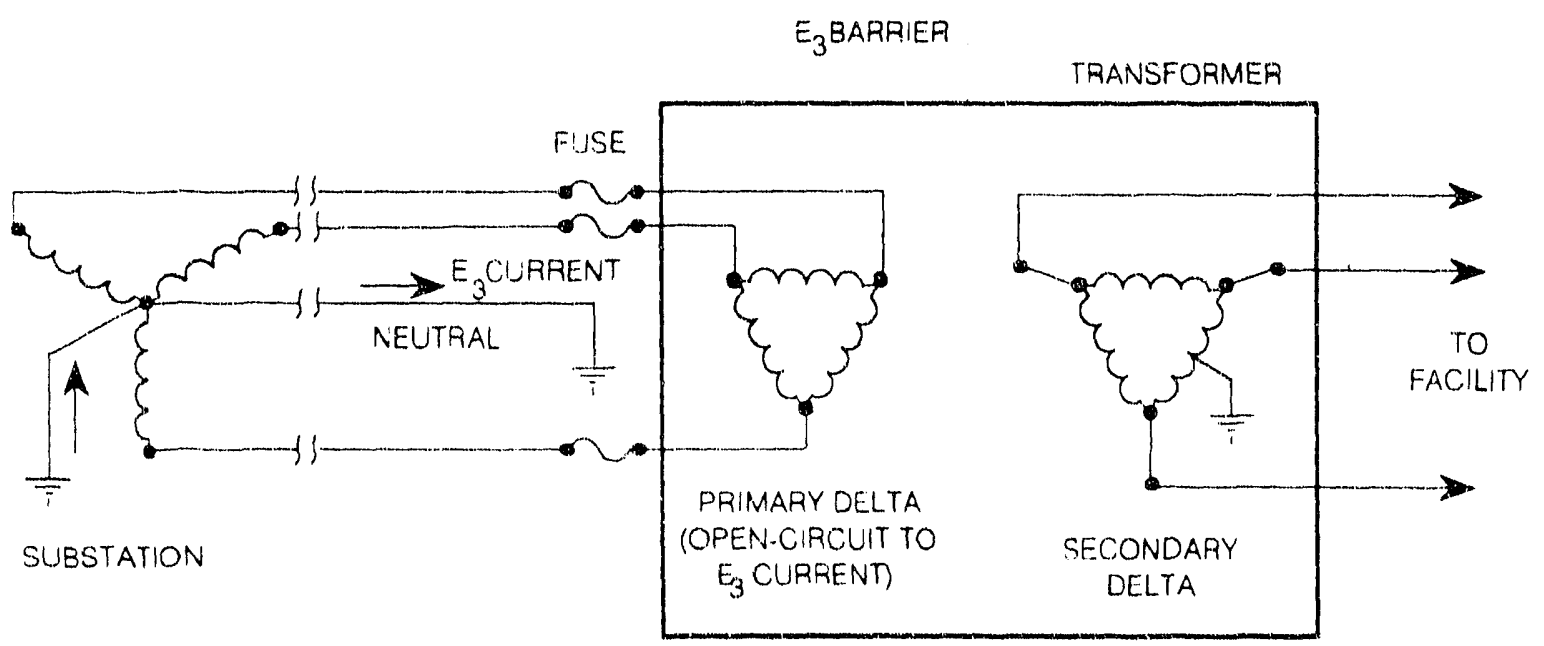

(b)

Fig. 3.2. Recommended three-phase power service to critical facilities. (a) Delta/grounded wye configuration, (b) delta/grounded delta configuration. 


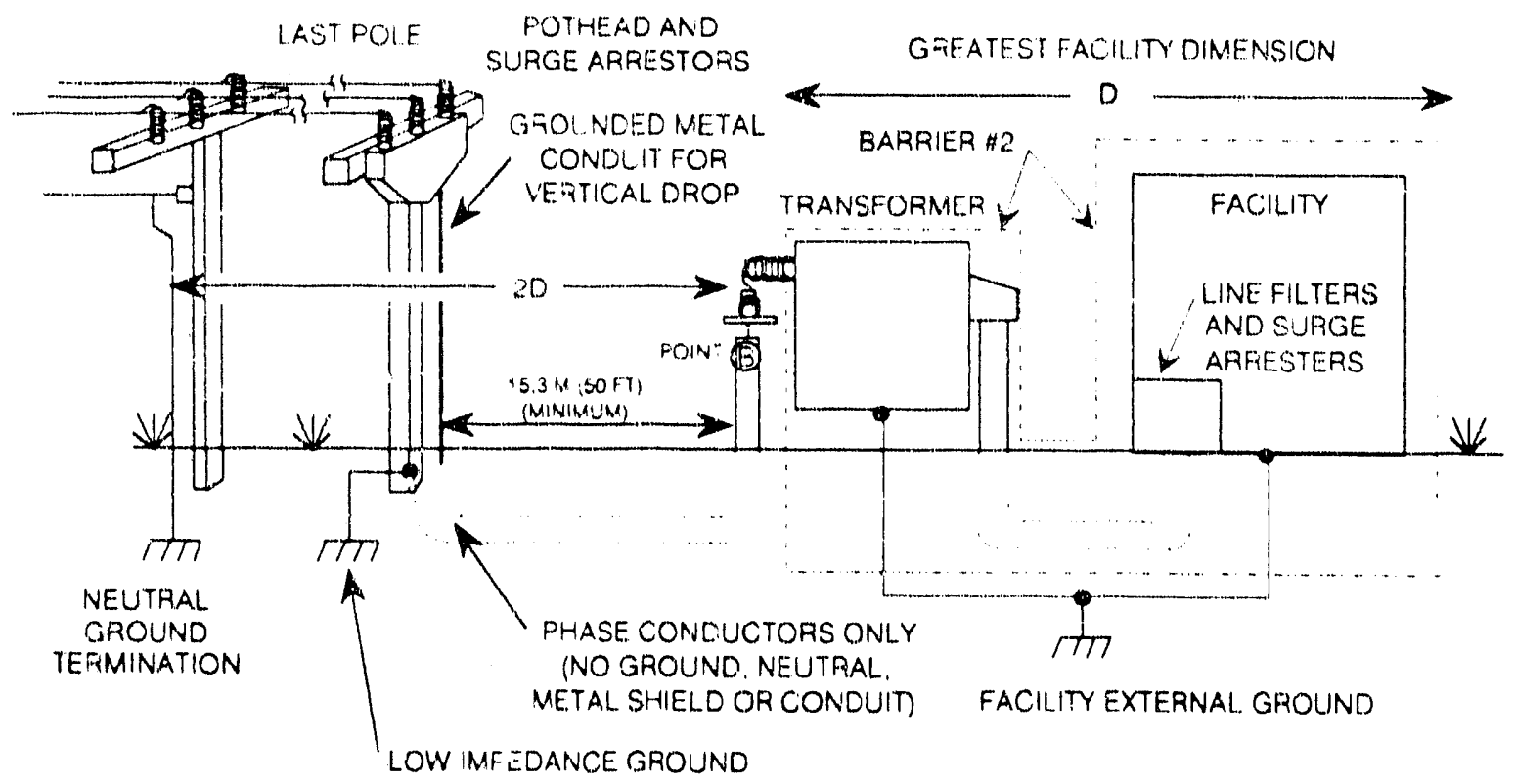

(a)

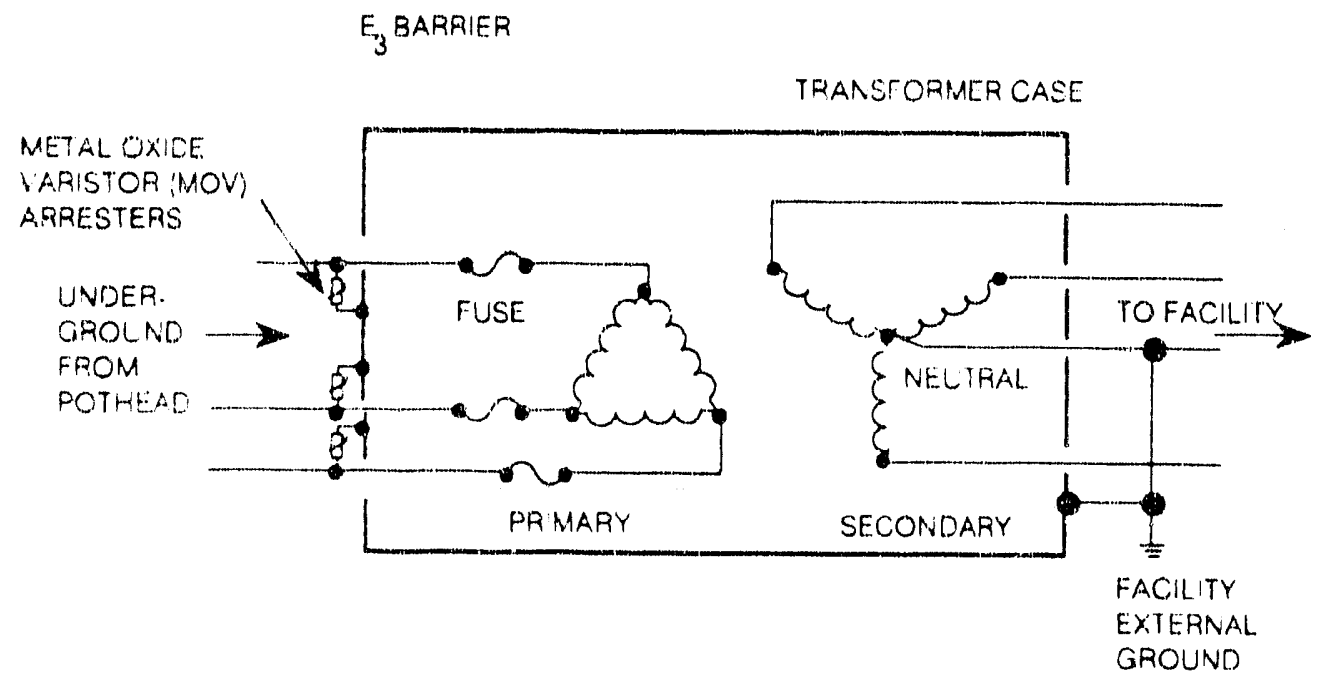

(b)

Fig. 3.3. Recommended power system design practice. (a) Primary distribution power line configuration, (b) facility power transformers. 
There are two alternatives to balancing the distribution circuit for eliminating $E_{3}$ currents in the facility transformer. A uniground three-wire (also called a three-wire delta) distribution system could be used. This type of distribution is used in portions of California, and involves placing the loads only across the phase conductors, with no connection to the ground or neutral. However, it is not likely that a utility will change a multigrounded line to a unigrounded line, due to the expense and changes required for relay protection. Another mitigation approach is to install series capacitors at the substation; series capacitors currently are used in distribution circuits for voltage control ${ }^{2}$. These capacitors will eliminate dc currents in the transformer at the substation, as well as in all of the other transformers in the circuit. This will greatly reduce the harmonic distortion, since no harmonics will be generated locally. However, this also is a costly solution.

For a large facility connected to a subtransmission line, delta/grou'.ded wye transformers are normally used in distribution substations and large industrial loads. To prevent GIC on the subtransmission line, a radial or loop configuration with power supplied by one bulk power transformer at a time (Fig. 3.4a) should be used. The subtransmission line should be configured as a unigrounded system to reduce harmonic distortion and voltage suppression at the subtransmission level.

Small facilities may use single-phase power. For single-phase service, a delta distribution type arrangernent can be employed, as shown in Fig. 3.4b. The two phases connected to the primary winding of the facility transformer should be balanced in a similar manner as that described for a three-phase delta system.

For small facilities with power requirements of $500 \mathrm{kVA}$ or less, $100 \%$ power line isolation can be achieved by a rotary power conditioner consisting of a motor, flywheel, dielectric shaft, and synchronous generator (Fig. 3.5). For a 500-kVA rated capacity, the installed cost is about $\$ 130,000$ (ref. 13). This approach will provide both $E_{1}$ and $E_{3}$ protection and will meet commurications security requirements (TEMPEST). 


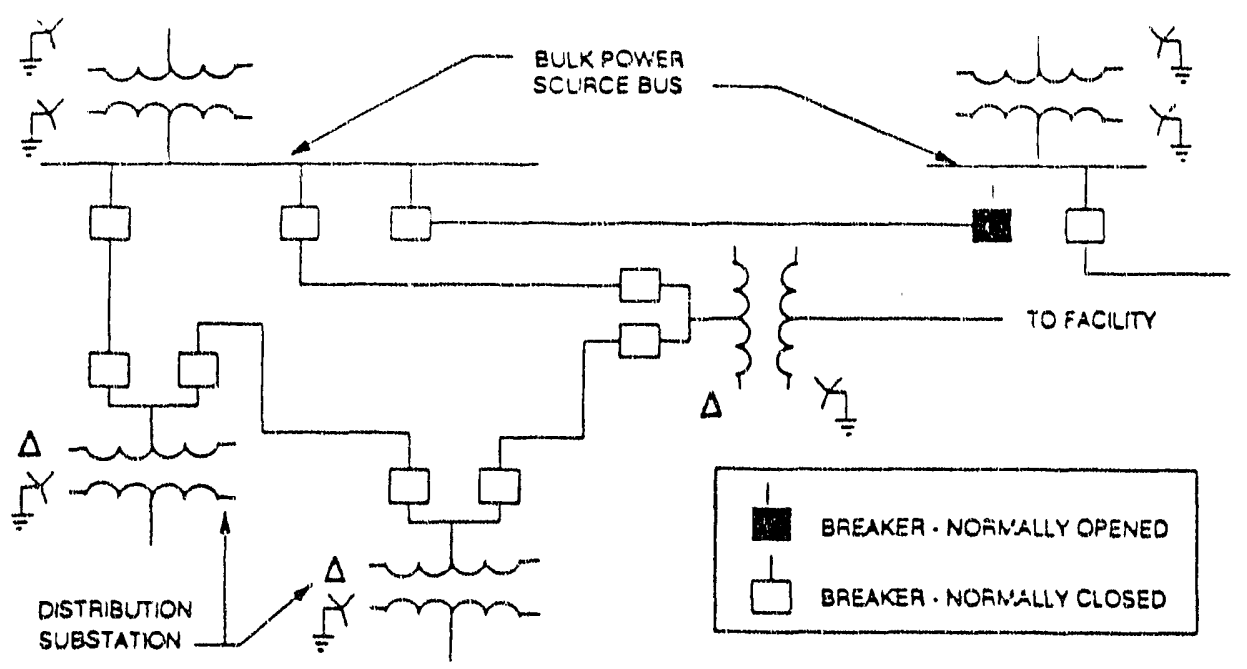

(a)
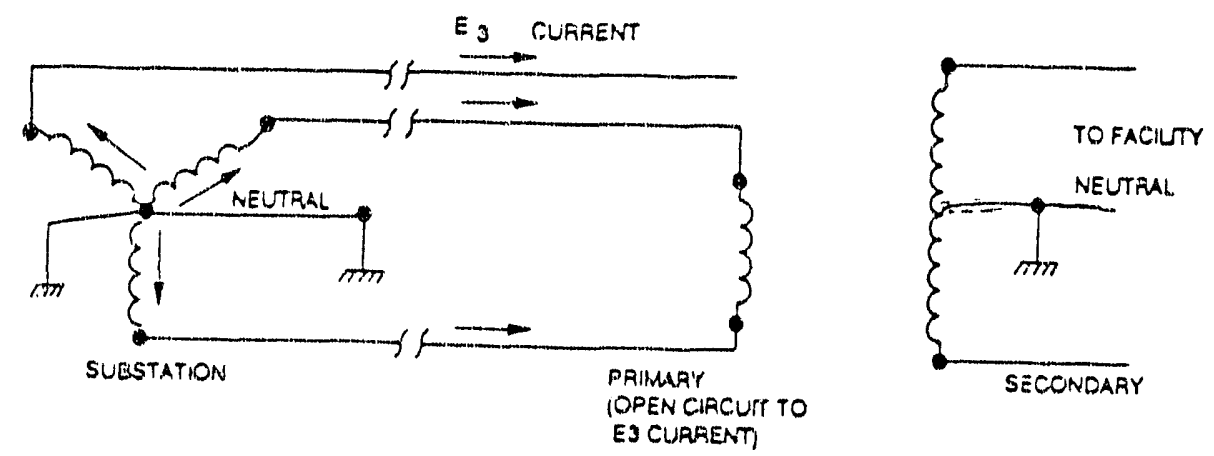

(b)

Fig. 3.4. Recommended power service configurations for large and small facility loads. (a) Large facility served by a loop subtransmission system, (b) single phase load served by two phases of a three-phase system. 


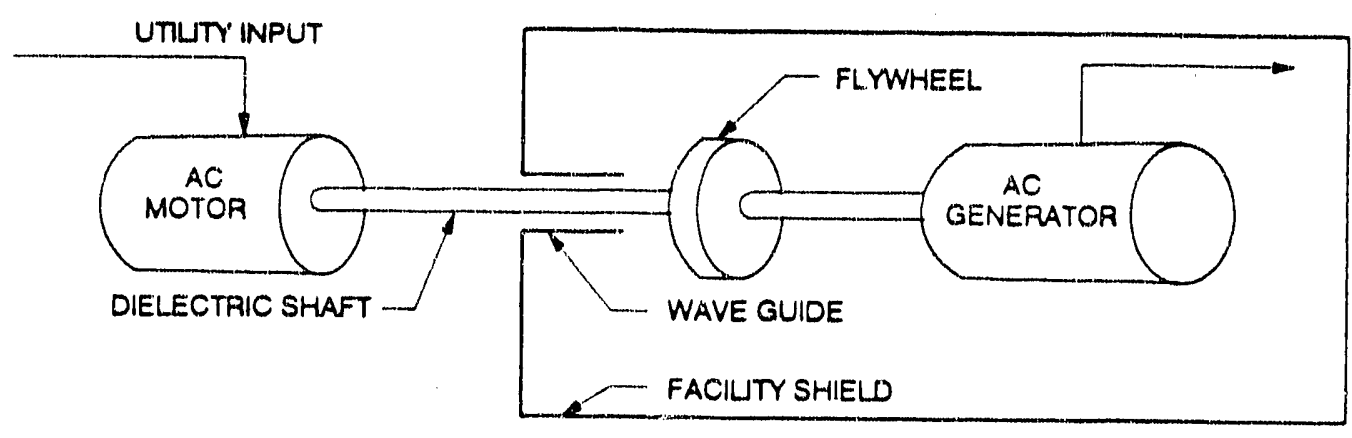

Fig. 3.5. Protection of a power system using a rotary isolator. 


\subsection{PROTECTION AGAINST HARMIONICS}

To protect facilities against the possible harmful effects of extreme harmonic distortion resulting from MHD-EMP or from severe geomagnetic storms, harmonic filters can be used in the incoming power line (Fig. 3.6a). However, due to the large number of possible harmonics, ranging from the second to the twelfth harmonic of the $60-\mathrm{Hz}$ frequency, an effective harmonic filter may be difficult to design and will be expensive to construct. A simpler and less costly approach is to install a power transfer switch, as shown in Fig. 3.6b. This protection device will isolate the facility from the commercial power by detecting the presence of the harmonics and transferring the facility to internal auxiliary power.

\subsection{NON-POWER LINE CONDUCTORS}

The phone cable, water pipes, and local power and control cables that enter the facility are potential means of transmitting MHD-EMP currents to the building. All conductors, therefore, should be isolated from the facility. A portion of the telephone cable should be replaced by a fiber cable, plastic water pipes should be used instead of metal pipes, and all external power should be separated from the facility (Fig. 3.7). Fiber optic cables should be used for instrument and control functions such as the gate control, gate telephone, surveillance cameras, etc. The grounds of external equipment and metal objects should be connected to the commercial power ground and kept well separated from the facility ground. The recommended design practices for these non-commercial power conductors are also shown in Fig. 3.7.

The optical converter for critical incoming telephone or data lines must be powered from the 'acility, and not by the commercial power as indicated in Fig. 3.7. Fig. 3.8 provides more details on the possible configuration for using optical converter protection of the facility. 


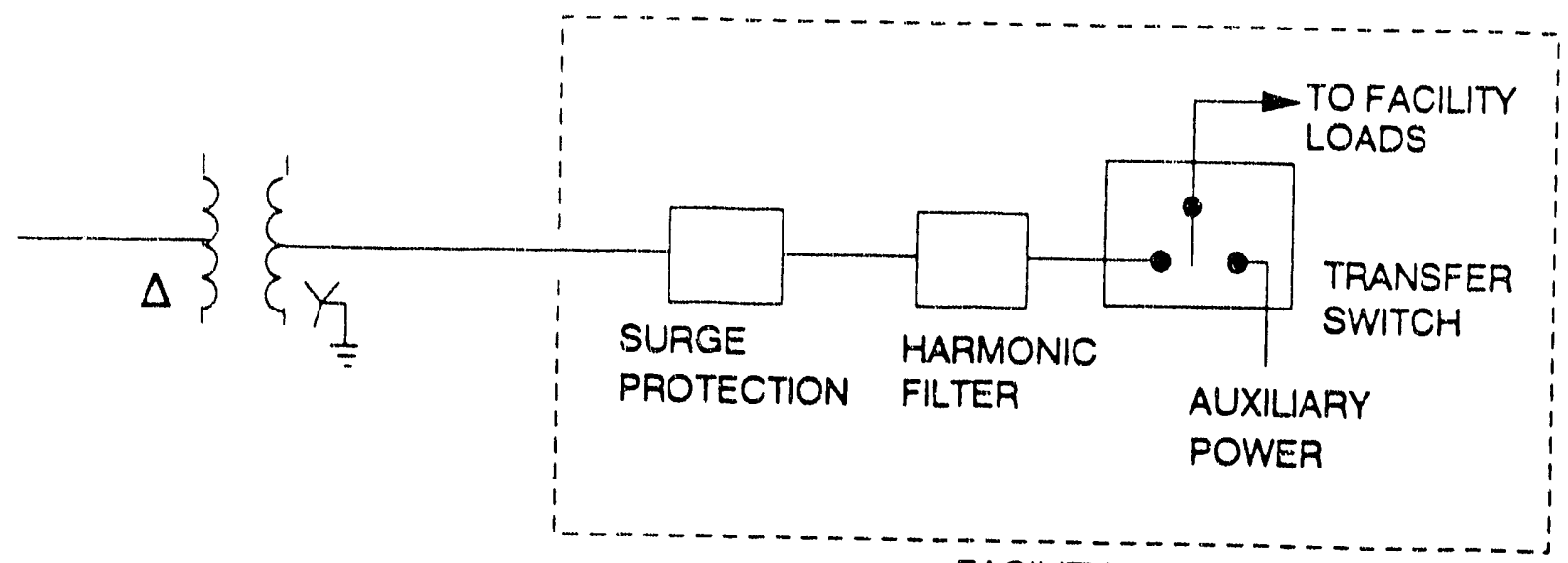

FACIUTY

(a)

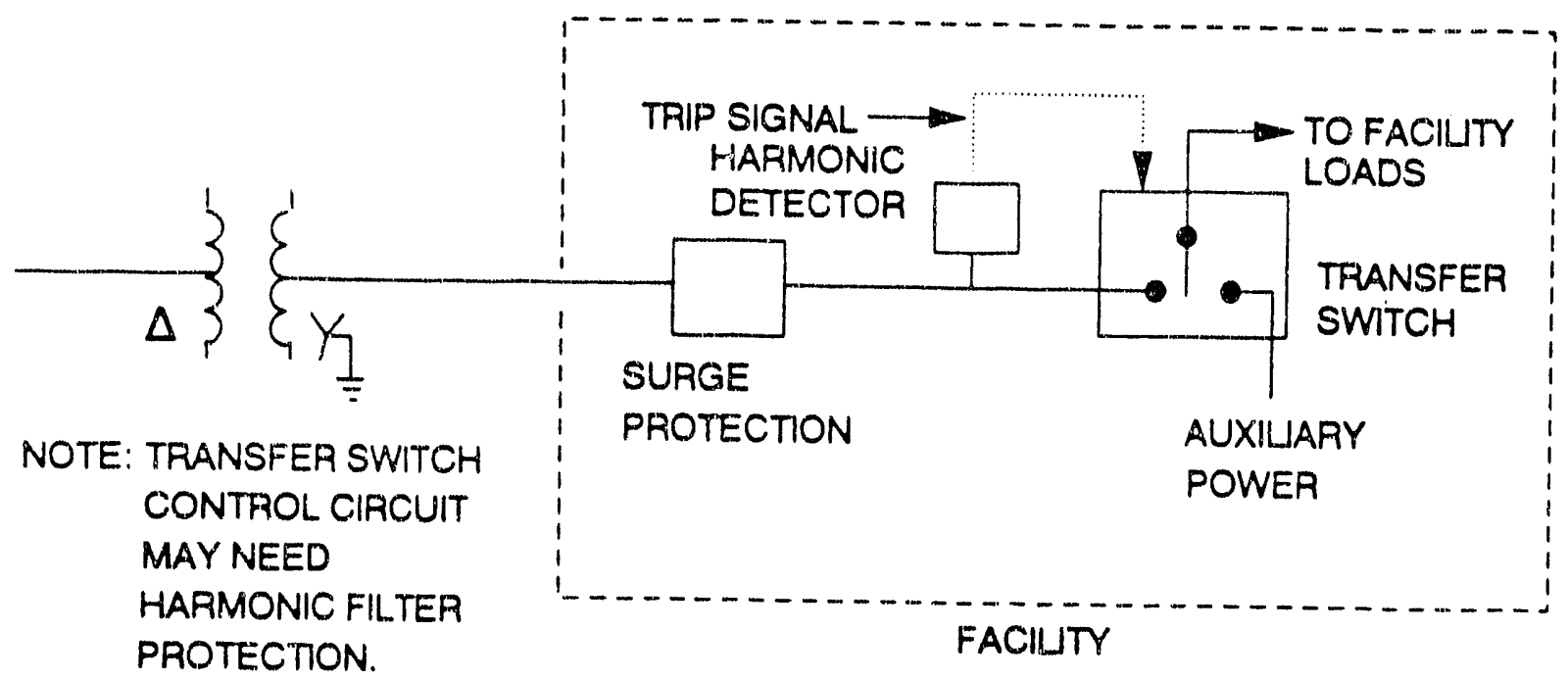

(b)

Fig. 3.6. Protection against harmonics. (a) Harmonic filter protection, (b) harmonic detection and switching. 


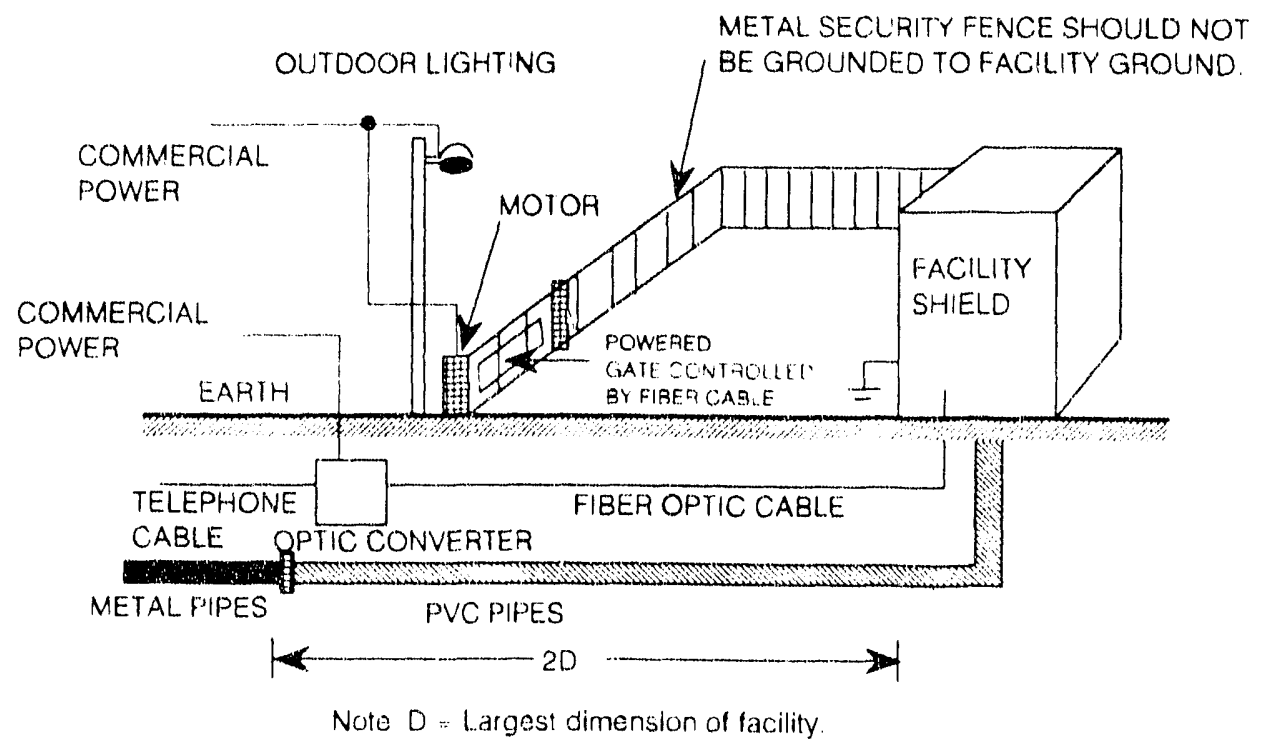

Fig. 3.7. Recommended design practice for non-power line conductors. 


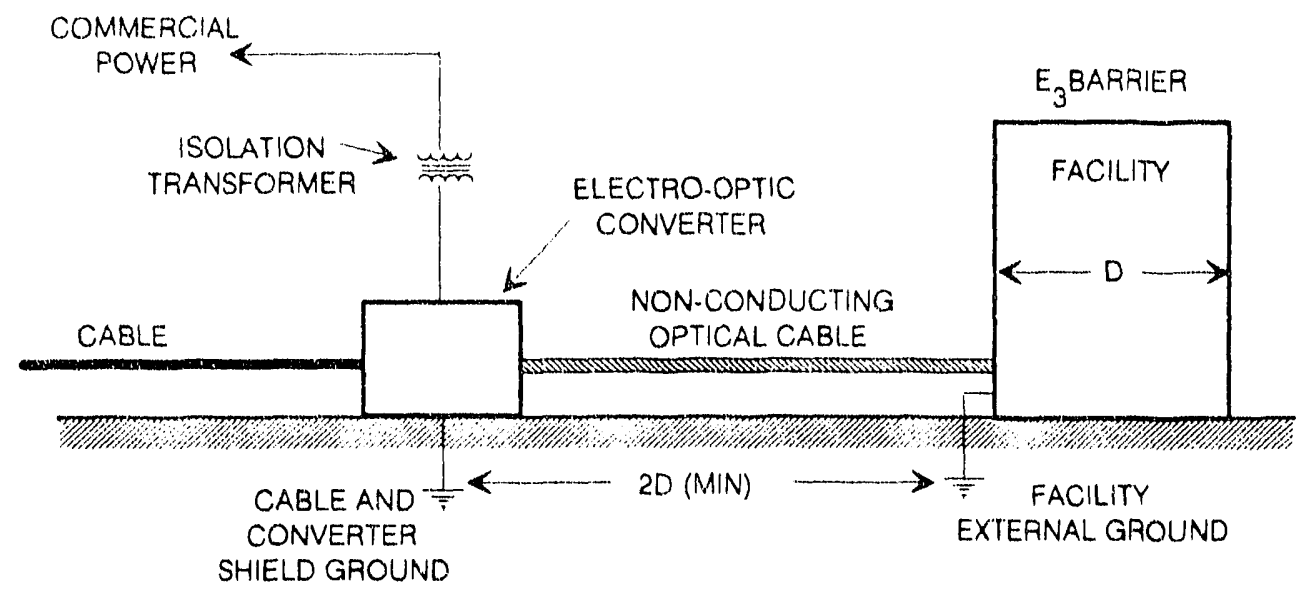

(a)

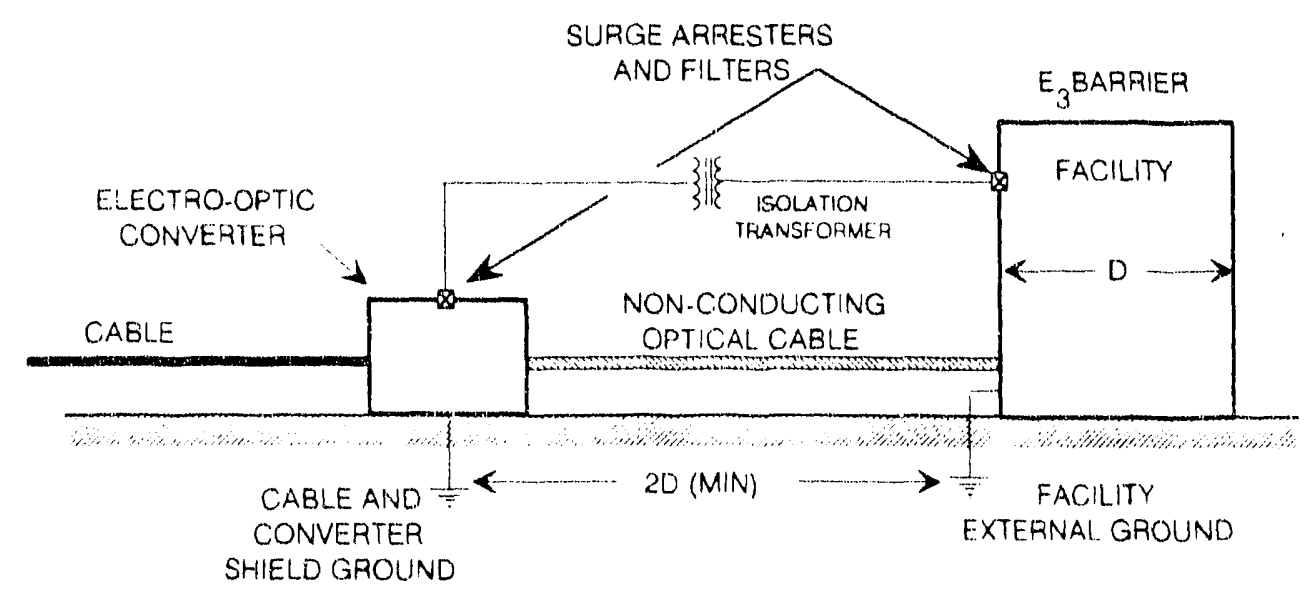

(b)

Fig. 3.8. Mitigation methods for an electro-optic converter on an audio/data cable. (a) Commercial power feed, (b) power feed from the facility. 


\subsection{SUMMARY OF RECONIMENDED DESIGN PRACTICES}

The following are recommended practices to mitigate MHD-EMP effects on critical facilities. Some of these recommendations will be implemented by the electric utility.

1. The facility power transformer should have a delta winding on the utility (high-voltage) side. The transformer should be protected by surge arresters and fast-blow fuses on the high-voltage side. A three-phase underground power cable without a neutral conductor should be used to power this transformer. The minimum distance of the underground cable should be $15 \mathrm{~m}(50 \mathrm{ft})$.

2. The power line neutral should be terminated at a distance of at least twice the longest dimension of the facility (D) from the power transformer.

3. The electric utility should balance the phases with the same number of similar size transformers in the same vicinity along the line. Subtransmission circuits should be configured as a unigrounded system, and distribution circuits should use a radial configuration.

4. The electric utility should consider series capacitors in the phase conductors at the substation.

5. All conductors that approach the facility should be electrically isolated from the building shield. If possible, all metal conductors should be terminated at a distance of at least twice the longest dimension of the facility (D) away from the enclosure.

6. The issue of harmonic distortion at the facility power input to the building should be addressed. This would improve the quality of commercial power during normal operations, as well as during an MHD-EMP event.

7. A rotary power system should be considered for critical facilities with small loads. A rociary power system will provide protection against $E_{1}, E_{2}$, and $E_{3}$, as well as a source-region EMP (SREMP), and also will meet TEMPEST requirements.

\subsection{EMERGENCY OPERATING PROCEDURES}

Upon a confirmed warning of an attack, commercial power should be disconnected from the facility. It is unlikely that commercial power will be available for very long during the event, unless the attack is limited and localized. Therefore, there is little advantage in continuing to use commercial power and disconnecting the facility from utility power increases the HEMP protection. If prior warning of an attack could be assured, the third mitigation recommendation 3 in Section 3.6 could be eliminated. If this recommendation is not applied and the distribution line is subjected to $\mathrm{E}_{3}$, the facility will be at increased risk to harmonic distortion, although the increase may or may not be significant, depending on the line parameters. 


\section{MHD-EMP TEST GUIDELINES}

\subsection{THE GENERAL SIMULATION CONCEPT}

A frequently used technique for simulating the effects of the $E_{1}$ - or $E_{2}$-component of HEMP on facilities is to use a current injection method. With this concept, a long line or other collector of HEMP energy entering a facility is disconnected, and a suitably designed pulser is connected in its place and is used to excite the facility. Internal stresses on subsystems or components are measured, and the state of hardness of the system is qualified.

Fig. 4.1 illustrates a similar simulation approach applied to the $E_{3}$ environment for a long, grounded line entering the facility. Frequently, the nature of the termination impedance $\left(R_{L 2}\right)$ within the facility is unknown; hence this is represented in the figure by a dashed line. The voltage source $\left(V_{S}\right)$ and the resistance of the pulser $\left(R_{S}\right)$ are the Thevenin equivalent circuit parameters for the excited line. Expressions for these quantities are developed in the Appendix.

There are some special considerations for $E_{3}$ simulation, however, that are not present in simulations for the other HEMP environmental components. Most long conductors entering the facility normally carry electrical signals or power. Many of the MHD-EMP effects on facilities are due to interactions between the $E_{3}$ excitation and normal operating signals. This implies that if the equivalent circuit approach for simulation shown in Fig. $4.1 \mathrm{~b}$ were to be used, it would be necessary for the $E_{3}$ pulser to provide the normal operating signal or power to the facility in addition to the $\mathrm{E}_{3}$ stimulus. If this is not possible, the simulation then should be designed so that it excites both the facility and the external network providing the operational signals.

This issue is especially important in testing long, energized, $60-\mathrm{Hz}$ commercial power lines, where harmonic distortion can be produced by transformers located outside the facility. In this case, the simple Thevenin-equivalent pulser shown in Fig. 4.1b will not produce the proper MHD-EMP response of the facility, even if the voltage source has the proper quasi-dc characteristics. The recommended approach to MHD-EMP simulation in the power system is discussed in more detail in Section 4.3.

There are cases, however, where the simple replacement of the incoming line with an equivalent pulser is acceptable, such as the case of a water pipe or the external part of a coaxial shield. Furthermore, if a power-off, or signal-free, test is to be conducted on the facility, the excitation of the off-site lines need not be simulated. 


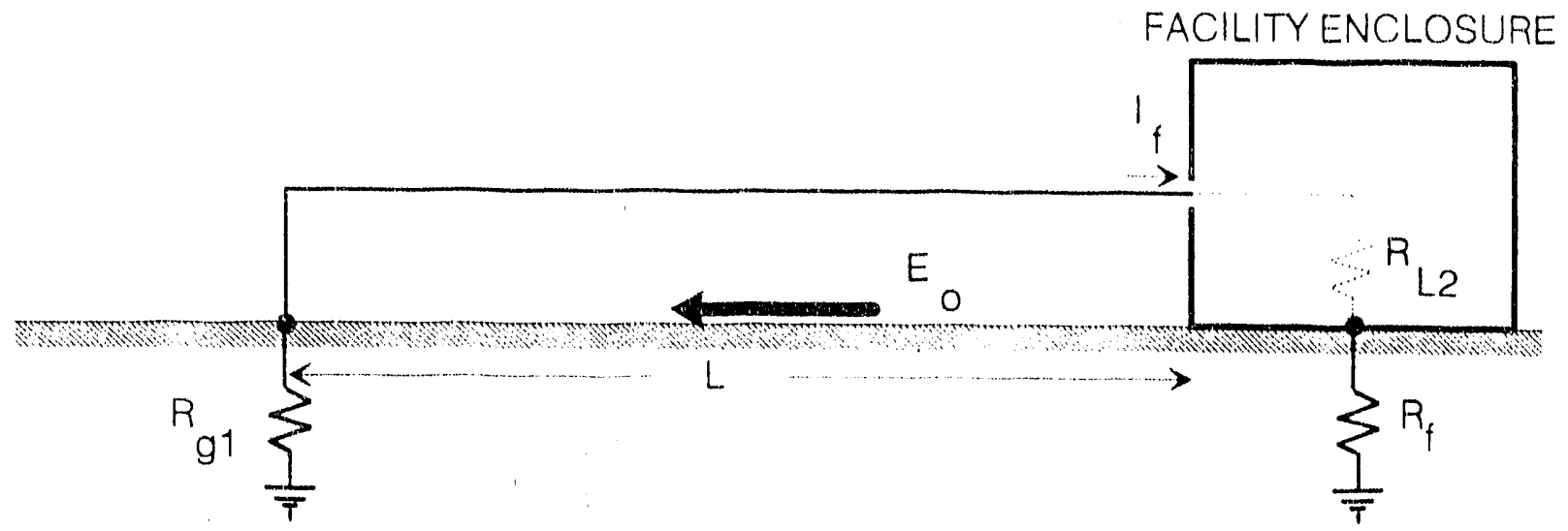

(a)

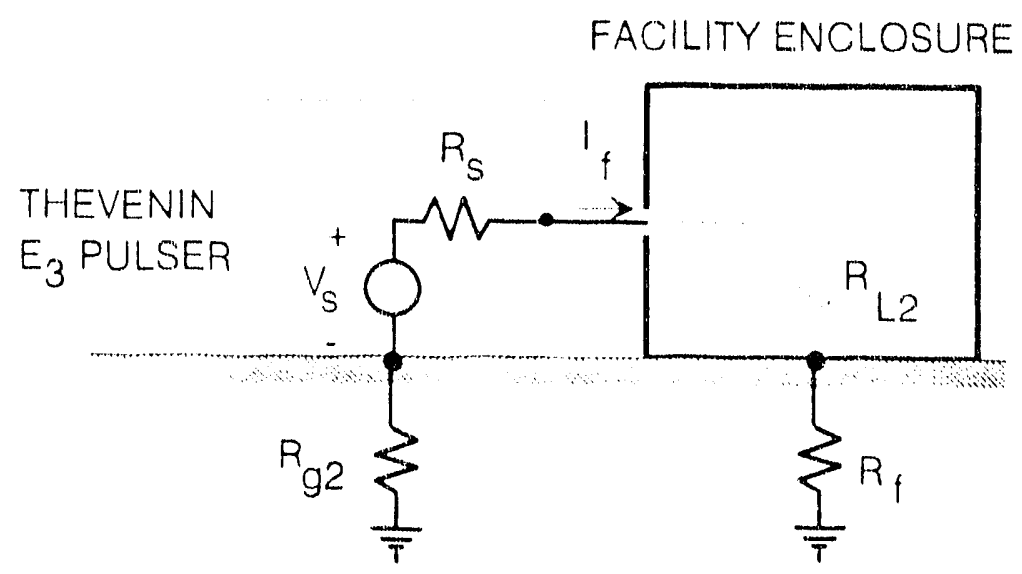

(b)

Fig. 4.1. A simple simulation of the MHD-EMP excitation of a long line. (a) Physical line configuration, (b) line replaced by a Thevenin equivalent MHD-EMP pulser. 
The requirement to produce a simulated $E_{3}$ excitation together with the normal operational input signal or power of the facility is different from that suggested in MIL-STD-188-125 (ref. 11). In this specification document, it is recommended to inject a $200 \mathrm{~A}$ double exponential current waveform having a rise time, $\tau_{\mathrm{r}}<0.5$ seconds and a fall time $\tau_{\mathrm{f}}>100$ seconds directly into the long conductors entering the facility. This results in a specified response of the system to MHD-EMP that may not be its actual response.

The actual level of MHD-EMP current entering the facility depends critically on the nature of the load resistance within the facility. If this resistance is very high due to a poor grounding connection, it will be difficult, if not impossible, to excite the specified current of ref. 11 using available MHD-EMP pulsers. Thus, the simulation approaches recommended in this section are independent of the internal facility load resistance. The circuit values for the $E_{3}$ pulser depend only on the MHD-EMF environment and the line properties, and if the proper values are used. the system response will be identical to that experienced by the actual $\mathrm{E}_{3}$ environment.

\subsection{OVERALL TEST OBJECTIVES AND PROCEDURES}

The MHL-EMP simulations may be conducted on either hardened or unhardened facilities. For unhardened facilities, the objective of the test is to determine the impacts of $E_{3}$ currents entering the facility and the effects of the harmonic distortion generated in the power circuits, either internally or externally to the facility. This may be a difficult test to conduct, since the $E_{3}$ currents may enter the facility from several different conductors simultaneously. Because of the nonlinear nature of harmonic generation, it is impossible to consider single-port excitation with an analytical combination of responses to infer the system-level response. Furthermore, little experience has been gained regarding the effect of the $E_{3}$ current waveform on the facility response. This, the use of an accurate and representative $E_{3}$ waveform is recommended, as opposed to the prescribed double exponential current waveform suggested in ref. 11. However, it is recognized that the pulser waveform will be constrained by practical design considerations, and that a true replication of the MHD-EMP stress may not be possible.

For hardened facilities, the main test objective is to validate the measures used to mitigate the MHD-EMP effects on the system. This is accomplished by driving all long conductors and verifying the fact that all protection schemes are working as designed. In addition, the possible presence of unknown coupling paths into the facility should be determined. Furthermore, the effects of harmonic distortion in the commercial power should be included in a hardened facility test. 
Little prior experience has been iccrued in $\mathrm{E}_{3}$ testing: consequently, there is some concern about possible permanent damage of the facility equipment by this low-frequency current injection testing. Therefore, prior to any testing, analysis and planning should be conducted and the following tasks performed:

- Identify the long line and other conducting penetrations into the facility.

- Develop a simple internal coupling model for the internal equipment based on the do topol.. ogy of the facility, the internal conducting paths, and the grounding scheme.

- Estimate the MHD-EMP current levels at locations of potentially susceptible or irreplaceable equipment within the system.

- If the system being tested is unhardened agsainst MHD-EMP, develop suitable protection measures or non-critical (dummy) replacements for the equipment that may be damaged by the $E_{3}$ testing.

- Identify suitable test-points for continuous measurements during the test to monitor the onset of possible equipment damage due to the testing.

- Instrument critical items and begin the tests at a low (safe) level.

In performing these steps, it is important to keep in mind that the internal coupling models and estimates of current levels at the internal equipment locations are extremely inaccurate, even for the quasi-dc environment of MHD-EMP. Thus, the calculations are only crude estimates and serve only to indicate areas of possible concern in the testing.

The basic procedure for the $E_{3}$ testing is to begin by injecting a suitable current into conductors entering the facility using one of the pulser configurations to be discussed in Sec. 4.3. This is done by starting at a low amplitude and then increasing the amplitude of the current injection in steps for each subsequent measurement. Currents and voltages should be monitored at the identified points of entry (POEs) and at the selected internal monitoring points. During this system testing, the functional behavior of the internal operating equipment should be carefully observed for signs of malfunctions. 


\subsection{RECONINENDED TEST CONFIGURATIONS}

This section presents recommended test configurations for the major penetration mechanisms encountered in a ground-based facility.

\subsubsection{Long, Non-Power-System Conductors}

An alternative to the simulation approach shown in Fig. $4.1 \mathrm{~b}$ for long conductors, such as water or gas pipes and telephone lines, is illustrated in Fig. 4.2a. In this approach, the line is broken, and the $E_{3}$ pulser is connected in series to simulate MHD-EMP currents in the conductors. The pulser is shown at the end of the line, far from the facility, but its location is not critical; it can be located at the facility end or in the middle of the line.

Because the line and its connections to the earth remain intact, the internal resistance of the pulser $\left(R_{S}\right)$ should be much lower than the line and its earthing resistances. The normal line resistance thus serves to properly adjust the current flowing in the line to be the correct MHDEMP current. As explained in the Appendix, the value of the voltage source is $E_{0} L$, where $E_{o}$ is the $E_{3}$ electric field, and $L$ is the line length. Thus, in this simulation approach the specification of the pulser's electrical characteristics is easier than in the simulation of Fig. $4.1 \mathrm{~b}$, where the pulser's resistance must be adjusted differently for each line being tested.

Although this test configuration is relatively simple, the test may require a great deal of time and money to perform if the facility has many conducting penetrations of this type. However, for hardened systems where these long conductors have a near infinite resistance, (due to plastic pipes, fiber optic communication links, etc.), it is only necessary to verify that the resistance of the line is very large so that the current entering the facility ( $\mathrm{I}_{\mathrm{f}}$ in Fig. 4.2a) will be very small.

Fig. $4.2 \mathrm{~b}$ illustrates a second possible $\mathrm{E}_{3}$ pulser placement for a simple conducting line. In this case, the pulser is shunted across the line at a location $\left(x_{s}\right)$. Although this configuration is suggested in ref. 11, it does not provide a good simulation of the $E_{3}$ excitation of the line. By adjusting the values of $V_{S}$ and $R_{S}$ appropriately, it is possible to inject the correct current $\left(I_{f}\right)$ into the facility. However, the current at the far end of the line $\left(I_{1}\right)$ is reversed, and there is a current flowing from the line to the ground at the pulser location $\left(\mathrm{x}_{\mathrm{s}}\right)$. Neither of these effects occur in the case of the line being excited by the $E_{3}$ field. 


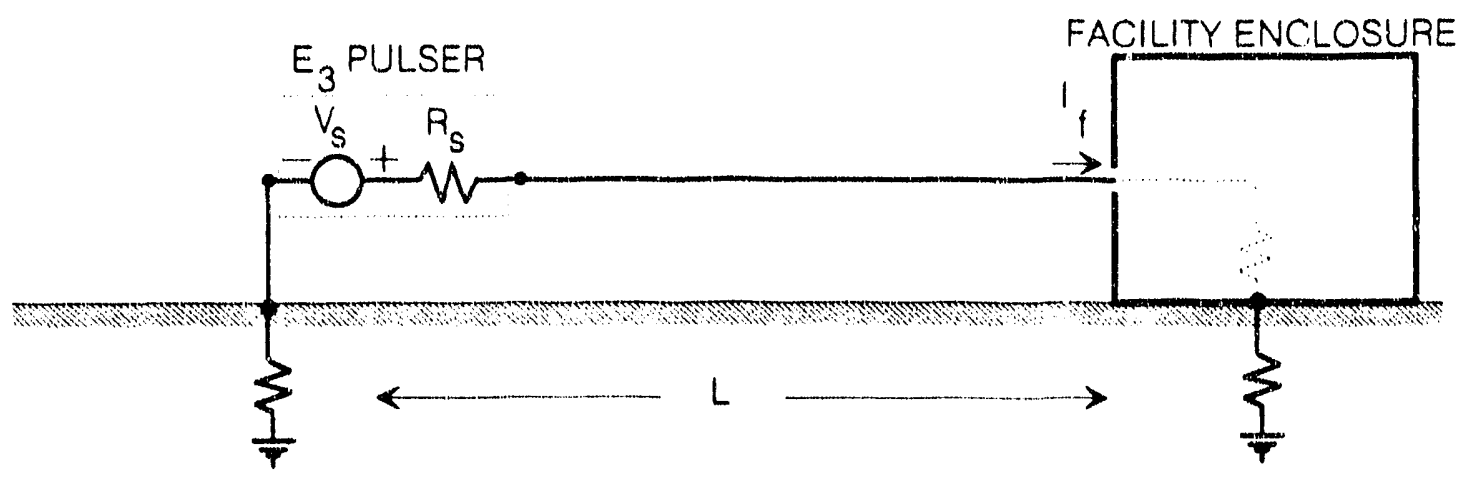

(a)

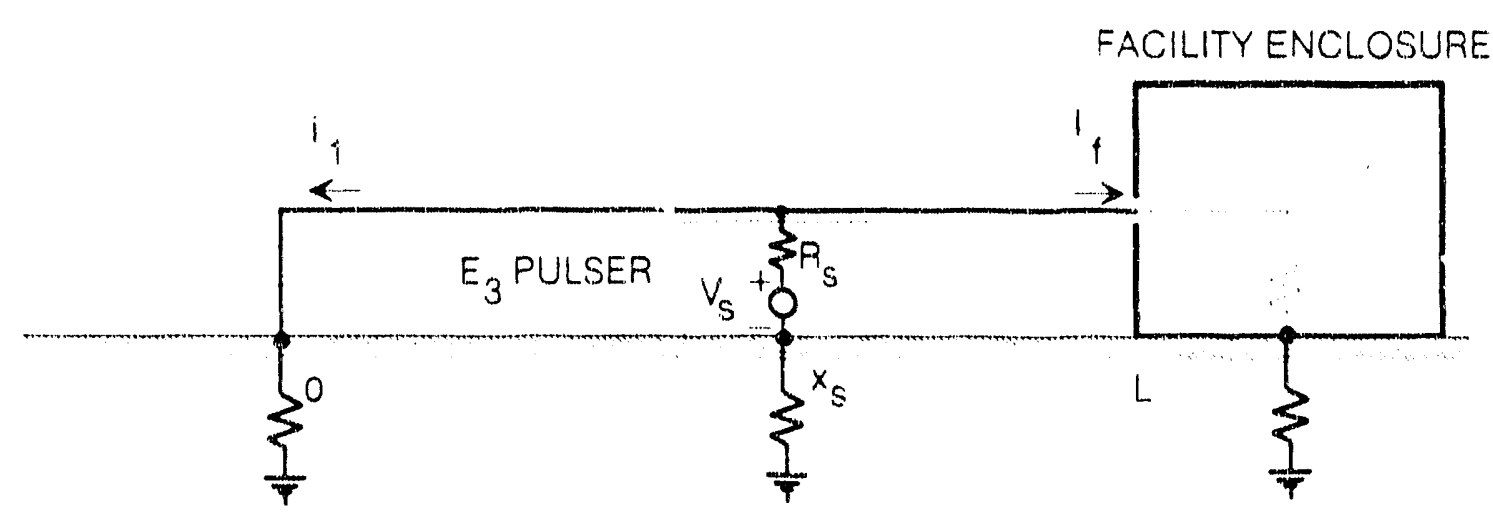

(b)

Fig. 4.2. Simulation Configurations for a Long, Isolated Line. (a) $E_{3}$ pulser in series (recommended), (b) $E_{3}$ pulser shunted across line (not recommended). 
For a simple line where the pulser ground connection is far from the facility, and where the absence of saturating loads can be assured, this abnormal current flow may not be important. However, if there are any non-linear interactions on the line, the resulting response at the facility can be different. This simulation configuration is not recommended.

\subsubsection{Power System Testing - Three-Phase Systems Without A Neutral Conductor}

Because of the large number of transformers in the power network that can generate harmonics and contribute to the voltage distortion in the system, completely simulating MHDEMP on the commercial power system is not technically feasible. Consequently, there will always be uncertainty in the conclusions arising from such power system testing. However, an attempt to simulate the effects of MHD.EMP can be made on the local subtransmissinn or distribution circuits that feed the facility in question. This can best be achieved by injecting currents into the neutral of the grounded wye substation transformer as shown in Fig. 4.3a. As discussed in the Appendix, the value of $V_{S}$ is equal to $E_{O} L$ and the resistance $\left(R_{S}\right)$ should be very small; the same $E_{3}$ pulser used in Fig. 4.2a may be used here. The individual phase currents entering the facility $\left(I_{\mathfrak{1} 1}, I_{\mathfrak{L}}\right.$, and $\left.I_{\mathfrak{Z}}\right)$ will be equal if the general load resistance is balanced. Otherwise, they will be different, depending on the degree of resistance imbalance in the lines and load.

The $E_{3}$ excitation arises from a earth-induced potential in the ground. As a result, it is a common mode excitation of the three phase conductors (Fig. 4.3a). It is possible to move the single $E_{3}$ pulser from the transformer neutral conductor into each of the three-phase conductors as shown in Fig. 4.3b. This will provide an identical response at the facility. However, there is a requirement to have three identical pulsers, and each pulser must be capable of passing the normal $60-\mathrm{Hz}$ phase currents of the power system (i.e., it must be a true voltage source). There is no benefit in exciting the three-phase line in this manner; in fact, this configlration would pose electrical safety hazards. This configuration is not recommended.

Tests similar to these have been performed in GIC studies 1.14. In the test described in ref. 14, no apparent damage occurred to a $230 / 115 \mathrm{kV} 200 \mathrm{MVA}$ shell-form autotransformer injected with a de current of $100 \mathrm{~A}$ for about 2 minutes. This injection current was about 15.9 times the normal transformer excitation current. It was also found that for a de current level equal to 15 times the transformer exciting current, an injection time period of about 15 seconds will be below the threshold of damage!.

An $E_{3}$ test on the power system will require the cooperation of the electric utility that serves the facility. The ideal injection point is at the distribution transformer shown in Fig. 4.3a. 
For large military installations, this transformer may no: be owned by the base or may not be readily accessible. If this is the case, the pulser may be located at the facility ground, denoted by $A$ in the figure, if it is accessible.

In a manner similar to that shown in Fig. $4.2 \mathrm{~b}$, the $E_{3}$ pulser for the three-phase power line can be shunted across the line. In Fig. 4.4a, there are three separate pulsers, one for each phase conductor. Fig. $4.4 \mathrm{~b}$ utilizes a single pulser, with a three-phase wye transformer to feed the line. As in the case of a shunt feed of a single line, this injection method can be used to provide the proper de currents flowing into the facility. However, this method it does not result in the proper dc currents in the distribution transformer, and additional harmonics can be introduced by the feeding transformer of Fig. $4.4 \mathrm{~b}$. This configuration thus is not recommended. 


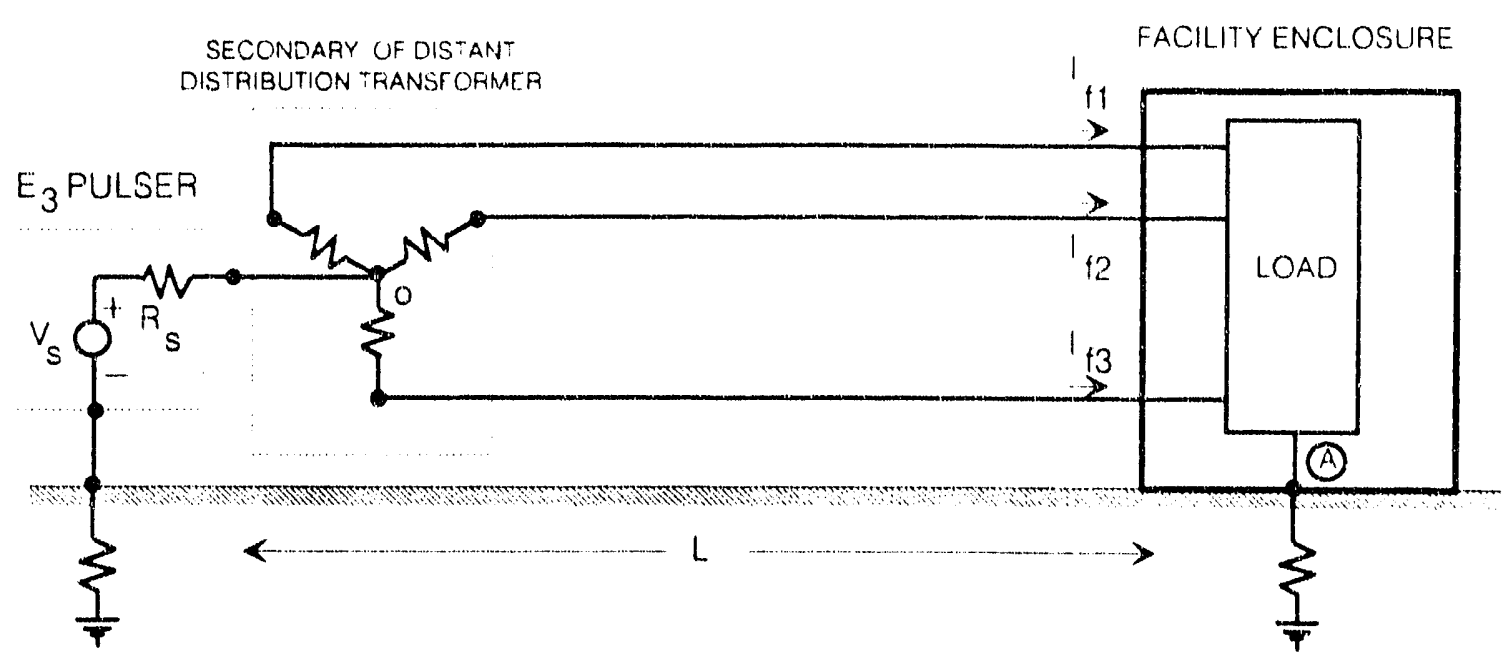

(a)

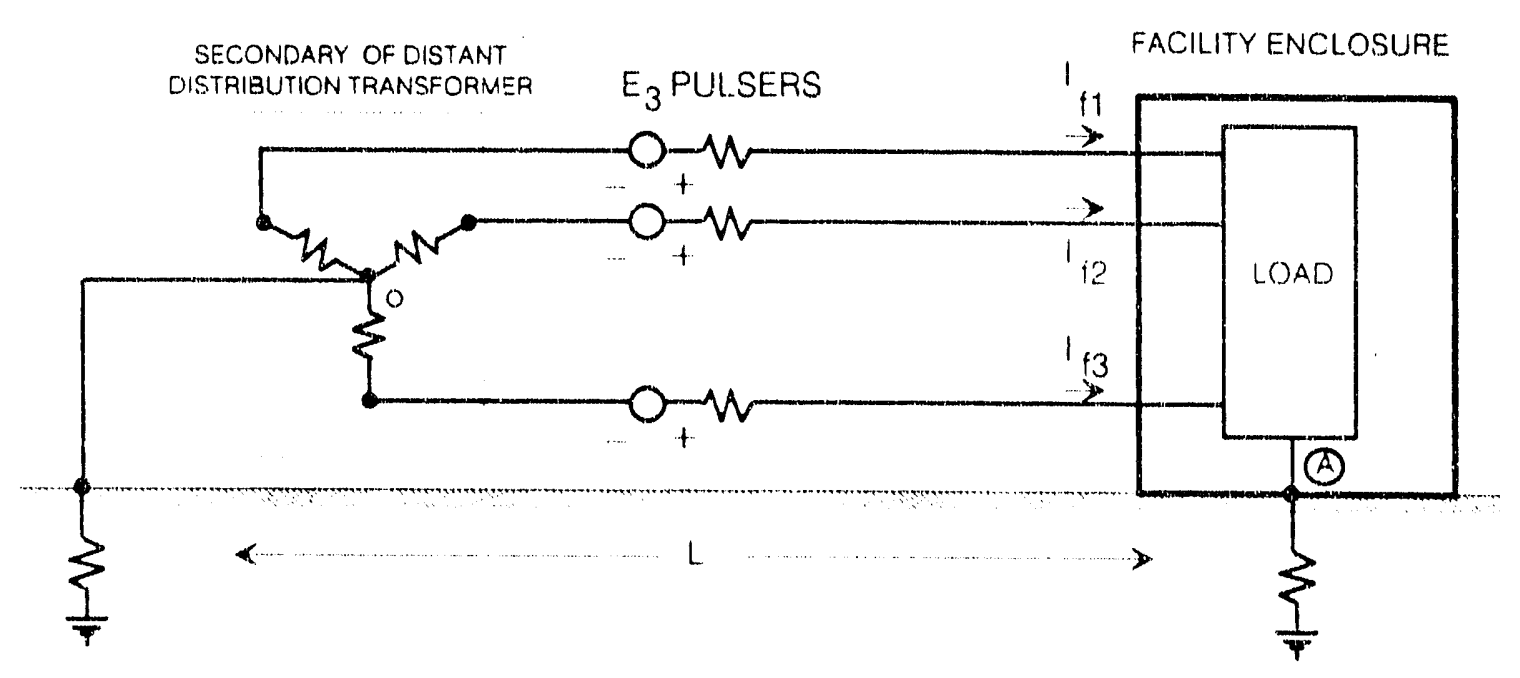

(b)

Fig. 4.3. $E_{3}$ pulser excitation of a three-phase distribution line. (a) Pulser located in the transformer neutral (recommended), (b) pulsers located in the phase conductors (not recommended). 


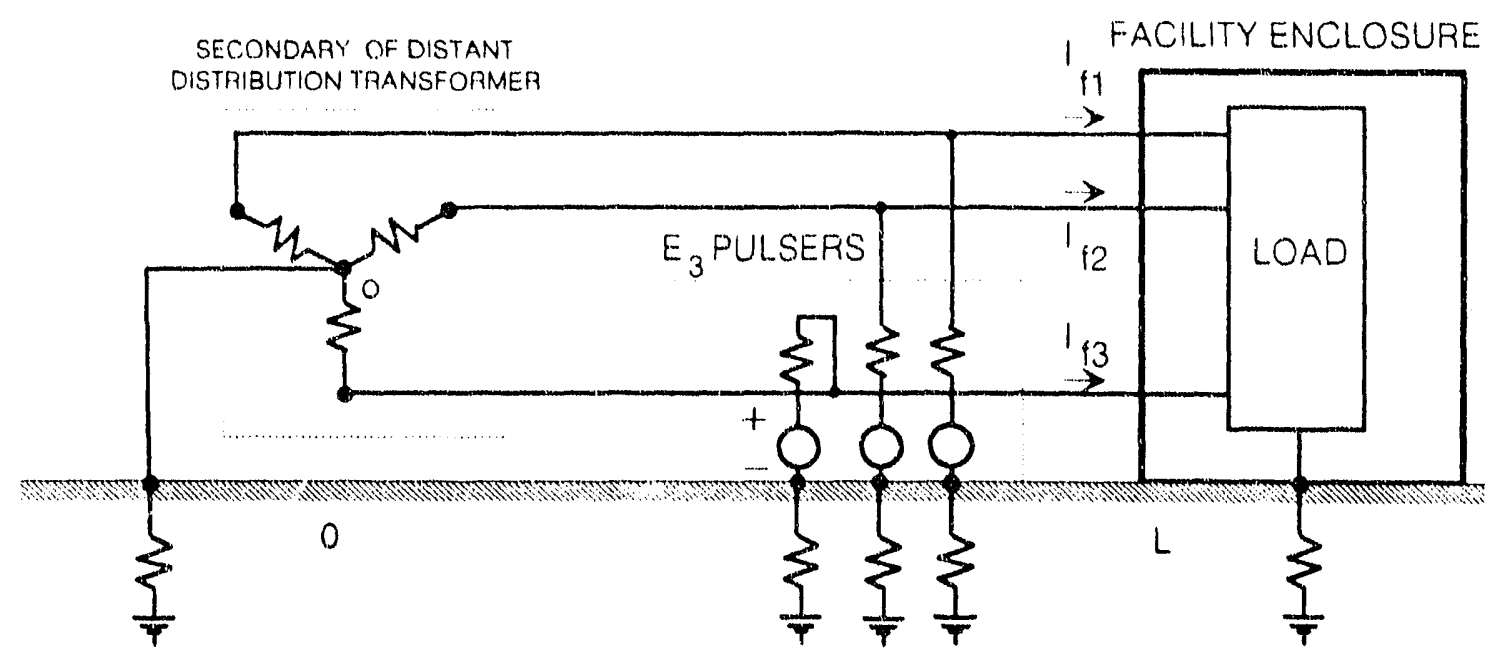

(a)

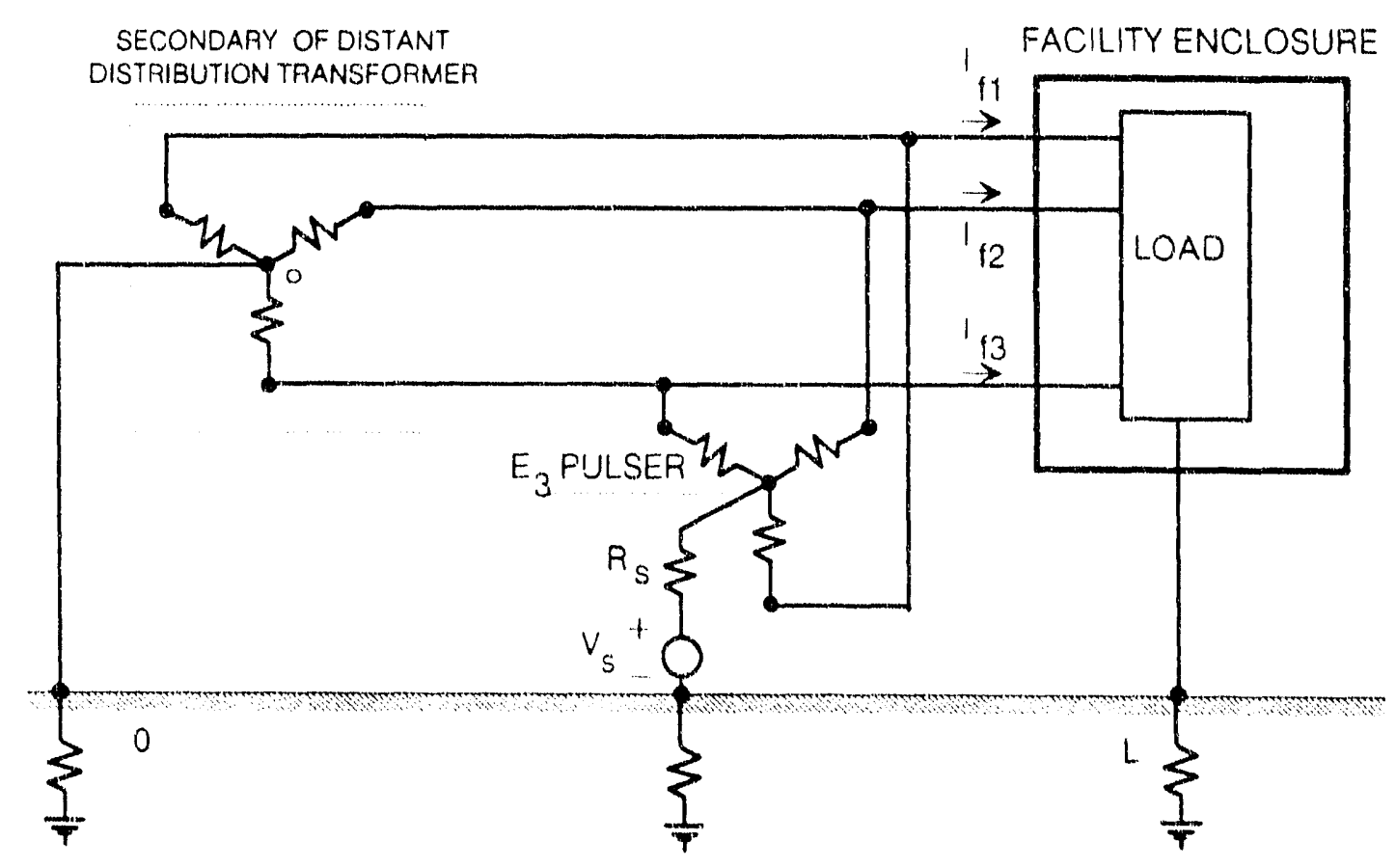

(b)

Fig. 4.4. Three-phase line excited by shunt sources (not recommended). (a) Three $E_{3}$ pulsers, (b) one $E_{3}$ pulser feeding with a three-phase winding. 


\subsubsection{Power System Testing - Three-Phase Systems With A Neutral Conductor}

Another common power system line configuration uses a neutral conductor carried with the three-phase conductors (Fig. 4.5). In this case, the neutral of the distribution transformer secondary wye is grounded. There is an additional grounding of the neutral at the facility. Inside the facility, the details of the grounding system may not be readily determined. However, the electrical code and MIL-STD-188-124 (ref. 15 require the neutral and facility ground to be connected together, as shown in the figure.

The desired location of the $E_{3}$ pulser in this case is indicated in the figure. This pulser has the same design parameters as in the previous cases. If the grounding scheme within the facility is well-defined, and a single point equipment ground can be defined (point $\mathrm{A}$ in the Figure), it may be tempting to try to locute the $E_{3}$ pulser at this location. However, due to the external grounding of the neutral circuit at the facility, this simulation configuration will not provide the proper responses. Other facility grounding schemes may be encountered in realistic systems, and they may be considerably different from that illustrated in Figs. 4.5 or 4.6. Prior to any facility testing, the details of the grounding scheme must be carefully examined to determine possible alternate pulser locations.

Fig. 4.6 shows an important case in which the three-phase facility load is an ungrounded delta transformer. As such, no dc current will flow along the phase conductors into the load. Although the location of the $E_{3}$ pulser as shown in the figure is recommended, it could be moved into the neutral or shield line at point B. However, as in Fig. 4.5, the internal location A is not suitable for the pulser, because of the code-required external neutral grounding.

As in the previous three-phase cases, the use of multiple $E_{3}$ pulsers in series with the phase conductors, or the use of pulsers shunting the line, is not recommended. 


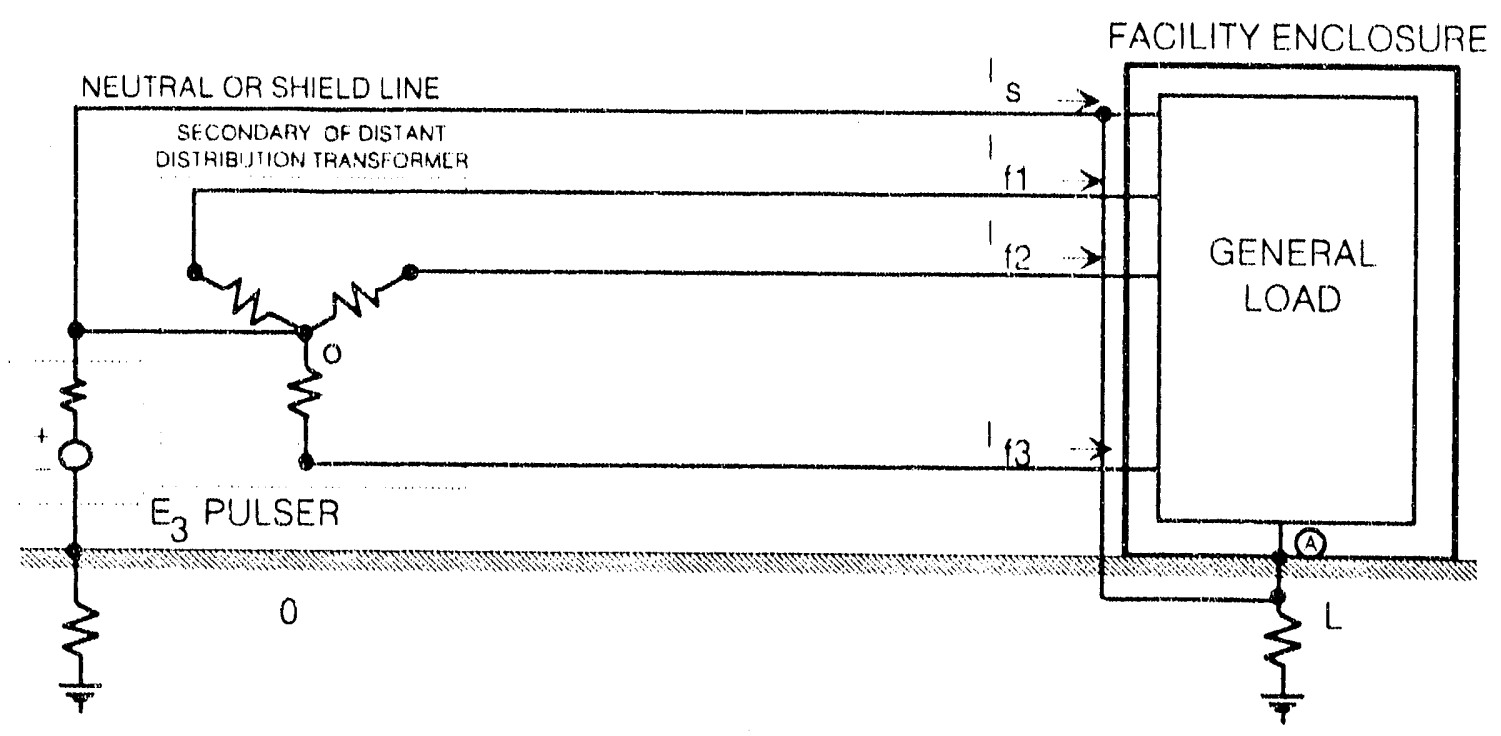

Fig. 4.5. $E_{3}$ simulation for a three phase line with neutral conductor.

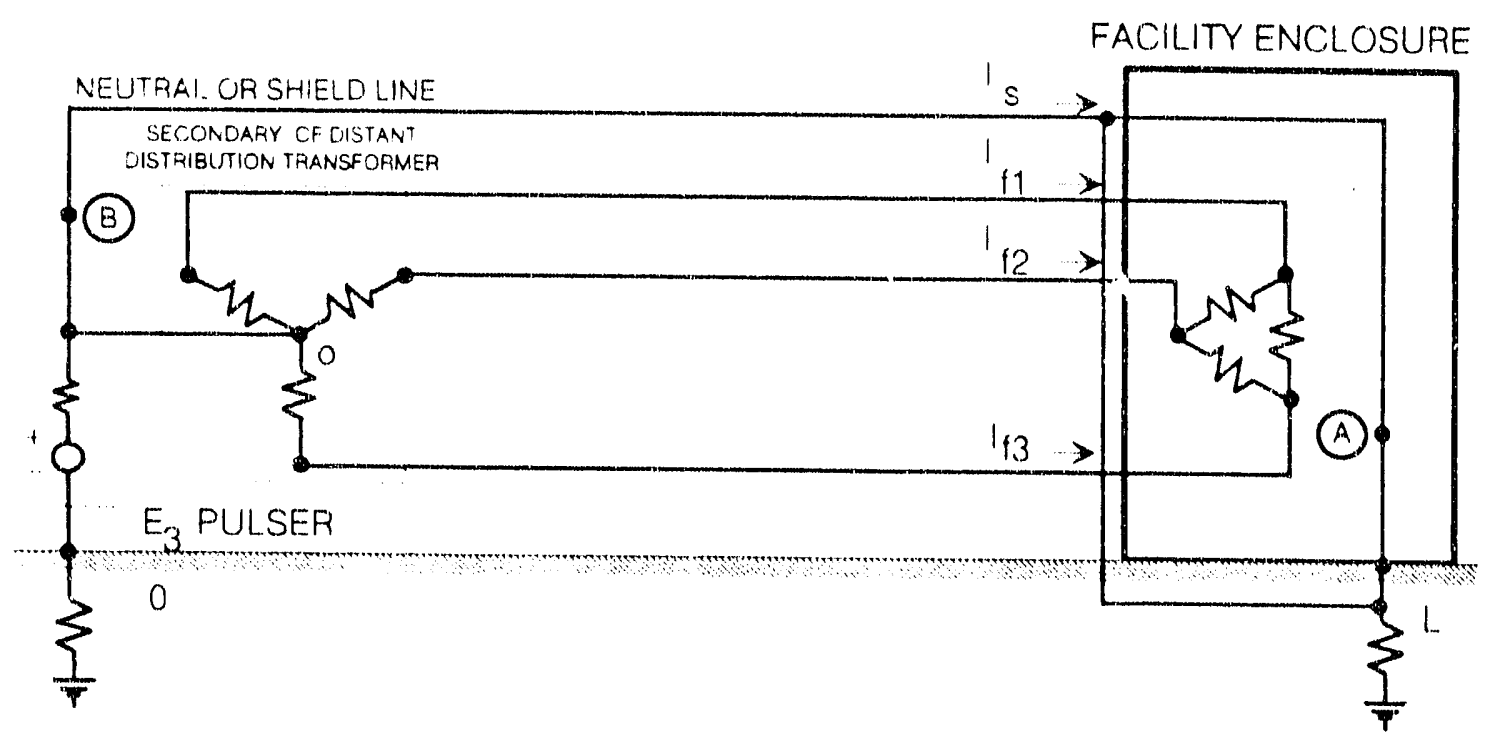
delta load.

Fig. 4.6. E $E_{3}$ simulation for a three phase line with neutral conductor and an ungrounded 


\subsubsection{Power System Testing - Three-Phase Systems With Periodically Grounded Neutral Conductors}

It is common to have the neutral conductor in a three-phase power system grounded at the towers, as shown in Fig. 4.7. This further complicates the MHD-EMP coupling to the line; for not only are the line resistances and transformer winding and grounding resistances important, but the tower grounding characteristics affect the coupling. These parameters include the number and spacing of the towers, the tower footing resistance, and the neutral-tower bonding resistance.

The analysis of such a grounded neutral configuration is discussed in the Appendix. In this case, the pulser voltage is not simply $E_{0} L$, but is a more complicated expression, given in terms of the many parameters of the problem. However, the resistance of the pulser is still required to be very small compared to the rest of the resistances in the network.

The simulation performed in this manner will produce the proper dc phase currents $\left(I_{[1}\right.$, $I_{\mathrm{f} 2}$, and $\left.\mathrm{I}_{\mathrm{f} 3}\right)$ entering the facility but will not provide the correct neutral current $\left(\mathrm{I}_{\mathrm{S}}\right)$. Normally, this will be small compared with the phase currents. However, if it is desired to simulate this current as well, an additional pulser located at point A may be used, with suitable parameters.

An even more complicated (but realistic) power system configuration is shown in Fig. 4.8 , where several electrical loads are placed across the three phase lines to the neutral conductor. These represent single-phase service drops at various locations along the line. An accurate simulation of this configuration is very difficult, because it involves an $E_{3}$ pulser at the transformer neutral, together with individual pulsers located in the neutral conductors of each of the loads along the line. Furthermore, if a concurrent simulation of the current entering the facility on the neutral is desired, an additional pulser at location $\mathrm{A}$ is required.

Clearly, this simulation concept is too complex to be practical. An alternative, therefore, is simply to use the single pulser at the transformer neutral along with an analytical model of the periodically grounded and loaded line to assess the errors involved in this approximate simulation. Because these errors will depend on the details of the line configuration and its parameters, it is difficult to make a general statement about the accuracy of the simulation. 


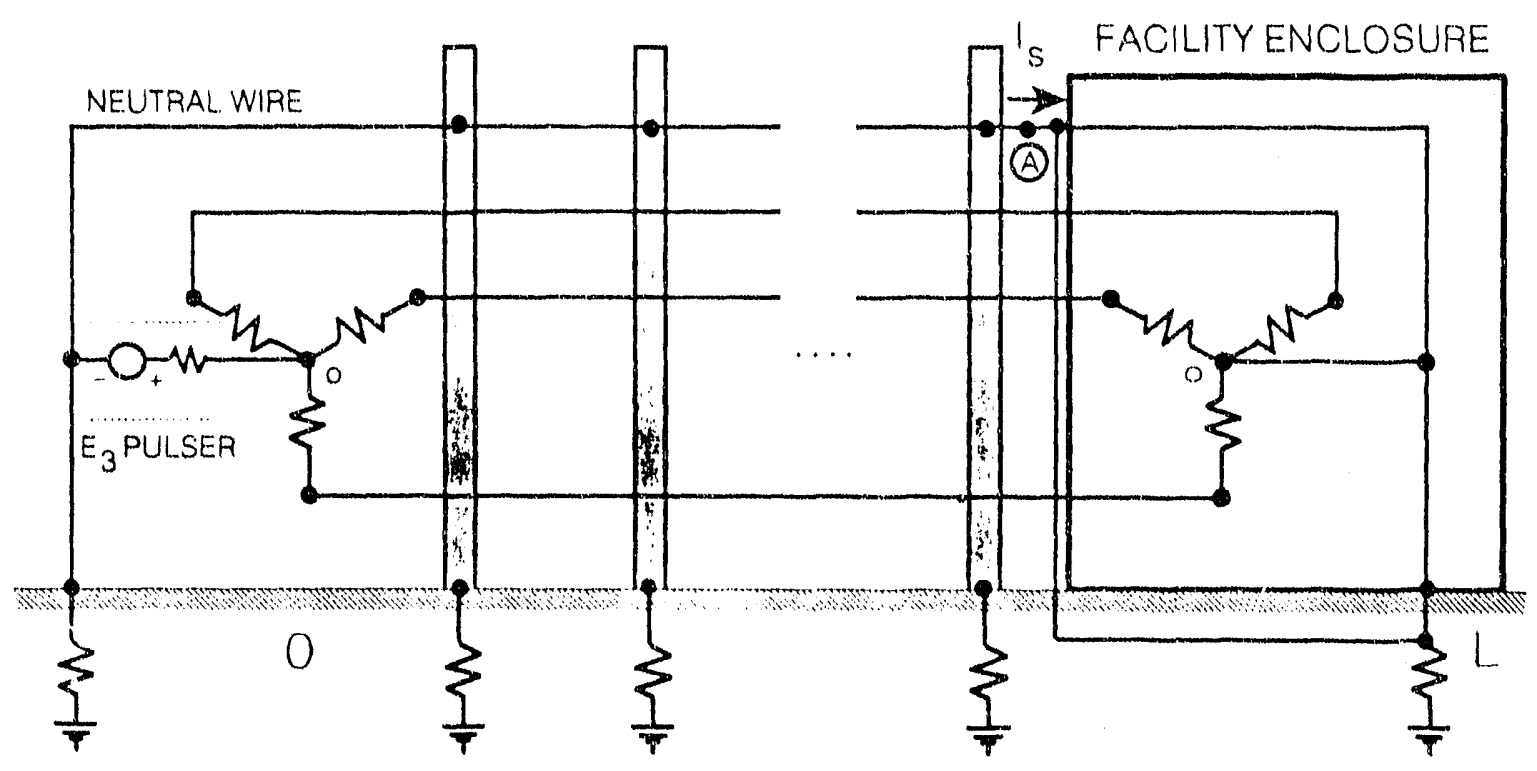

Fig. 4.7. $E_{3}$ simulation for three-phase systems with a periodically grounded neutral.

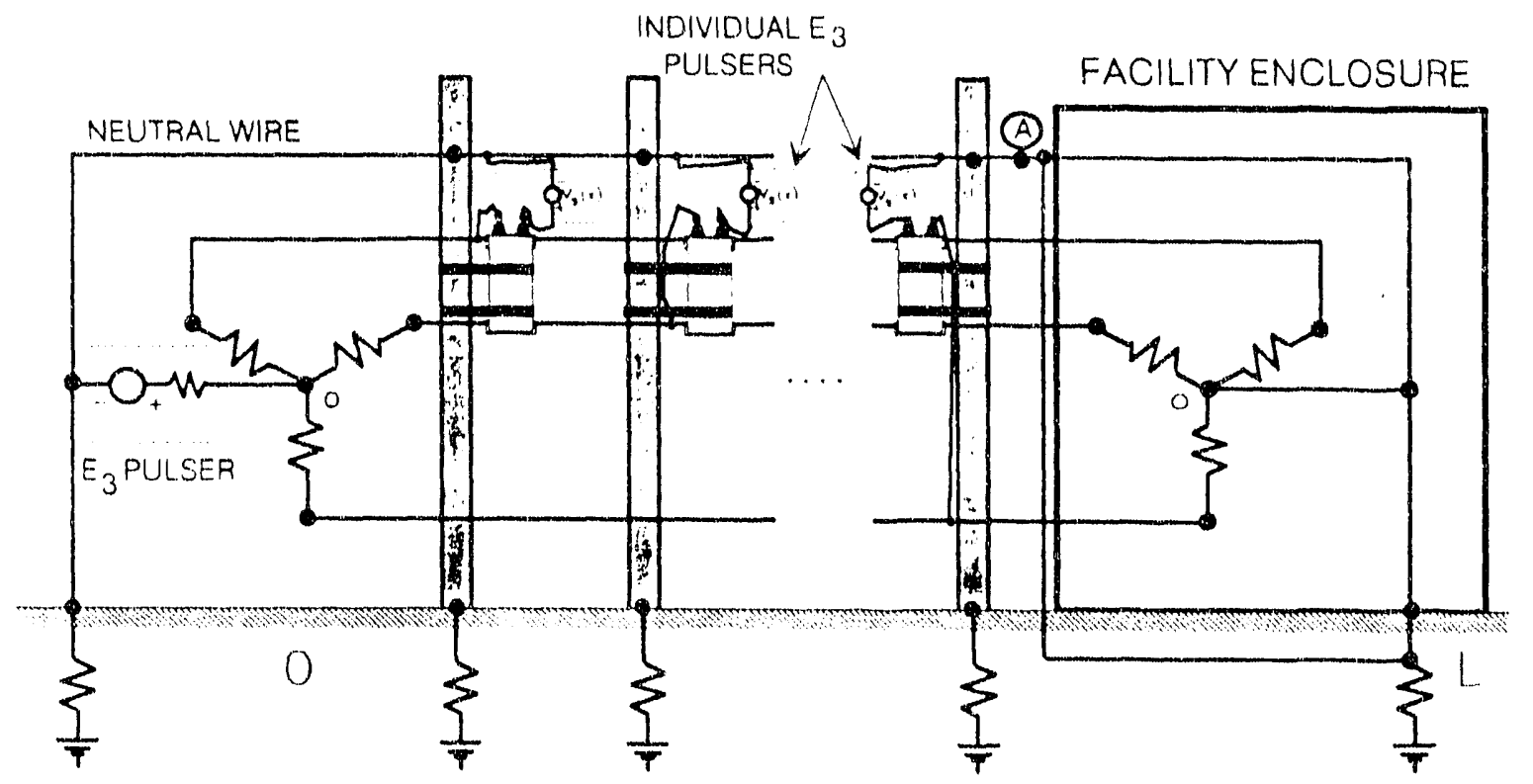

Fig. 4.8. $E_{3}$ simulation for three-phase systems with a periodically grounded neutral and service loads. 


\subsubsection{Testing of a Protected Power System}

Fig. 4.9 shows the $E_{3}$ pulser configuration for testing a power transmission and distribution system that has been constructed according to the recommended design practices presented in Fig. 3.2. In this configuration, the three-phase power distribution line is isolated from the facility by the delta primary winding of the facility transformer. The neutral conductor of the distribution line is connected to the earth at a distance (d) from the ground connection of the facility transformer, and this distance should be at least twice the largest dimension of the facility (D). As before, the voltage of the $E_{3}$ pulser is equal to $E_{0} L$, and the pulser resistance is very small. An alternate and equivalent location for this pulser is at location B shown in the figure.

The only coupling of the quasi-static MHD-EMP currents picked up by the long distribution line is through the mutual earth resistance between the two grounding electrodes separated by the distance (d). The pulser location in Fig. 4.9 will simulate this effect properly. It is possible to consider injecting current directly into the neutral of the secondary winding of the facility transformer at location $A$ shown in the figure. However, the required pulser voltage source will not be the same as that for the other simulation; its value will be reduced due to the poor coupling between the grounding electrodes. While it is possible to develop an expression to estimate the value of the required pulser voltage, this expression relies on assumptions of the local earth conductivity in the vicinity of the grounding electrodes and thus will not be very accurate. Consequently, this type of neutral injection testing is not recommended.

These test configurations will also permit the concurrent testing of any harmonic detection and protection measures. The injection of the dc current into the transformer tieutral will produce $60 \mathrm{~Hz}$ harmonics during the test, and the effectiveness of any installed harmonic mitigation measures will be evident. 


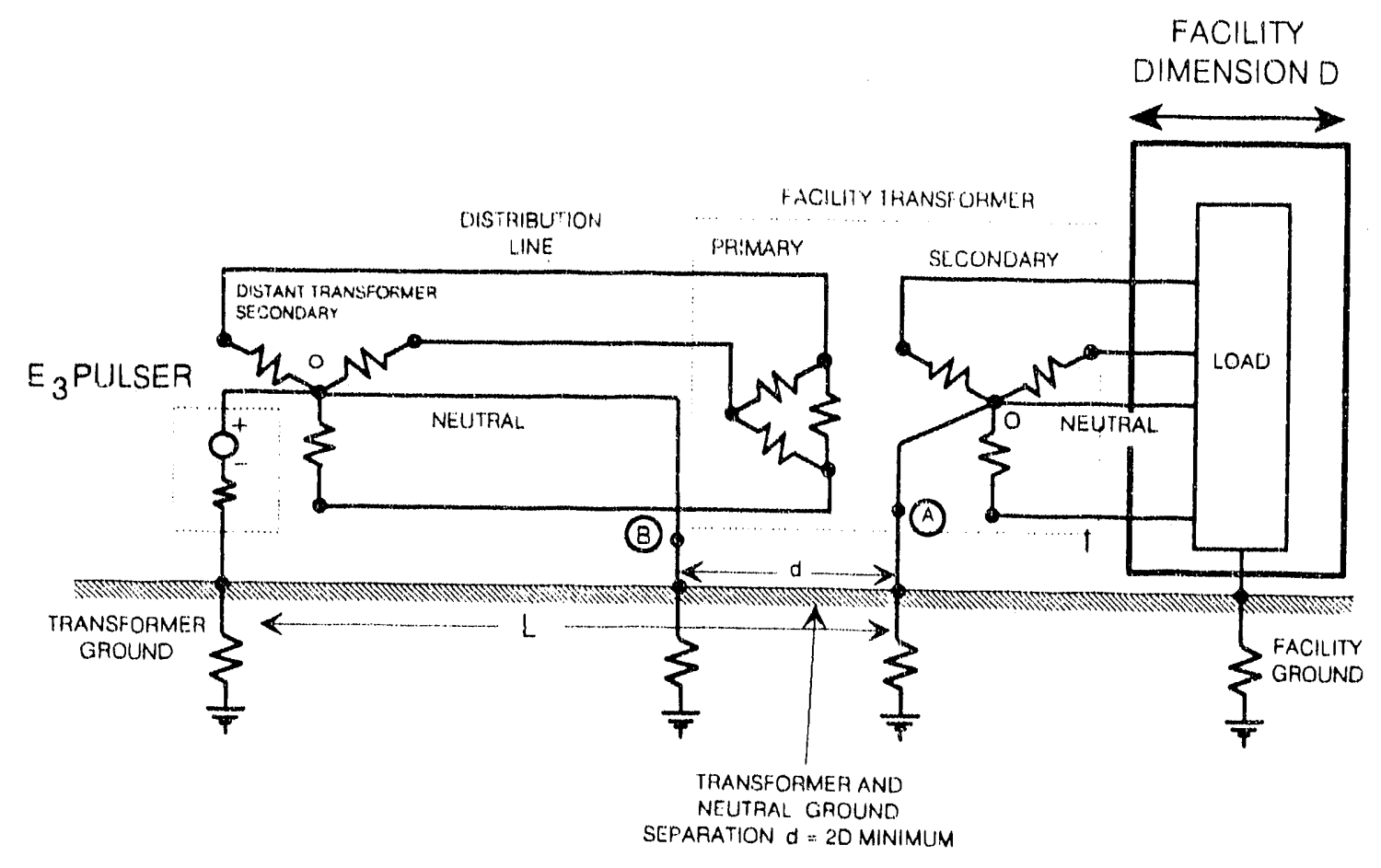

Fig. 4.9. E E $_{3}$ pulser configuration for testing a protected facility.

\subsubsection{Isolation Gap Evaluation}

The isolation gap required in long lines to limit the MHD-EMP current delivered to the facility was estimated to be twice the largest dimension of the facility. This estimate was obtained by determining the current flowing through a conducting (metal) sphere immersed in a finitely conducting medium (soil) between two current injection points ${ }^{16}$ In this model, the current injection points simulate the grounding points of two long lines on opposite sides of the facility. The metal sphere simulates the facility shield.

It was found that a gap equal to twice the diameter of the sphere would reduce the current through the sphere to one-tenth of the current injected into the soil. It was postulated that this fraction of a nominal 200 A MHD-EMP line current (20 A) would probably be safe for the facility. However, it has been proposed to perform an experiment using the test configuration shown in Figure 4.10 to evaluate this postulate. The distance (d) between the facility and each injection point would be varied from zero to at least twice the largest facility dimension $(D)$ to evaluate 
the shield current collection. The current in the facility external grounding conductor and in internal paths through the conduits and ironwork should be monitored, and potential differences between electrical wiring and local structural grounds should be monitored.

If it is found that a gap smaller than 2D is adequate for most facilities, the requirement for the isolation gap can be relaxed. The possibility of using a shorter isolation gap is important for retrofitting facilities to incorporate $E_{3}$ protection; it could be very difficult and costly to achieve a large gap in some facilities. Thus, if a smaller gap is satisfactory, it should be used.

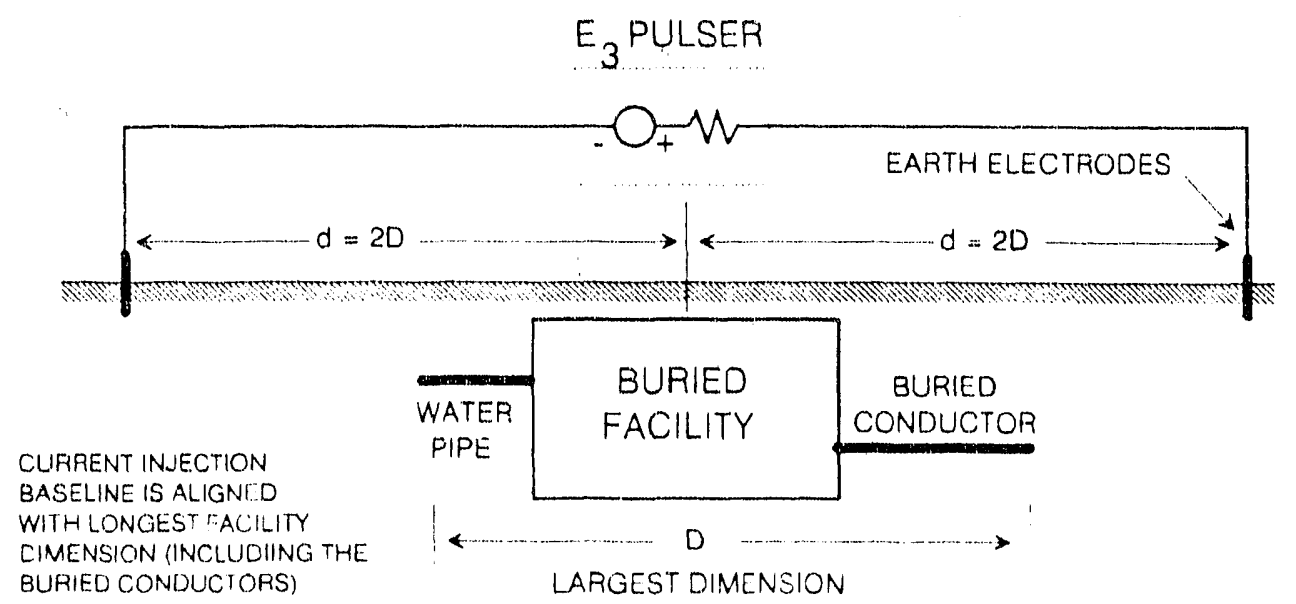

Fig. 4.10. $E_{3}$ testing of buried facilities. 
(Blans) 


\section{SUMMARY}

This report has discussed methods of mitigating the effects of MHD-EMP on critical facilities, with an emphasis on the electrical power system. Most of the mitigation methods are based on a very simple approach: to prohibit the flow of dc current through grounded earth conductors. This can be accomplished either by ungrounding one end of the conductor or by adding a large series resistance in the conductor. Problems arise with either of these methods, however, for conductors that are normally designed to carry signals or information. Furthermore, safety related concerns become important in modifying the grounding configuration in power systems.

Due to the similarit, of the MHD-EMP environment and that arising from a geomagnetic storm, there are some historical data regarding system responses to these quasi-dc E-fields, as well as existing measures for protecting systems. Simulations of the effects of geomagnetic storms also have been conducted and these form the basis for possible tests of the effects of MHD-EMP on critical facilities. This report discusses a number of different test configurations, both for non-signal lines (i.e., water pipes) and signal or power lines, which can collect MHDEMP energy.

Unfortunately, there is very little experience with this type of quasi-dc testing on large facilities. Previous testing of geomagnetic storm effects has involved mainly component (transformer) testing to observe the degree of saturation and harmonic distortion caused by the injected dc current. The degree of possible permanent damage induced by such testing in the facility is unknown. Similarly, the inadvertent effects of testing on the power utility is unknown. Such test programs should be conservative by nature until the system-level effects of the $\mathrm{E}_{3}$ environment are better understood. 
(Blank) 


\section{REFERENCES}

1. J.R. Legro et al., Study to Assess the Effects of Magnetohydrodynamic Electromagnetic Pulse on Electric Power Systems, ORNL/Sub-83/43374/1/V3, Martin Marietta Energy Systems, Inc., Oak Ridge Natl. Lab., May 1985.

2. G. Cucchi, and J. Ponder, "Summary of March 13, 1989 Geomagnetic Storm Effects," Panel Session 25, Proceedings of the 12th IEEE/PES Transmission and Distribution Conference and Exposition, Dallas, September 22-27, 1991.

3. G.B. Rackcliff et al., "Simulation of Geomagnetic Currents Induced in a Power System by Magnetohydrodynamic Electromagnetic Pulses," IEEE Transactions on Power Delivery, 3 (1), pp.392-397 (January 1988).

4. V.J. Kruse, and G. B. Rackcliff, "Load Flow Studies in the Presence of Magnetohydrodynamic Electromagnetic Pulse," Proceedingsof the 1/th IEEE/PES Transmission and Distribution Conference and Exposition, New Orleans, April 2-7, 1989.

5. P. R. Barnes et al., Electric Utility Industry Experiences with Geomagnetic Disturbances, ORNL-6665, Martin Marietta Energy Systems, inc., Oak Ridge Natl. Lab., September 1991.

6. R. A. Walling, A.H. Khan, "Characteristics of Transformer Exciting-Current During Geomagnetic Disturbances," Paper 91 WM 095-0 PWRD, presented at the IEEE/PES Winter 1991 meeting, New York, February 3-7, 1991.

7. A. Freund, "Double the Neutral and Derate the Transformer or Else," EC\&M, December 1988 .

8. R.C. Dugan, D. T. Rizy, and J. P. Stovall, Electric Power System Harmonics Design Guide, ORNL/Sub/81-95011/3, Martin Marietta Energy Systems, Inc., Oak Ridge Natl. Lab., September $198 \%$.

9. C.E. Baum, Electromagnetic Topology for the Analysis and Design of Complex Electromagnetic Sysems, pp. 467-547 in Fast Electrical and Optical Measurements, Vol Y, eds. I.E. Thompson and L.H. Luessem, Martinus Nijhoff, Dordrecht, 1986.

10. F.M. Tesche, "Topological Concepts for Internal EMP Interaction," IEEE Trans. EMC, 20 (1), February 1978.

11. High-Altitude Electromagnetic Pulse (HEMP) Protection for Ground-Based C4I Facilities Performing Critical, Time-Urgent Missions, MIL-STD-188-125, U.S. Department of Defense, June 26, 1990. 
12. E.R. Taylor, and V. Albertson,"GlC Mitigation Methods and Considerations," Panel Session 25, Proceedings of the 12th IEEE/PES Transmission and Distribution Conference and Exposition, Dallas, September 22-27, 1991.

13. C. Crisp, Crisp Enterprises, Maryville, TN, Private communication with the authors, May 1, 1991.

14. J.G. Kappenman, Transformer DC Excitation Field Test and Results, pp. 14-22 in Effects of Solar-Geomagnetic Disturbances on Power Systems, Special Panel Session Report 90TH0291-5 PWR at the IEEE PES Summer Meeting, Long Beach, CA, July 12, 1989.

15 Grounding, Bonding and Shielding, MIL-STD-188-124, U.S. Department of Defense.

16 W.J. Karzas, Evaluation of Low-Frequency Current Flow as a Function of Grounding Distance, Technical Memorandum, Metatech Corp., Santa Monica, CA, September 16, 1990. 


\section{APPENDIX}

\section{THE THEORETICAL BASIS FOR MHD-EMP CURRENT INJECTION SIMULATION}

A possible approach for simulating the effects of MHD-EMP on critical facilities is to inject a quasi-dc current into the facility. This is realized by exciting the long lines entering the facility with a suitably designed $E_{3}$ pulser. The term "pulser" is slightly misleading, because the injected current is not a fast-rising pulse as is needed in testing for the early-time $E_{1}$ system responses. Rather, it is a slowly varying, quasi-dc, waveform, having a rise time on the order of 0.5 seconds and a fall time of several hundred seconds. Nevertheless, this terminology has been adopted to refer to the source circuitry and hardware producing a simulated MHD-EMP response.

The design of a pulser suitable for an $E_{3}$ test is based on the specification of Thevenin equivalent circuit connected to the conductor entering the facility. This amounts to specifying a

suitable open.circuit voltage for the pulser, as well as its internal resistance. Such a pulser will then provide the proper MHD-EMP current to flow into the system, regardless of the details of the $d c$ resistances within the facility. This is in contrast to the $E_{3}$ simulation approach suggested in ref. Al, which puts a specification on the response of the current entering the facility without regard to its internal electrical configuration.

This appendix summarizes the theoretical basis for $\mathrm{E}_{3}$ simulation based on current injection techniques. This summary starts with the simple case of an isolated single conductor and proceeds through the more complicated cases involving three-phase power lines. For each case, the required pulser voltage and impedance is discussed, and various alternatives in the simulation concept are explored.

\section{A.1 AN ISOLATED SINGLE CONDUCTOR}

The simplest conductor configuration for $E_{3}$ testing consists of a conductor of length $L$ that is terminated by a load resistance $\left(R_{L_{1}}\right)$ and a grounding, or footing resistance $\left(R_{g_{1}}\right)$ at the far end of the line (Fig. A.1). In a real facility, conductors of this type can be found in the form of coaxial cables from external antennas; buried conducting pipes; signal wires; or a single power conductor having an earth return. 
The conductor is assumed to have a per-unit-length resistance of $r_{c} \Omega / m$, and consequently, there is a total conductor resistance of $R_{c}=r_{c} L$ along the line. Within the facility, there is a general load resistance $\left(R_{L 2}\right)$. Frequently, the value for this resistance is not easily calculated, because it depends on the electrical topology within the enclosure and may be comprised of many different parallel grounding paths that are difficult to trace. The fact that the value of $\mathrm{R}_{\mathrm{L} 2}$ may not be well-known is denoted in the figure by a dashed line. However, the value of $R_{L 2}$ can be measured, if desired.

At the facility, there is an additional external grounding resistance $\left(R_{f}\right)$ as shown in Fig. A.1. As with the case of the internal facility resistance, the value of this resistance is difficult to calculate, as it depends on the unseen construction details of the facility foundation.

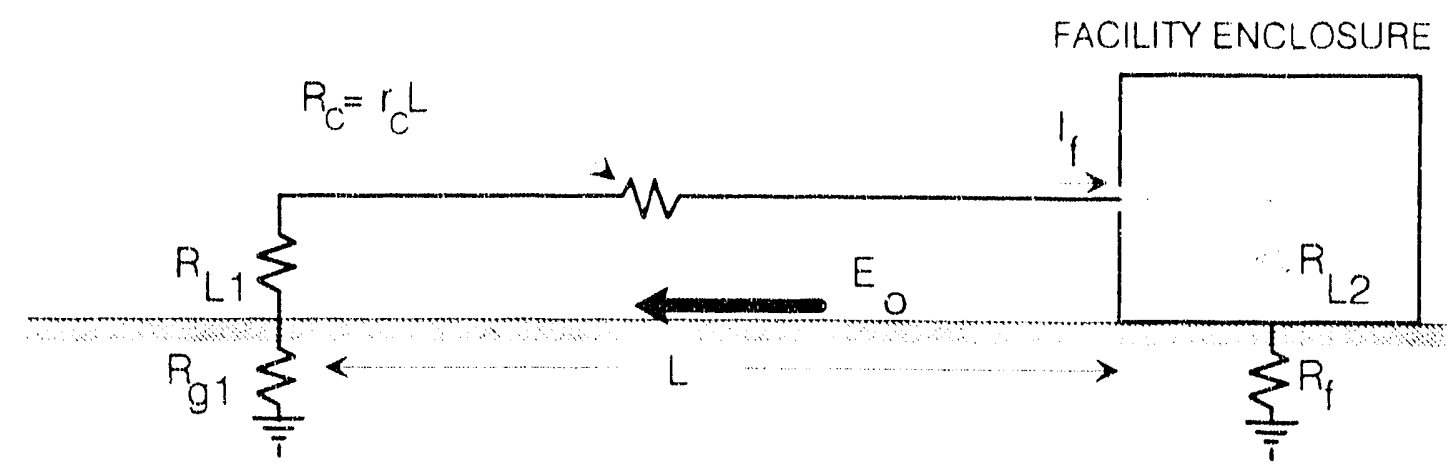

Fig. A.1. An isolated single conductor entering a facility excited by MHD-EMP.

The MHD-EMP E-field waveform induced in the earth $\left(E_{0}(t)\right)$ exists over the entire length of the line, and produces an effective voltage source $\left(E_{0} L\right)$. Because of the simple quaside nature of this excitation, the MHD-EMP-induced current flowing into the facility $\left(\mathrm{I}_{\mathrm{f}}\right)$ can be written as a simple expression involving only the source and the various resistarices as $\mathrm{A} 2$

$$
I_{f}=\frac{E_{o} L}{R_{1}+R_{2}+r_{c} L}
$$

where $R_{1}=\left(R_{L 1}+R_{g 1}\right)$ and $R_{2}=\left(R_{L 2}+R_{f}\right)$. In any of the simulation procedures to be discussed below, the goal of the pulser design is to insure that the same quasi-dc current flows into the facility when the $E_{3}$ excitation is replaced by the pulser. Several different pulser configurations are possible for injecting this simulated currents, and these are discussed below. 


\section{A.1.1 $\mathrm{E}_{3}$ Pulser at Facility Entrance}

Fig. A.2 illustrates one possible simulation configuration, in which the long conducting line is removed and an $E_{3}$ pulser is located at the facility enclosure. This pulser is represented either by a Thevenin equivalent circuit (part (a)) with an open-circuit voltage source $\left(\mathrm{V}_{\mathrm{S}}\right)$ and a source resistance $\left(R_{S}\right)$, or by a Norion equivalent circuit (part (b)) using a short-circuit currenı source $\left(I_{S}\right)$ and a source admittance $\left(G_{S}\right)$. Because the location of the ground connection has changed, it is possible that its grounding resistance $\left(R_{\mathrm{g} 2}\right)$ in Fig. A.2 will be different from the value of $R_{g 1}$ shown in Fig. A.1. This possibility must be taken into account in defining the $E_{3}$ pulser properties.

The values of the equivalent circuit elements of Fig. A.2 are independent of the facility load resistance $\left(R_{L 2}\right)$ and have the following simple forms:

$$
\begin{aligned}
& R_{s}=R_{L 1}+r_{c} L+\left(R_{g 1}-R_{g 2}\right) \text {, and } \\
& V_{s}=E_{o} L,
\end{aligned}
$$

for the Thevenin circuit; and

$$
\begin{aligned}
& \mathrm{G}_{\mathrm{S}}=1 / \mathrm{R}_{\mathrm{s}}, \text { and } \\
& \mathrm{l}_{\mathrm{s}}=\mathrm{E}_{\mathrm{O}} \mathrm{L} \mathrm{G}_{\mathrm{s}}
\end{aligned}
$$

for the Norton equivalent circuit of the pulser. In both of these equivalent circuits, there is a resistance correction term $\left(\mathrm{R}_{\mathrm{g} 1}-\mathrm{R}_{\mathrm{g} 2}\right)$ that accounts for the possible changes in the grounding resistances. This term usually is smaller than the other resistances $\mathrm{R}_{\mathrm{L} 1}$ and $\mathrm{r}_{\mathrm{c}} \mathrm{L}$, and may not important. However, for short lines with $\mathrm{R}_{\mathrm{L}_{1}} \approx 0$, this correction term can be significant.

Either the Thevenin or the Norton form of the pulser can be used to represent its desired electrical behavior for simulating the $E_{3}$ environment. For the remainder of this discussion, only the Thevenin equivalent circuit for the $\mathrm{E}_{3}$ pulser shown in Fig. A.2a will be discussed. 


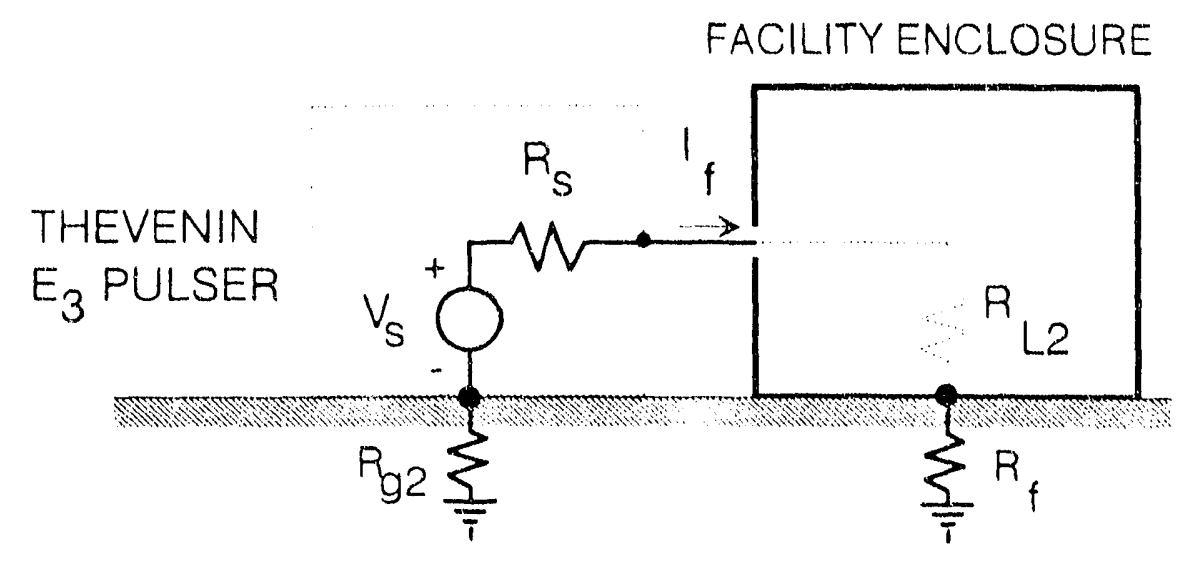

(a)

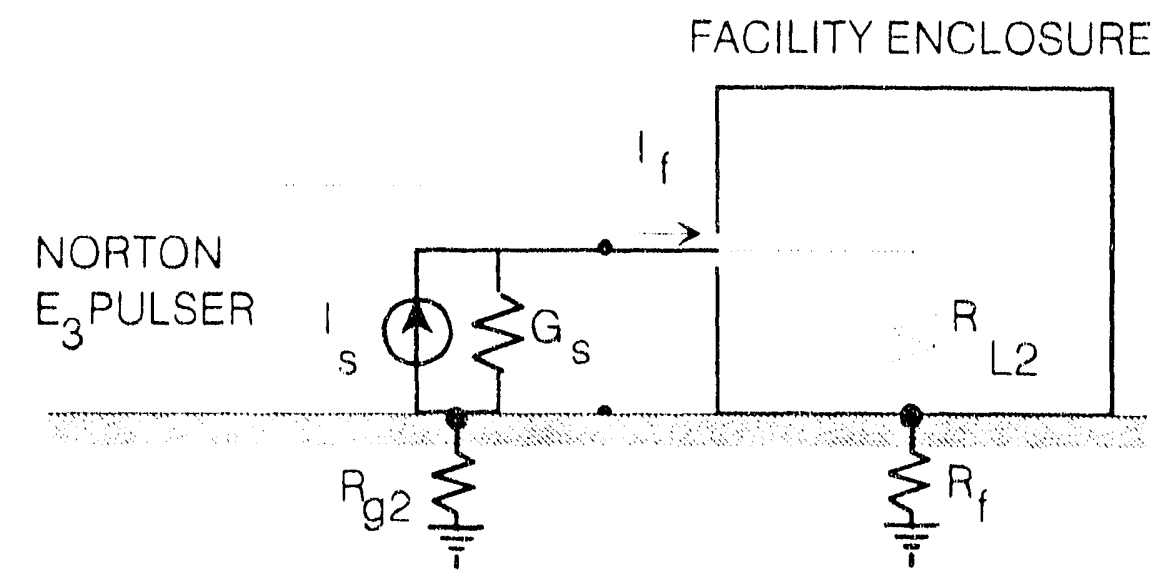

(b)

Fig. A.2. Simulation of MHD-EMP excitation by an equivalent circuit. (a) Thevenin equivalent pulser, (b) Norton equivalent pulser. 
Frequently, it is desired to perform a worst-case simulation on a facility by injecting the largest current that could be collected by the incoming line. This will occur when the line becomes very long and the term $r_{c} L$ dominates. In this case the $E_{3}$ pulser has the following pa. rameters:

$$
\begin{aligned}
& \mathrm{R}_{\mathrm{s}}=\mathrm{r}_{\mathrm{c}} \mathrm{L}, \text { and } \\
& \mathrm{V}_{\mathrm{S}}=\mathrm{E}_{\mathrm{O}} \mathrm{L} .
\end{aligned}
$$

The resulting current flowing into the facility in this case is

$$
I_{f}=\frac{E_{o} L}{r_{c} L+R_{L 2}+R_{f}} .
$$

Note that the maximum current that would flow into the facility, if the internal load resistance $\left(R_{L_{2}}\right)$ and the facility grounding resistance $\left(R_{f}\right)$ are both short circuits, is given by $\left[l_{f}\right]_{\max }=E_{0} / r_{c}$. The resistances $R_{L 2}$ and $R_{f}$ in the denominator in Eq. (A5) both serve to reduce this current. Thus, for a simulation of the worst-case response, the pulser circuit parameters should be chosen according to Eq. (A4), with the added requirement that $r_{c} L>R_{L 2}+R_{f}$.

For this simulation, it is evident that the maximum excitation depends on the electrical resistance of the long line entering the facility. Tables A.1 and A.2 present values of $r_{c}$ for different sizes of aluminum and copper wires that may be used in Eq. (A4) to determine the correct value of $R_{S}$ for the $E_{3}$ pulser. Reference $A .3$ presents additional resistance data for other wire sizes. Also shown in Tables A.1 and A.2 is the maximum simulated MHD-EMP current that could flow. This current is presented normalized form for a $1 \mathrm{~V} / \mathrm{km}$ MHD.EMP field as $\left[\mathrm{I}_{\mathrm{f}}\right]_{\max } / \mathrm{E}_{\mathrm{O}}(\mathrm{A}-\mathrm{km} / \mathrm{V})$.

If the long conductor normally carries an electrical signal or power, the $E_{3}$ pulser must also provide this excitation to the facility if a power-on test is to be conducted. This can add considerable complications to the pulser design in this case, since the original source is no longer available to power the facility. The following simulation concept for a long, single conductor can help to alleviate this problem. 
Table A.1

Per-unit-length resistance and maximum normalized maximum response current for different aluminum wires.

\begin{tabular}{ccc}
\hline Wire size & $\begin{array}{c}\text { Per-unit-length resis- } \\
\text { tance }\end{array}$ & $\begin{array}{c}\text { Normalized }\left[\mathbf{I}_{\mathbf{f}}\right]_{\max }(\boldsymbol{\Omega} / \mathbf{k m}) \\
\mathbf{E}_{\mathbf{0}}\end{array}$ \\
$4 / 0$ & 0.27 & 3.65 \\
$3 / 0$ & 0.34 & 2.90 \\
$2 / 0$ & 0.44 & 2.29 \\
$1 / 0$ & 0.55 & 1.82 \\
1 & 0.70 & 1.44 \\
2 & 0.88 & 1.14 \\
3 & 1.11 & 0.90 \\
4 & 1.39 & 0.72 \\
5 & 1.75 & 0.57 \\
6 & 2.21 & 0.45 \\
\hline
\end{tabular}

Table A.2

Per-unit-length resistance and maximum normalized maximum response current for different copper wires.

\begin{tabular}{ccc} 
Wire size & $\begin{array}{c}\text { Per-unit-length resis- } \\
\text { tance }\end{array}$ & $\begin{array}{c}\text { Normalized } \mathbf{r}_{\mathbf{c}}(\mathbf{\Omega} / \mathbf{k m}) \\
\mathbf{A m p s - k m} / \mathbf{m a x} / \mathbf{E}_{\mathbf{o}}\end{array}$ \\
$4 / 0$ & 0.17 & 5.83 \\
$3 / 0$ & 0.22 & 4.61 \\
$2 / 0$ & 0.27 & 3.66 \\
$1 / 0$ & 0.34 & 2.90 \\
1 & 0.43 & 2.33 \\
2 & 0.55 & 1.83 \\
3 & 0.69 & 1.45 \\
4 & 0.86 & 1.16 \\
5 & 1.09 & 0.92 \\
6 & 1.37 & 0.73 \\
\hline
\end{tabular}

\section{A.1.2 E3 Pulser at Far End of the Line}

A second simulation concept for the long, single conductor line is to locate the $E_{3}$ pulser in series with the line, perhaps at the far end, as shown in Fig. A.3. The advantage in doing this is that the resistances $R_{L 1}, R_{L 2}, r_{c} L$ and $R_{g 1}$ remain intact; and if there is an excitation source on the line providing normal operational power of signals, it also can remain intact during the simulation. For the correct simulation in this case, the $E_{3}$ pulser parameters are given as 


$$
\begin{aligned}
& R_{S} \ll\left(R_{L 1}+R_{g 1}+R_{L 2}+R_{f}+r_{c} L\right), \text { and } \\
& V_{S}=E_{0} L
\end{aligned}
$$

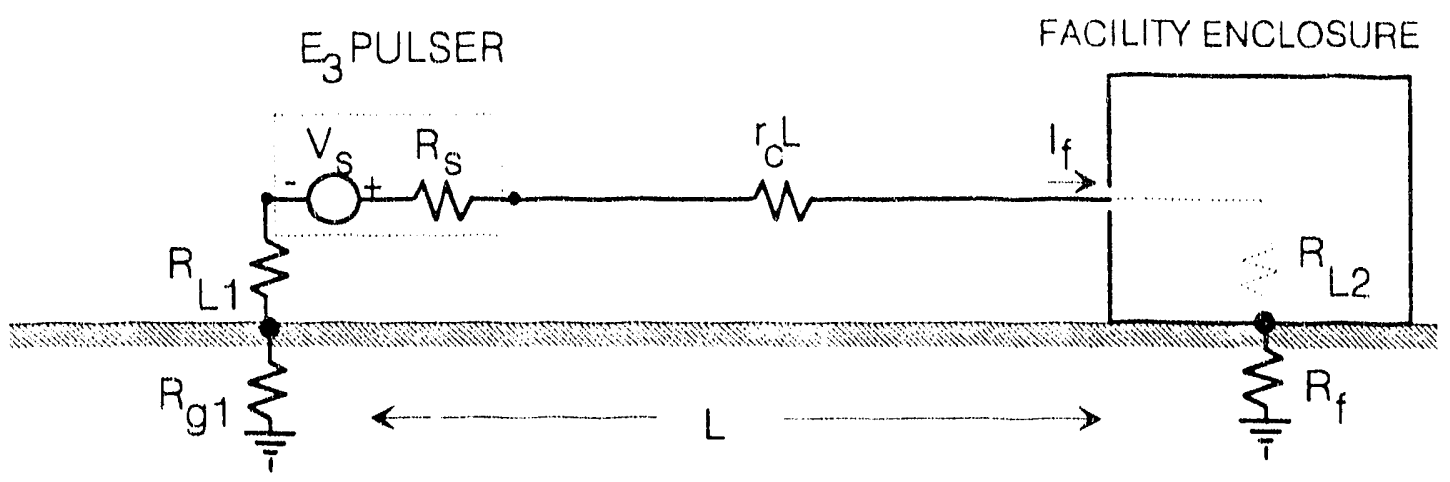

Fig. A.3. MHD-EMP simulation with the pulser in series with the line.

At times, it may be difficult to insure that the pulser resistance $\left(R_{S}\right)$ is sufficiently low, according to Eq. (A6a). In this case, an increase in the pulser voltage can overcome the effect of the additional resistance. Given a non-zero value of the source resistance $\left(R_{S}\right)$, the augmented source voltage is expressed as

$$
V_{\mathrm{s}}=\mathrm{E}_{\mathrm{O}} \mathrm{LF} \text {, }
$$

where the function $F$ is

$$
F=\left[1+\frac{R_{s}}{\left(R_{L 1}+R_{g 1}\right)+\left(R_{L 2}+R_{f}\right)+r_{c} L}\right]
$$

Note that this function also involves the facility resistances $R_{L 2}$ and $R_{\mathrm{g} 2}$. These must be known or estimated for the pulser voltage to be properly increased. When this method is used to produce the proper simulated current, it should be kept in mind that current interrupters or other protection devices may be overtested by the increased open-circuit pulser voltage.

\section{A.1.3 $E_{3}$ Pulser Along the Line}

A third simulation configuration locates the $E_{3}$ pulser at a location $x_{5}$ along the line (Fig. A.4.). This is similar to one of the current injection configurations suggested in MIL-STD-188125 (ref. A 1). As in the previous case, the normal operational signal source for the long line is left intact, so that the $E_{3}$ pulser need not simulate this component of the excitation. However, 
the presence of the pulser will tend to short out a portion of the signal or power at its location $\left(\mathrm{x}_{\mathrm{s}}\right)$.

To minimize this loading that the pulser has on the system, the pulser impedance should be large at the power or signal frequency. This can be achieved by constructing the pulser impedance as a series $R-L$ circuit, so that $Z_{S}=R_{S}+j \omega L_{S}$. The inductance $L_{S}$ is chosen such that $\omega L_{s} \gg R_{L_{1}}+R_{g 1}$ or $R_{L_{2}}+R_{f}$. In this way, the pulser can inject an E3 signal into the system, but the normal operation of the system is not adversely affected.

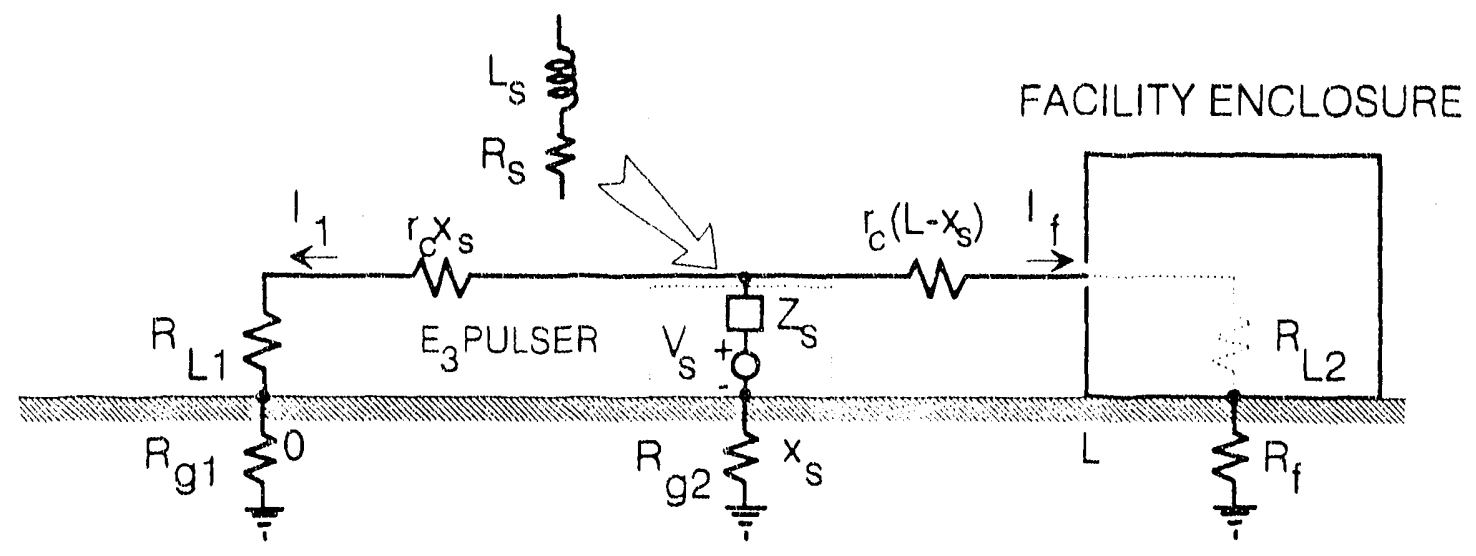

Fig. A.4. MHD-EMP simulation with the pulser across the line.

To develop an expression for the necessary pulser voltage level, the line resistances are divided into two parts, one to the left and another to the right of the pulser. Requiring that the simulated facility current be the same as in the MHD-EMP excitation case leads to the following requirements on the $E_{3}$ pulser voltage:

$$
V_{\mathrm{s}}=\mathrm{E}_{\mathrm{O}} L \mathrm{~F} \text {, }
$$

where the function $F$ is now

$$
F=\frac{\left(\left(R_{1}+r_{c} x_{s}+R_{s}^{\prime}\right)\left(R_{2}+r_{c}\left(L-x_{s}\right)+R_{s}^{\prime}\right)-\left(R_{s}^{\prime}\right)^{2}\right)}{\left(R_{1}+R_{2}+r_{c} L\right)\left(R_{1}+r_{c} x_{s}\right)}
$$

where $R_{1}=R_{L 1}+R_{g 1}, R_{2}=R_{L 2}+R_{f}$ and $R_{s}^{\prime}=R_{s}+R_{g 2}$. Note that this is a quasi-dc expres. sion, as only the resistive component of the pulser impedance is used.

Several simplifications can be made for this function for limiting cases of the parameters. For the case in which the $E_{3}$ pulser resistance $\left(R_{S}\right)$ is large, $F$ becomes 


$$
F=\frac{R_{s}}{\left(R_{1}+R_{2}+r_{c} L\right)}
$$

Note that as $R_{s}$ is made large compared with the other resistances in the circuit, the required pulser voltage also becomes large However, $R_{s}$ can not be made too large, because unreasonable values of $\mathrm{V}_{\mathrm{s}}$ would be required for the simulation. However, this is the configuration that MILSTD-188-125 requires: an effective current source across the line at the location $\left(x_{\mathrm{s}}\right)$.

For the case in which the line length becomes very long and the pulser is located a finite distance $d=L-x_{3}$ from the facility, the function $F$ becomes

$$
F=\frac{\left(R_{2}+r_{c} d+R_{s}^{\prime}\right)}{r_{c} L} \approx \frac{d}{L} \text { for finite } R_{L 2} \text { and } R_{s} .
$$

When the load resistance $\left(R_{L 1}\right)$ or the ground resistance $\left(R_{g 1}\right)$ at the far end of the line becomes large, the function $\mathrm{F}$ becomes

$$
F=\frac{\left(R_{2}+R_{s}^{\prime}+r_{c}\left(L-x_{s}\right)\right)}{R_{L 1}+R_{g 1}} \rightarrow 0 \text { as } R_{L 1} \text { or } R_{g 1} \rightarrow \infty .
$$

This term approaches zero, indicating that the required pulser voltage of $E_{O} L F$ is zero for this case. This is due to the fact that in the real case of MHD-EMP excitation, no current flows into the facility due to the open circuit condition at the end of the line. This clearly illustrates the fact that the choice of the $E_{3}$ pulser parameters can depend critically on the nature of the line connections to earth.

A final limiting case of interest is when the resistance within the facility enclosure becomes large. In this case, the function $\mathrm{F}$ is

$$
F=\frac{\left(R_{1}+r_{c} x_{s}+R_{s}^{\prime}\right)}{\left(R_{1}+r_{c} x_{s}\right)} \quad\left(\text { for } R_{L 2} \rightarrow 0\right)
$$

and for very long lines when $L$ and $x_{S} \rightarrow \infty$, this function $F$ approaches unity. 


\section{A.2 A SINGLE CONDUCTOR IVITH CONNECTIONS TO GROUND}

\section{A.2.1 E3 Pulser At Facility Entrance}

Frequently, a single conductor entering a facility can be connected to earth at several points along its length. Although this is not the usual configuration for signal or power carrying lines, it is encountered in shield or neutral conductors in power ystems that may be grounded at each support tower. The case of a bare, buried, coaxial cable or water pipe can be also viewed in this manner.

Fig. A.5 illustrates a periodically grounded single line of length L. Each ground connection is assumed to have a footing resistance of $R_{t} \Omega$, and the length of line in each of the $N$ "cells" between the ground connections is $\Delta$. Consequently, with the per-unit-length line resistance of $r_{c} \Omega / m$, the line resistance in each cell on the line is $r_{c} \Delta \Omega$. As in the previous case, $R_{L 1}$ and $R_{L 2}$ represent the load resistances at each end of the line, and $R_{g 1}$ and $R_{f}$ are the grounding resistances.

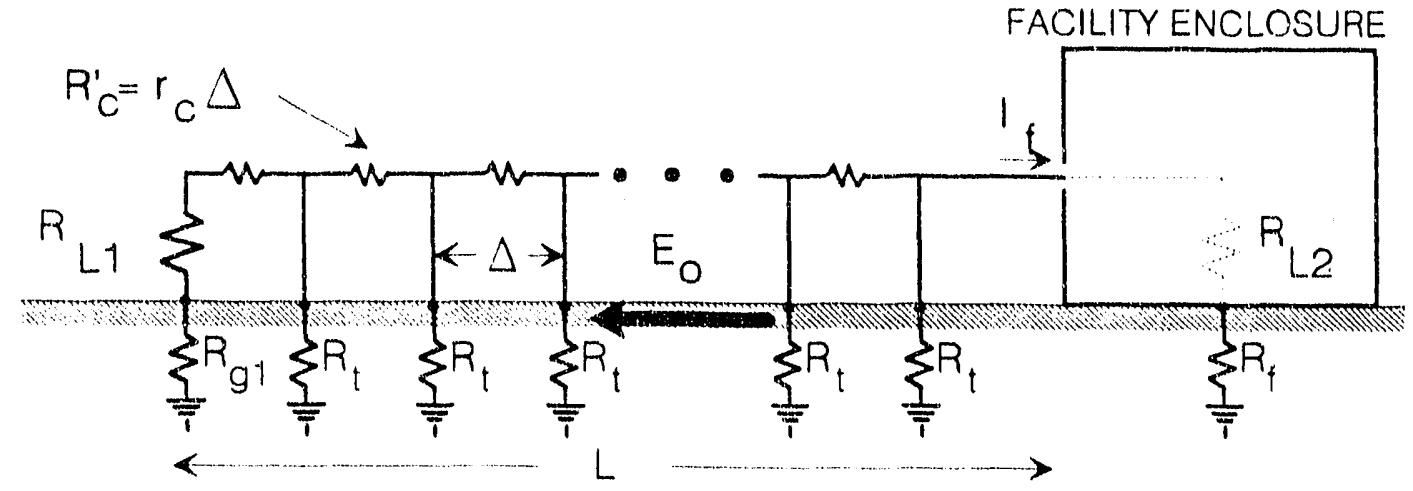

Fig. A.5. Configuration of a single line periodically connected to earth.

At the facility entrance, this grounded line can be replaced by the equivalent $E_{3}$ pulser circuit of Fig. A.2a. Using the analysis procedure developed in ref. A2, the pulser resistance and the required voltage source can be expressed as 


$$
V_{s}=\frac{E_{0} L}{\alpha L} \frac{\left(1-e^{-2 \alpha \mathrm{L}}\right)^{2}}{\left(1-e^{-2 \alpha L}\right)}\left[1+\frac{2 e^{-\alpha \alpha L} \cdot R}{\left(\Re\left(1+e^{-2 \alpha L}\right)+R_{1}\left(1-e^{-2 \alpha L}\right)\right)}\right]
$$

and

$$
R_{s}=\frac{\Re}{\left(1-e^{-2 \alpha L}\right)}\left[\left(1-e^{-2 \alpha L}\right)^{2}+\frac{2 e^{-\alpha L}\left(\Re\left(1-e^{-\alpha L}\right)^{2}+R_{1}\left(1-e^{-2 \alpha L}\right)\right)}{\left(\Re\left(1+e^{-2 \alpha L}\right)+R_{1}\left(1-e^{-2 \alpha L}\right)\right)}\right]
$$

where $\Re$ and $\alpha$ are characteristic parameters of the line and are given by

$$
\begin{aligned}
& \Re=P_{f} \sqrt{r_{c} L /\left(R_{f} N\right)}(\Omega) \text {, and } \\
& \alpha=\sqrt{N r_{c} /\left(R_{f} L\right)} \quad(1 / m)
\end{aligned}
$$

and $\mathrm{R}_{1}=\mathrm{R}_{\mathrm{L} 1}+\mathrm{R}_{\mathrm{g} 1}$.

For the case of a continuously grounded line, such as a water pipe having a per-unitlength contact conductance to the earth of $g_{\mathrm{f}}$ mhos/meter, these parameters have the form

$$
\begin{aligned}
& \Re=\sqrt{r_{c} g_{f}}, \text { and } \\
& \alpha=\sqrt{r_{c} / g_{f}} .
\end{aligned}
$$

Figure A.6 presents normalized pulser parameters $\left(R_{S} / R_{L 1}\right)$ and $\left(V_{s} / E_{0} L\right)$ obtained from Eq. (A9), shown as a function of the dimensionless quantity $\alpha \mathrm{L}$. These parameters are presented as a family of curves for different values of the dimensionless ratio $\mathrm{R}_{\mathrm{L} 1} / \Re$. With the definition of $\alpha$ and $\Re$ above, the proper choice of the pulser voltage and resistance can be made either or a discretely grounded line or for a buried line.

\section{A.2.2 $E_{3}$ Pulser at the Far End of the Line}

Figure A.7 shows an alternate simulation configuration for grounded lines, in which an $E_{3}$ pulser is located at the far end of the line. The internal resistance of the puiser $\left(R_{S}\right)$ is assumed to be much smaller than the line termination resistance, and consequently, it is not shown in the figure. 


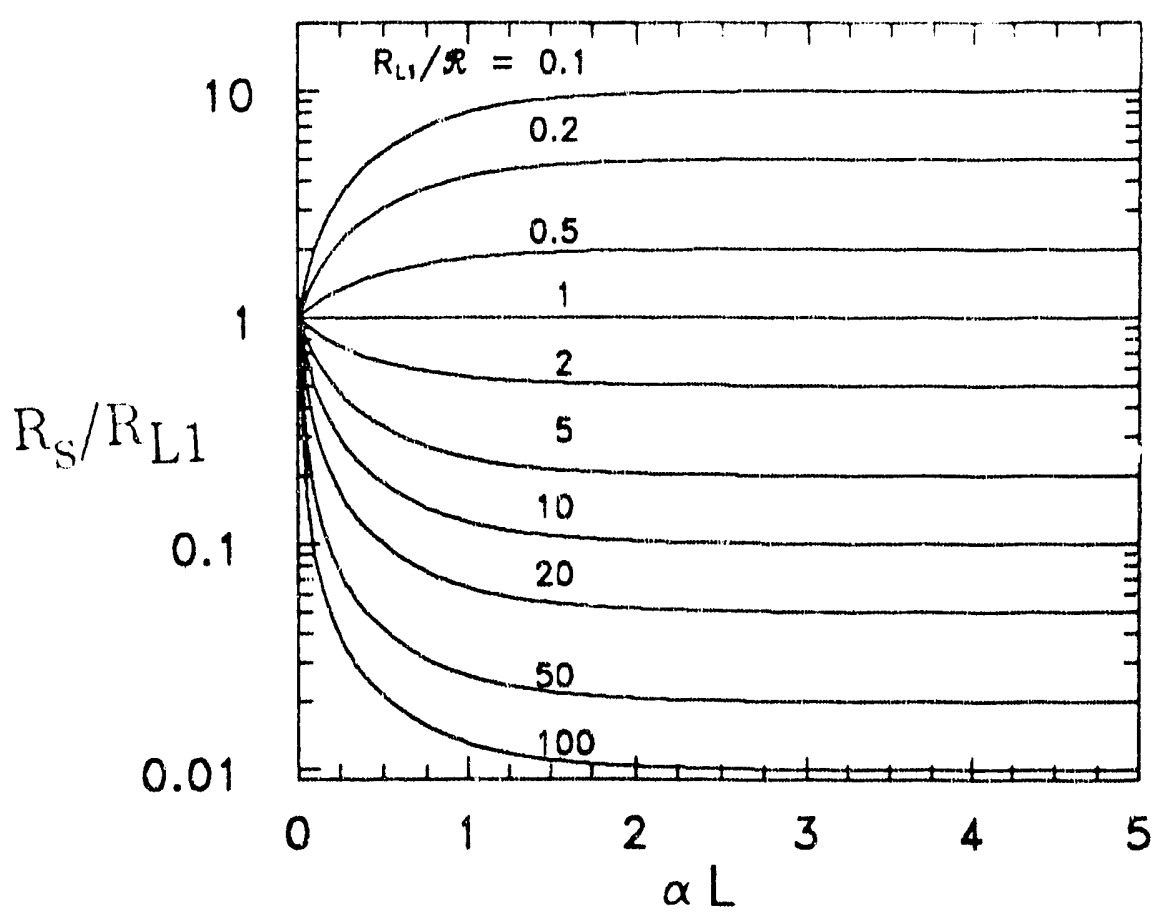

(a)

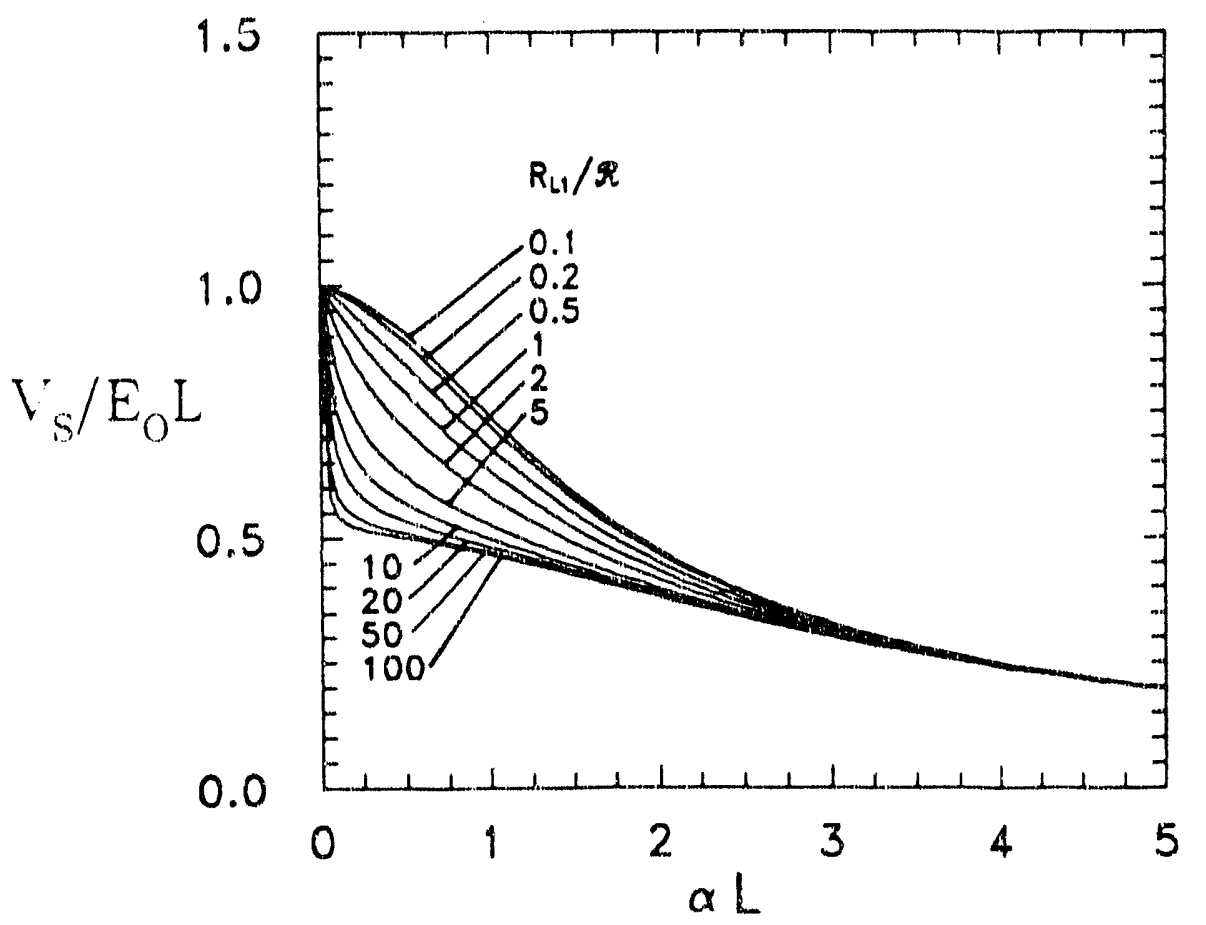

(b)

Fig. A.6. $E_{3}$ pulser parameters for a grounded penetrating conductor using the simulator configuration of Fig. A.2a. (a) Normalized pulser impedance $\left(R_{s} / \Re\right)$, (b) normalized pulser volt$\operatorname{age}\left(V_{\mathrm{s}} / \mathrm{E}_{\mathrm{O}} L\right)$. 
The pulser source is required to drive the line sufficiently strongly to provide the correct current $\left(I_{f}\right)$ entering the facility. Due to the periodic grounding of the line, much of the current induced by the pulser is shunted off of the line to the ground. Thus, it is expected that a much larger lumped voltage source will be required for the pulser in this location than if the pulser were located at the facility. The analysis in ref. A2 can provide an analytical expression for the current $\left(\mathrm{I}_{f}\right)$ due to this lumped voltage source, and this can be equated to the current for the MHD-EMP excited line. This yields an expression for the required voltage source $\left(V_{s}\right)$. Since the line is not disturbed by the addition of the voltage source, the resistance of the line as seen by the facility enclosure has not changed, as long as the pulser resistance is negligible.

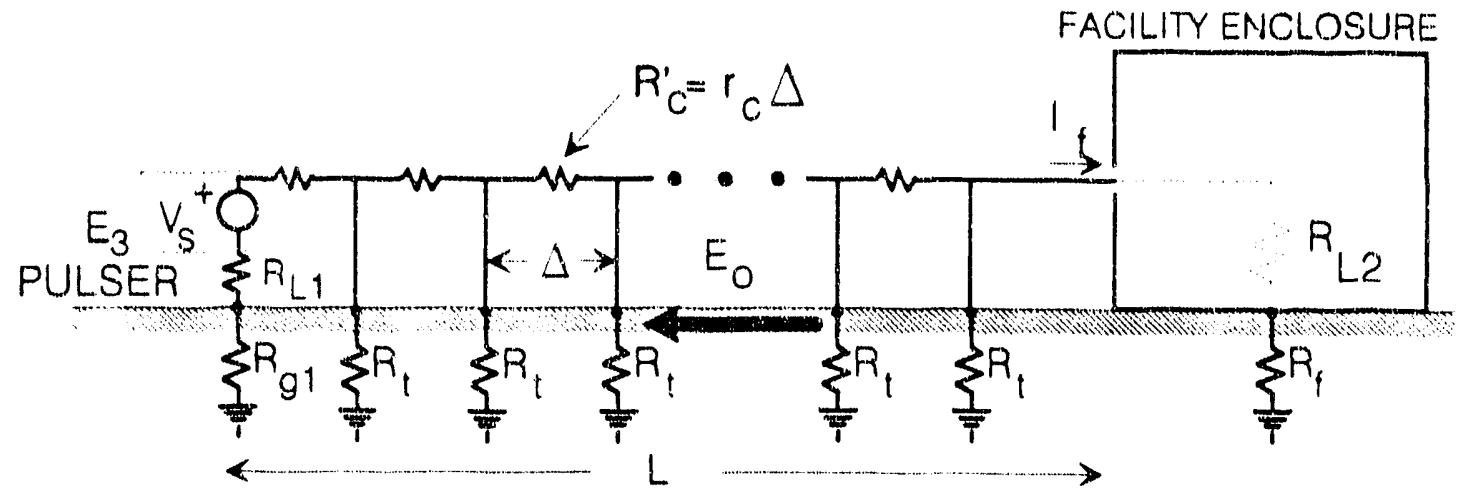

Fig. A.7. E $E_{3}$ simulation for a periodically grourded line using a pulser at the far end of the line.

For this simulation concept, Fig. A.8 presents the required normalized voltage source as a function of the dimensionless constant $\alpha \mathrm{L}$. As in the previous figures, a family of curves is presented for different ratios of $R_{\mathrm{L} 1} / R$, with the effects of the line grounding resistances being manifested in both the parameters $\alpha$ and $\Re$ through Eqs. (A.10) or (A.11). In this calculation, the effect of the grounding resistance $\left(R_{g 1}\right)$ is assumed to be included in the resistive element $R_{L 1}$. It is clear that for many combinations of parameters, a very large pulser voltage source will be required. However, for this simulation the only requirement placed on the pulser resistance is than it be small. 


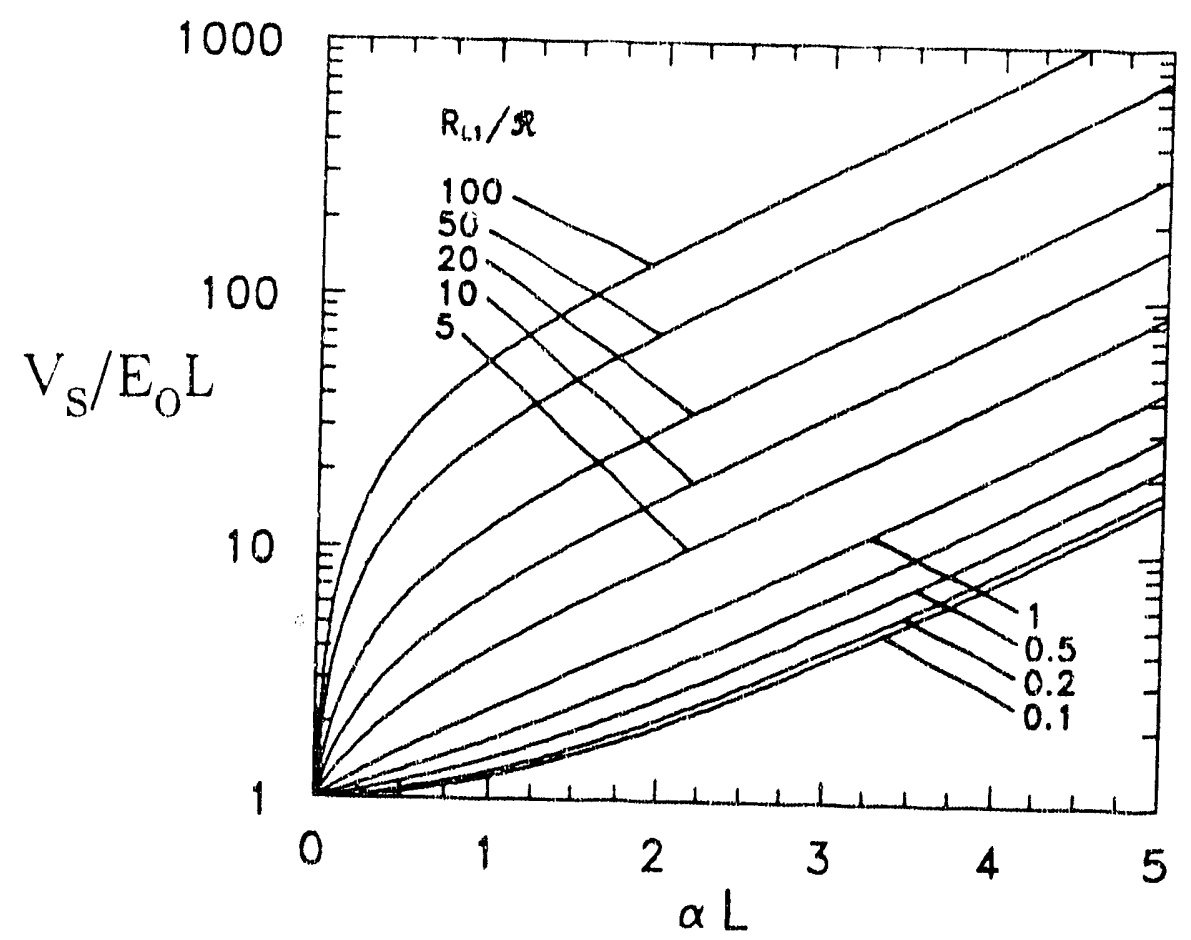

Fig. A.8. Normalized $E_{3}$ pulser voltage for a grounded penetrating conductor with the pulser at the far end of the line.

\section{A.2.3 E E $_{3}$ Pulser Along the Line}

A logical extension of the simulation configuration of Fig. A.4 for the grounded line is to locate the pulser at an intermediate location along the line. The analysis of ref. A2 can be used to develop an expression for the required voltage, and curves similar to those of Fig. A. 8 can be calculated. Generally, the required voltage source will be less than that given in Fig. A.8 as the pulser is located closer to the facility. Since the simulation configuration of locating the pulser at the facility enclosure (Fig. A.2a) is the most desirable in this case, this concept has not been pursued further. 


\section{A. 3 MULTI-PHASE AC POWER PENETRATIONS}

Due to their long lengths, three phase ac power lines entering the facility are potentially important collectors of MHD-EMP energy. In contrast with most single penetrating conductors discussed in the previous section, the three-phase conductors carry normal $60 \mathrm{~Hz}$ power, and the MHD-EMP-induced currents on the line can interact with the energized power equipment to saturate transformers. This saturation creates harmonics within the system, and unless the testing is performed with energized equipment, the effects of these harmonics cannot be fully determined. The requirement for performing $E_{3}$ simulations on energized power equipment poses many problems, including personnel and equipment safety, and the desirability of not interrupting the normal operation of the facility or the commercial power network.

As in the case of the single conductor penetration into the facility, there are a number of different $E_{3}$ simulator configurations that are possible for the case of three-phase penetrations. This section discusses some of the technical aspects of these designs.

\section{A.3.1 Balanced 3-Phase Conductors}

\section{A.3.3.1.1 Unshielded conductors}

A possible line configuration for supplying AC power to a facility is the three-phase line shown in Fig. A.9. A simple version of this line consists of three parallel conductors of length $L$, each having a per-unit-length resistance of $r_{c} \Omega / \mathrm{km}$. At the end of the linc distant from the facility, the line is terminated in a grounded wye transformer secondary having winding resistances $\left(R_{y}\right)$ for each phase, a neutral conductor resistance $\left(R_{L_{1}}\right)$ and a grounding resistance $\left(R_{g_{1}}\right)$. Normally, these transformers are balanced so that the resistances in each phase are identi. cal. In this example, no neutral conductor is carried with the phase conductors. Different electrical utilities have different practices for constructing transmission and distribution lines, and this case is typical of some lines in California. In other instances, a fourth neutral line might be carried with the phase conductors. This latter case also will be discussed in this section.

For this configuration, the primary of the transformer is connected to other parts of the electrical power network, and this supplies the normal $60-\mathrm{Hz}$ power to the line and the facility. Although this power source is not explicitly indicated in Fig. A.9, it could be represented by three voltage sources in series with the transformer secondary resistances $\left(R_{y}\right)$. In addition to these normal operating voltages, there is the earth-induced E-field caused by the MHD-EMP. 
As in the case of the single conductor line, the MHD-EMP currents entering the facility depend on the nature of the load configuration within the facility. Two common load configurations are illustrated in Fig. A.9b and A.9c, in which a grounded wye and an ungrounded delta loads are portrayed. Normally, there is an attempt to balance these loads so that the three resistances $\left(R_{y}{ }^{\prime}\right.$ or $\left.R_{\Delta}\right)$ in each figure are the same for each load configuration. Clearly, in the case of the grounded wye load of Fig. A.9b a quasi-dc current can flow from the earth, up through the grounded wye transformer at the far end of the line, along the line, and then back down to the earth through the wye load. For the usual case of the three phases being balanced, the total quasi-dc current flowing into the facility can be described combining the parallel phase conductors into a single conductor, as shown in Fig. A.10. In this case, the total current is $I_{f}=I_{f 1}+I_{f 2}$ $+\mathrm{I}_{\mathrm{f}}$, and this is given by

$$
I_{f}=\frac{E_{o} L}{\left(R_{1}+R_{2}\right)+\frac{\left(R_{y}+R_{y}^{\prime}+r_{c} L\right)}{3}},
$$

where, as in the previous cases, $R_{1}=R_{L 1}+R_{g 1}$, and $R_{1}=R_{L 2}+R_{f}$.

For the case of the load configuration of Fig. A.9c, there is no conducting path to ground, so there will be no $E_{3}$ current flowing into the facility. Of course, due to the phase differences of the normal $60-\mathrm{Hz}$ power, there will be current flowing in each of these conductors; however, the dc component remains zero. Similarly, if the grounded wye transformer at the far end of the line were replaced with an ungrounded delta transformer, there will be no dc path and no MHD. EMP response.

Several different simulation concepts are possible for this line configuration. Fig. A.11 iliustrates the most general concept, which replaces the excited line with a generalized Thevenin circuit, similar to that in Fig. A.2a for the single line. In this case, the individual resistances in the wye circuit are $R_{s}$ and consist of the series combination of the transformer winding resistances and the phase conductor resistances as

$$
R_{s}=R_{y}+r_{c} L
$$

The other pulser resistance $\left(R_{\mathrm{s} 1}\right)$ takes into account the possible difference in grounding resistances, and is given as

$$
\mathrm{R}_{\mathrm{s} 1}=\mathrm{R}_{\mathrm{L} 1}+\left(\mathrm{R}_{\mathrm{g} 1}-\mathrm{R}_{\mathrm{g} 2}\right)
$$




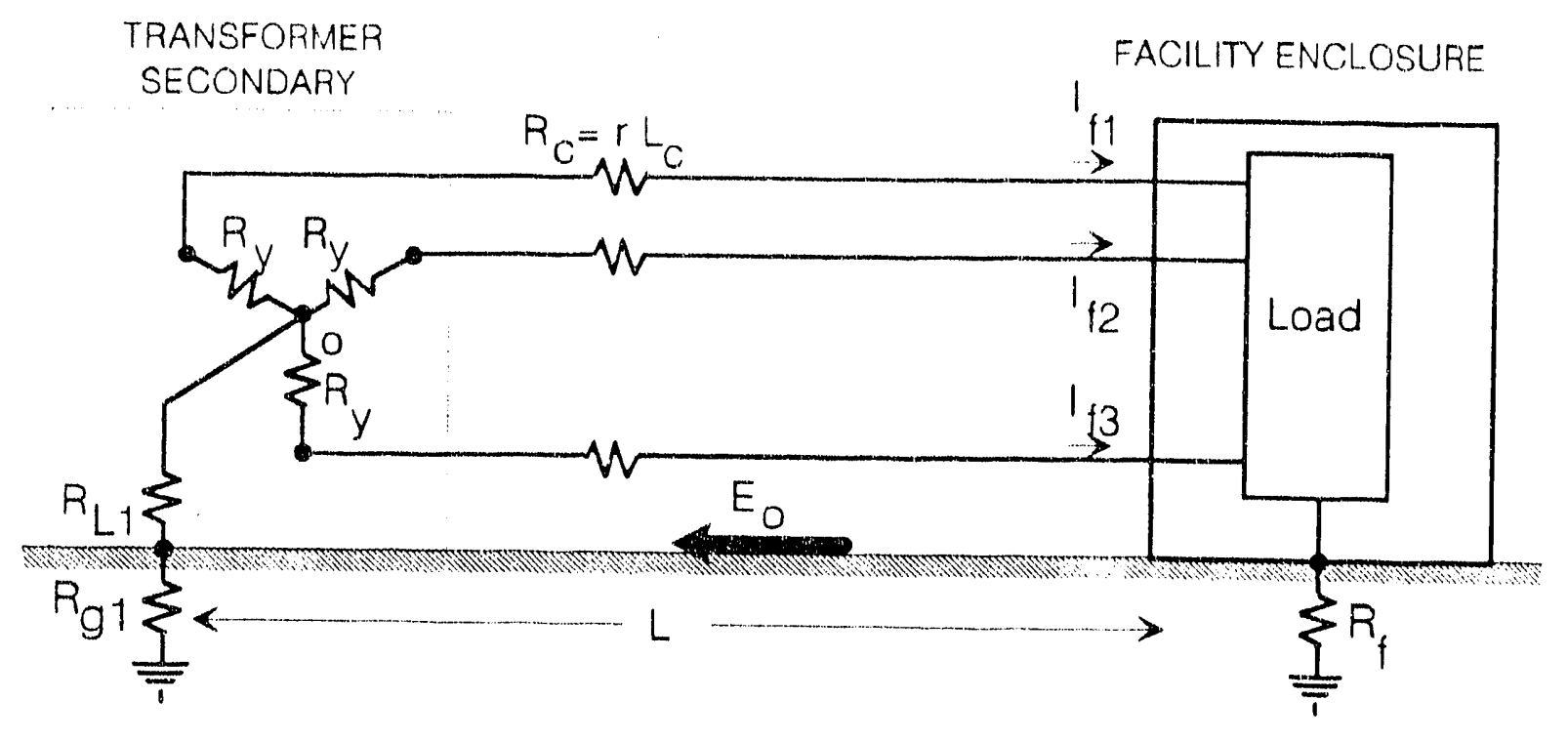

(a)

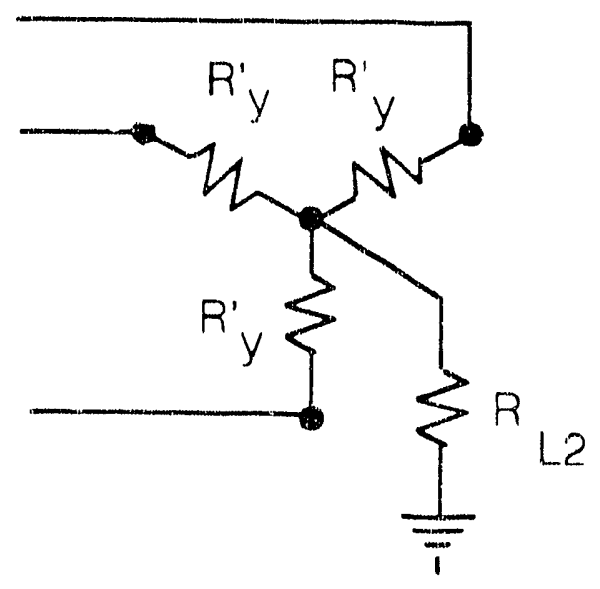

(b)

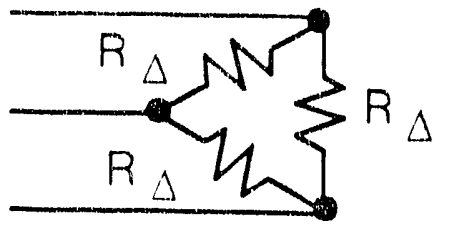

(c)

Fig. A.9. E 3 excitation of a three-phase power line. (a) Line configuration, (b) grounded wye load, (c) isolated delta load. 


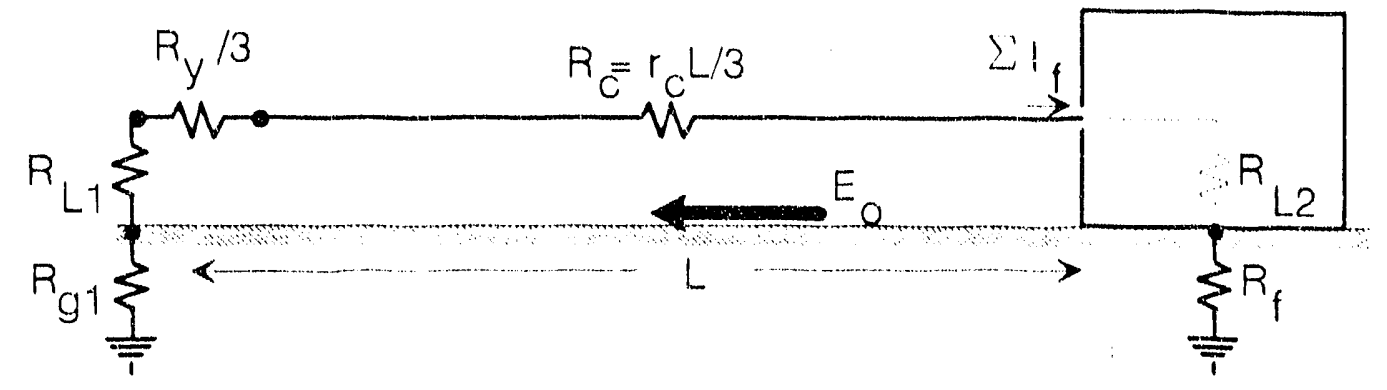

Fig. A.10. Single line equivalent for a balanced three-phase line.

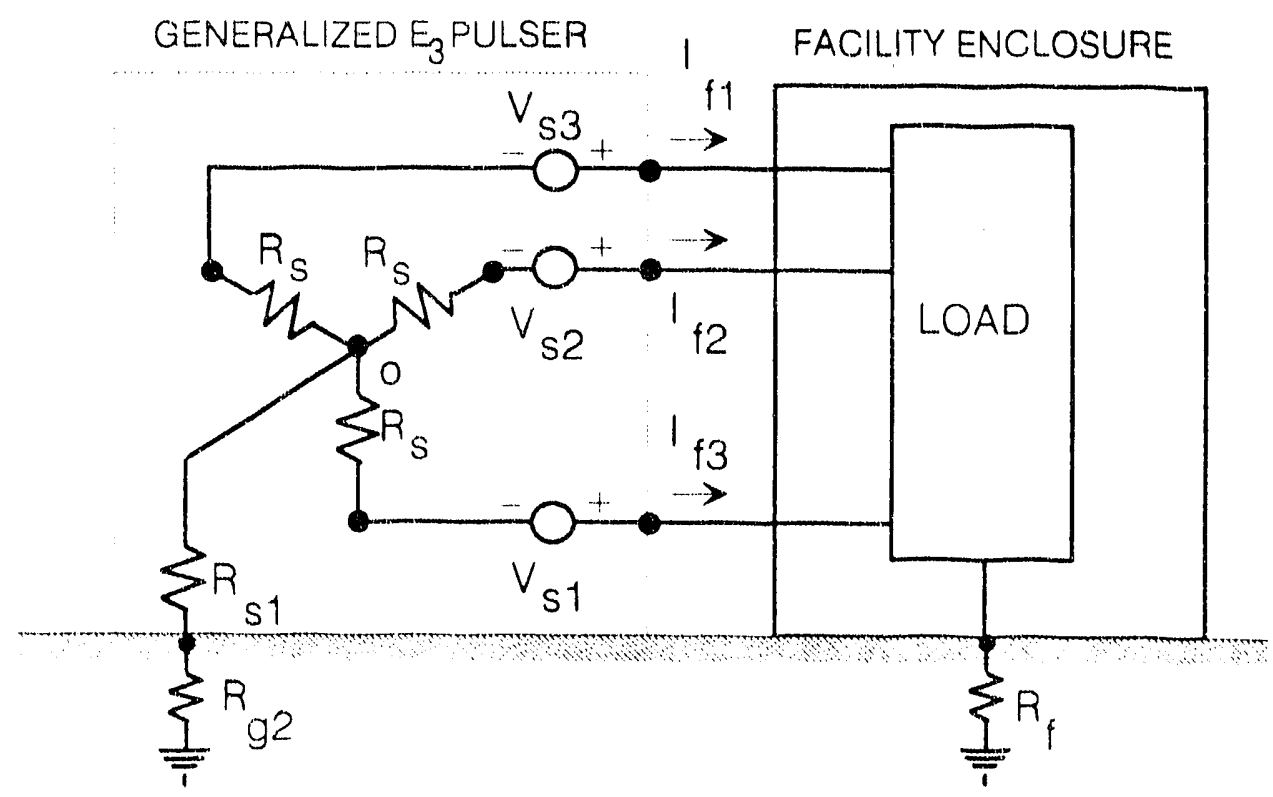

Fig. A.11. Thevenin Equivalent Circuit Excitation Of A Three-Phase Line.

Other equivalent resistance networks are possible for this three-phase pulser, and these may be obtained transforming the wye network to a pi network.

The voltage sources in Fig. A.11 are all equal, and are given by

$$
\mathrm{V}_{\mathrm{s} 1}=\mathrm{V}_{\mathrm{s} 2}=\mathrm{V}_{\mathrm{s} 3}=\mathrm{E}_{\mathrm{o}} \mathrm{L}
$$

In addition to these quasi-dc voltage sources, there must be the provision of the normal threephase $60-\mathrm{Hz}$ power, which could be viewed as three additional voltage sources in the pulser. The requirement to provide these extra sources adds considerable complexity to the pulser design. 
An alternate simulation procedure is suggested in Fig. A.12, in which the three-phase line is left intact and the quasi-dc MHD-EMP voltage is injected through the neutral of the grounded wye transformer. In this manner the normal operation of the transformer continues during the simulation, and the $60-\mathrm{Hz}$ power remains on the lines without additional sources. In addition, the normal saturation characteristics of both the wye transformer and possibly of the internal facility loads will automatically be included in the simulation. If the internal load grounding connection is a well-defined, single-point ground, as shown in the figure, the $E_{3}$ pulser could be located at point $A$ in the figure, instead of at the end of the line. This might be desirable if the line is very long.

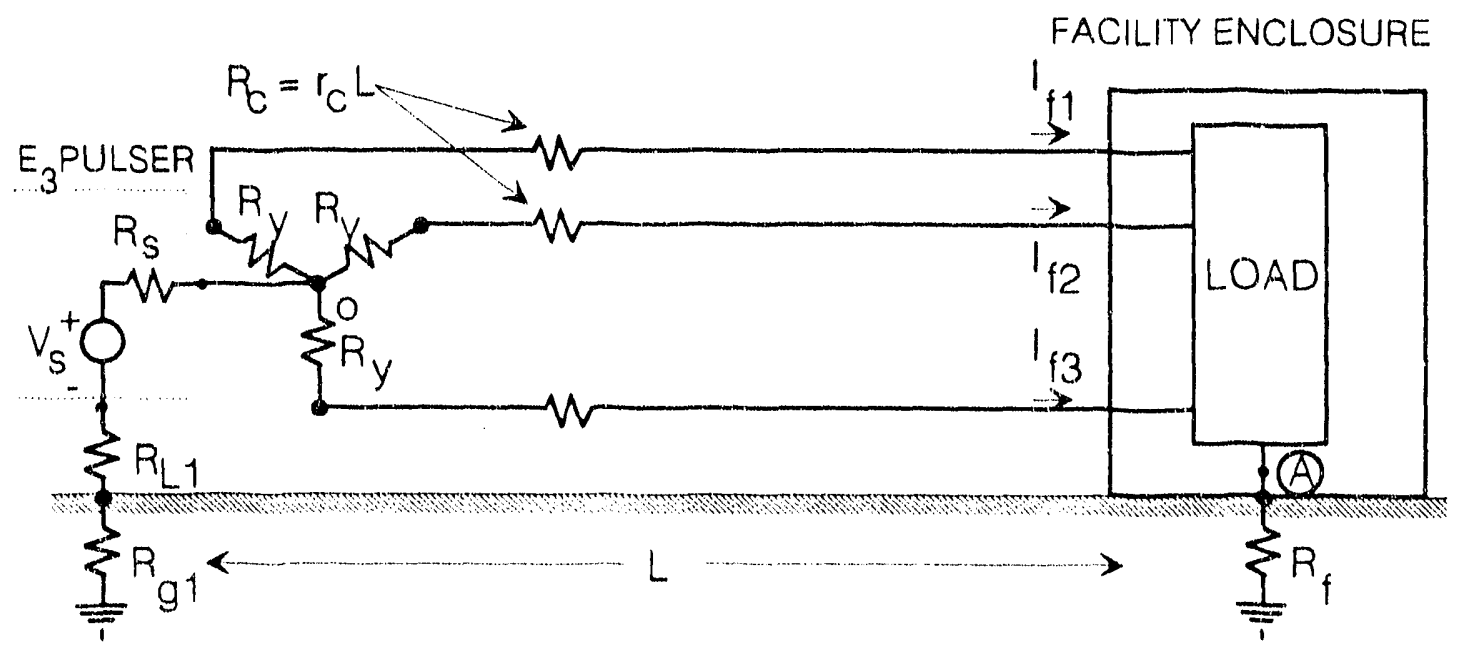

Fig. A.12. $E_{3}$ simulation of a three-phase line with pulser in the transformer neutral conductor.

The single quasi-dc $E_{3}$ pulser for this case has the same voltage characteristics as in the previous case,

$$
\mathrm{V}_{\mathrm{s}}=\mathrm{E}_{\mathrm{O}} \mathrm{L}
$$

and the requirement on the internal pulser resistance $\left(R_{S}\right)$ is simply that

$$
R_{\mathrm{s}} \ll\left(R_{L 1}+R_{g 1}+\left(R_{y} \cdot r_{c} L\right) / 3\right.
$$

This simulation approach is attractive, not only because of the features mentioned above, but also because only a single low resistance voltage source is required. Furthermore, this source need not be designed to pass the $60 \mathrm{~Hz}$ power because it is in the neural circuit. If the 
line is unbalanced, the effects of the unbalanced transformer, line, or load resistances are automatically taken into account. In the simulation approach of Fig. A.11, any line unbalancing must be accounted for explicitly by modifying the individual pulser resistances and voltage sources.

It is also possible to consider locating the $E_{3}$ pulser along the line at a location $x_{5}$. Fig. A.13a shows a pulser consisting of three voltage sources and resistance elements, and Fig. A.13b shows a concept using a single voltage source together with an inductive wye feeding network. These cases are similar to the single-line simulation shown in Figure A.4. This latter network is formed by three large reactive elements providing a low do resistance $\left(R_{t}\right)$ from the pulser to the line, but has a high reactance at $60-\mathrm{Hz}$ to minimize the ac current flow. Furthermore, for a balanced system, the net ac current flow through the wye network is zero. As in the previous single wire case, the goal here is to choose the voltage source(s) in such a way that the quasi-dc current entering the facility is the same as in the case of MHD-EMP excitation. In addition, there is a requirement that the presence of the pulser should not significantly affect the normal operation of the power line. Thus, the source resistances $\left(R_{S}\right)$ in Fig. A.13a should be large compared with the normal resistances of the line.

An analysis of the currents flowing into the facility in Figs. 4.13a and $4.13 \mathrm{~b}$ can be performed by using the dc models discussed in ref. A2, and this can ultimately lead to explicit expressions for the voltage source $(s)\left(V_{s}\right)$ in terms of the $E_{3}$-field and line properties. This is not done here, however, because this simulation approach is not particularly recommended for the testing of three-phase power systems due to the fact that it is important to insure that both the source transformer and the load circuit have the proper simulated excitation. This is particularly critical if the effect of the $60-\mathrm{Hz}$ harmonics generated within the system is to be monitored. In the present simulation concept, there is no guarantee that these harmonics will be generated properly, for the current flowing into the source transformer is considerably different from that experienced with the actual MHD-EMP excitation.

\section{A.3.1.2 Three-phase line with shield or neutral line}

The addition of a fourth neutral conductor to the three-phase line of Fig. 4.9a complicates the simulation procedure. Due to the fact that the internal load can have either of the electrical configurations shown in Figs $4.10 \mathrm{~b}$ and $4.10 \mathrm{c}$, different simulation configurations are possible. 


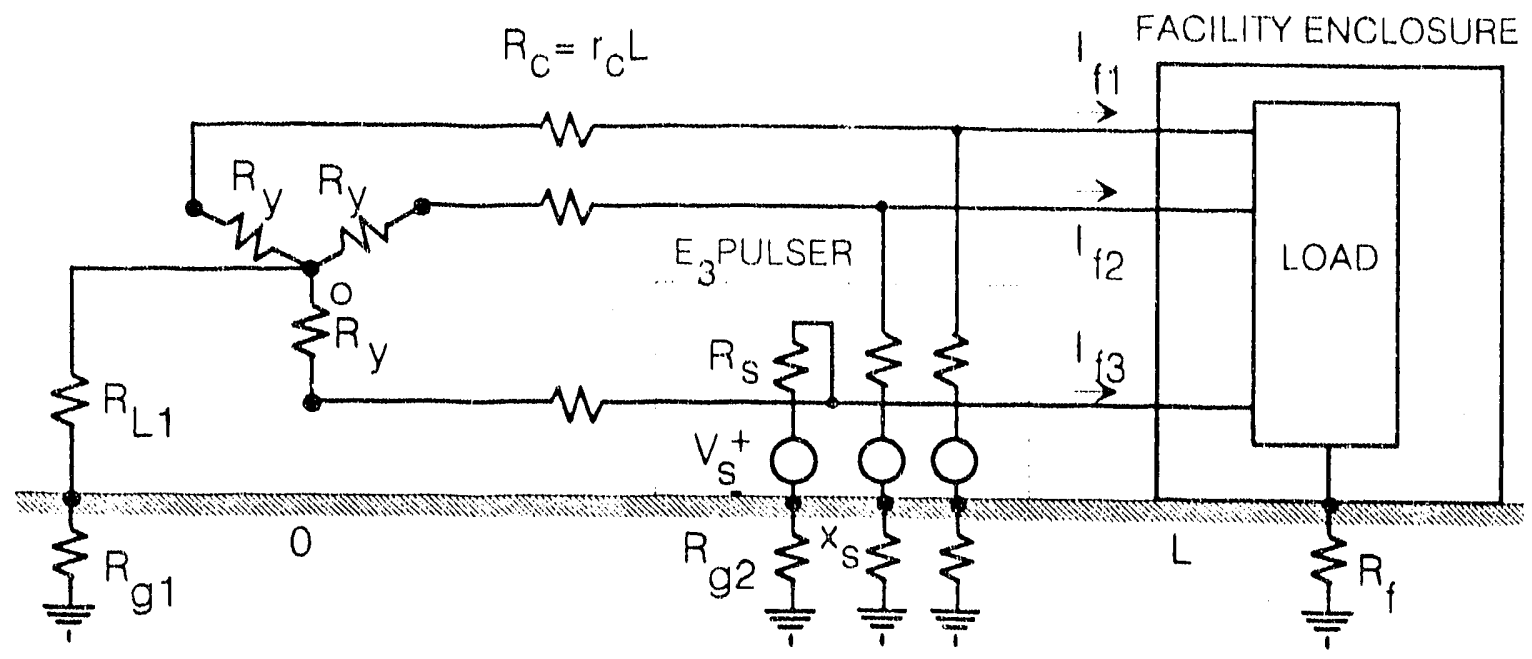

(a)

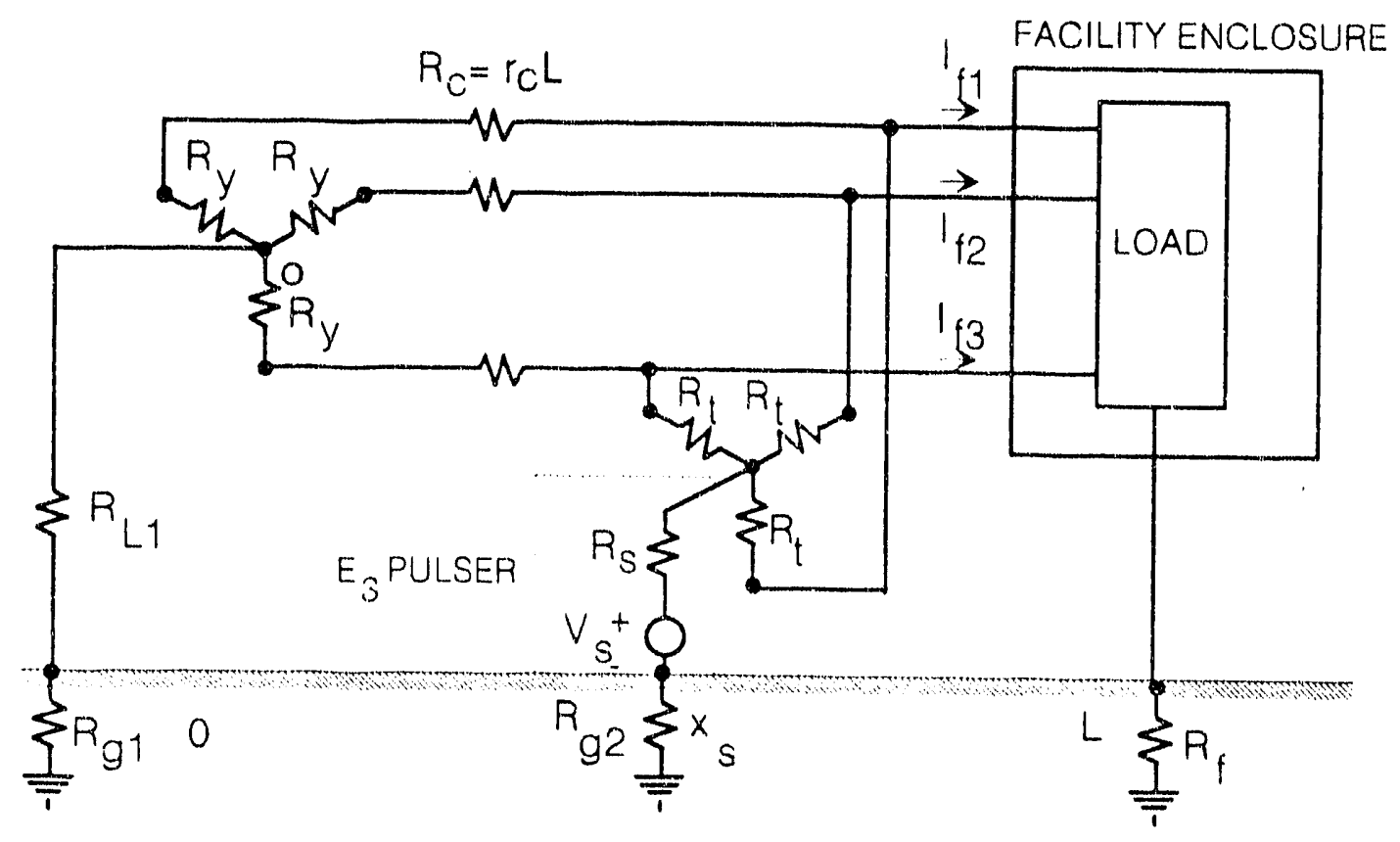

(b)

Fig. A.13. $E_{3}$ simulation of a three-phase line with pulser along the line. (a) Three source configuration, (b) single source configuration. 
Consider first the case of the internal load having an ungrounded delta configuration (Fig. A.14). The neutral line, which has a per-unit-length resistance of $r_{s} \Omega / k m$, is connected to the transformer neutral at the far end of the line, and is connected to earth through the earthing resistance of $R_{\mathrm{L} 1}$. At the facility end of the line the conductor branches into two conductors, one of which is connected to earth through a grounding resistance $R_{f}$, and the other which penetrates into the facility. As in the case of the single conductor, the details of the internal grounding system, and its effective dc load $\left(\mathrm{R}_{\mathrm{L} 2}\right)$ are largely unknown, and this fact is illustrated by the dotted line within the facility.

The MHD-EMP-induced current on the shield wire $\left(I_{S}\right)$ will split at the entrance to the facility, with the major part flowing outside the facility to the ground. This current splitting is controlled by the resistance of the external conductor connecting the overhead shield conductor to the facility grounding element $\left(R_{f}\right)$. This resistance is not pictured in the figure.

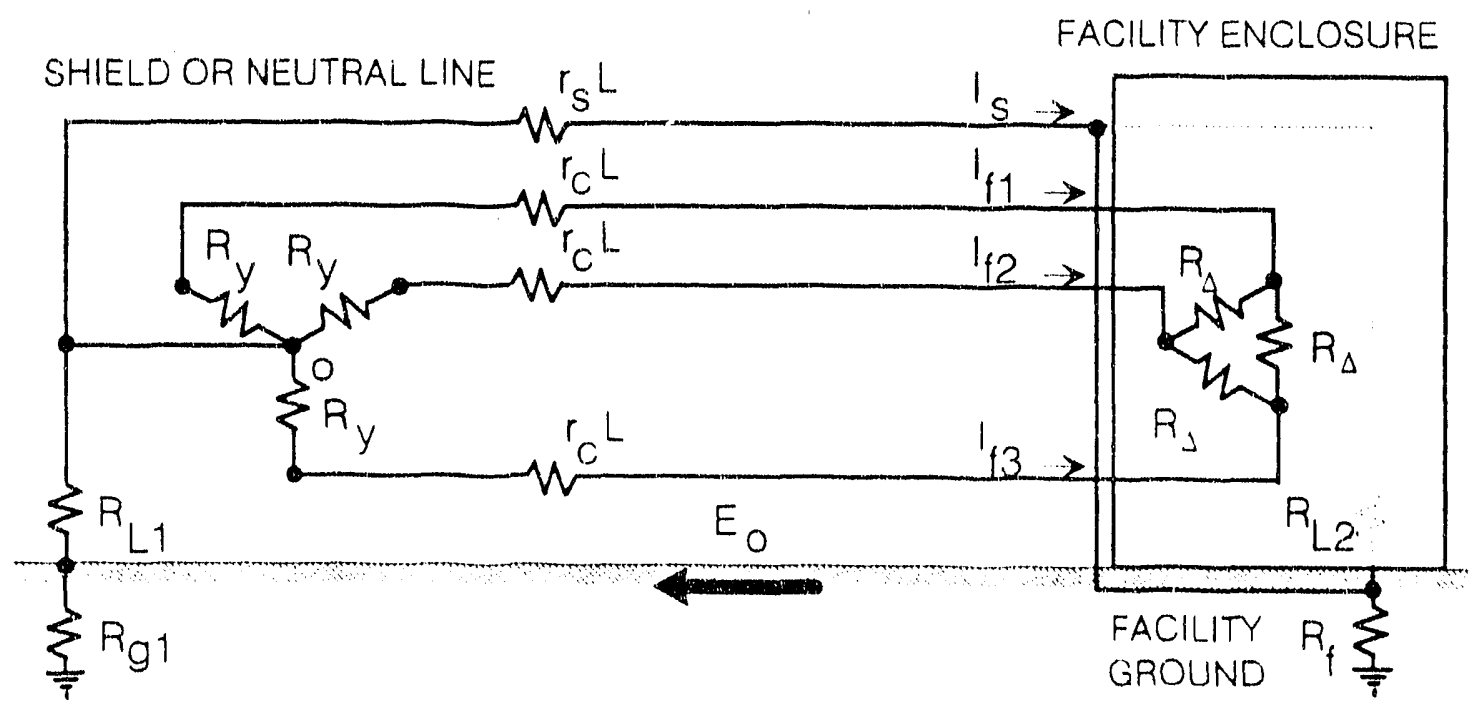

Fig. A.14. Three-phase power line with neutral conductor.

Because of the dc open-circuit on the phase conductors, no MHD-EMP currents will flow into the facility along the power lines; the only current entering the facility will be that fraction split off from the shield line through the internal neutral conductor. Consequently, a possible $E_{3}$ simulation configuration is shown in Fig. A.15a, in which the three-phase conductors are opencircuited, and the external neutral conductor is driven as if it were an isolated, single conductor penetration. In this case, Eqs. (A2a) and (A2b) provide the necessary pulser parameters, with $r_{c}$ being replaced by $r_{s}$. 


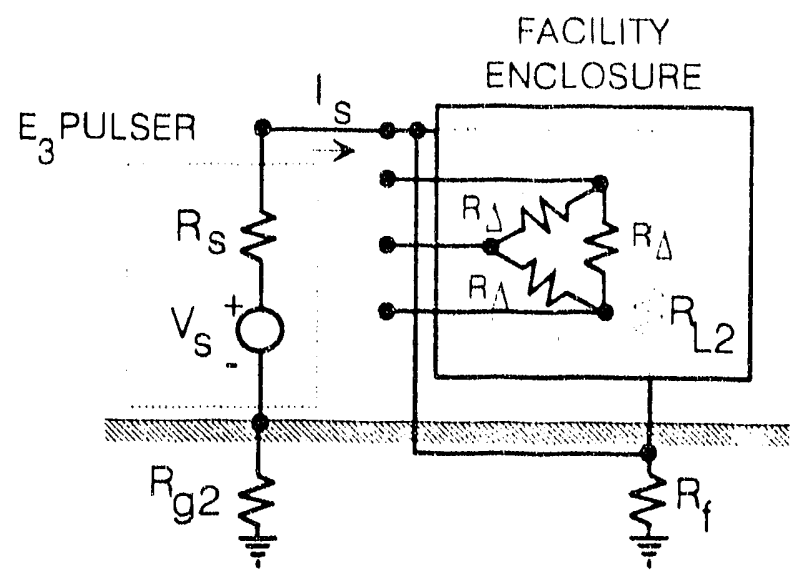

(a)

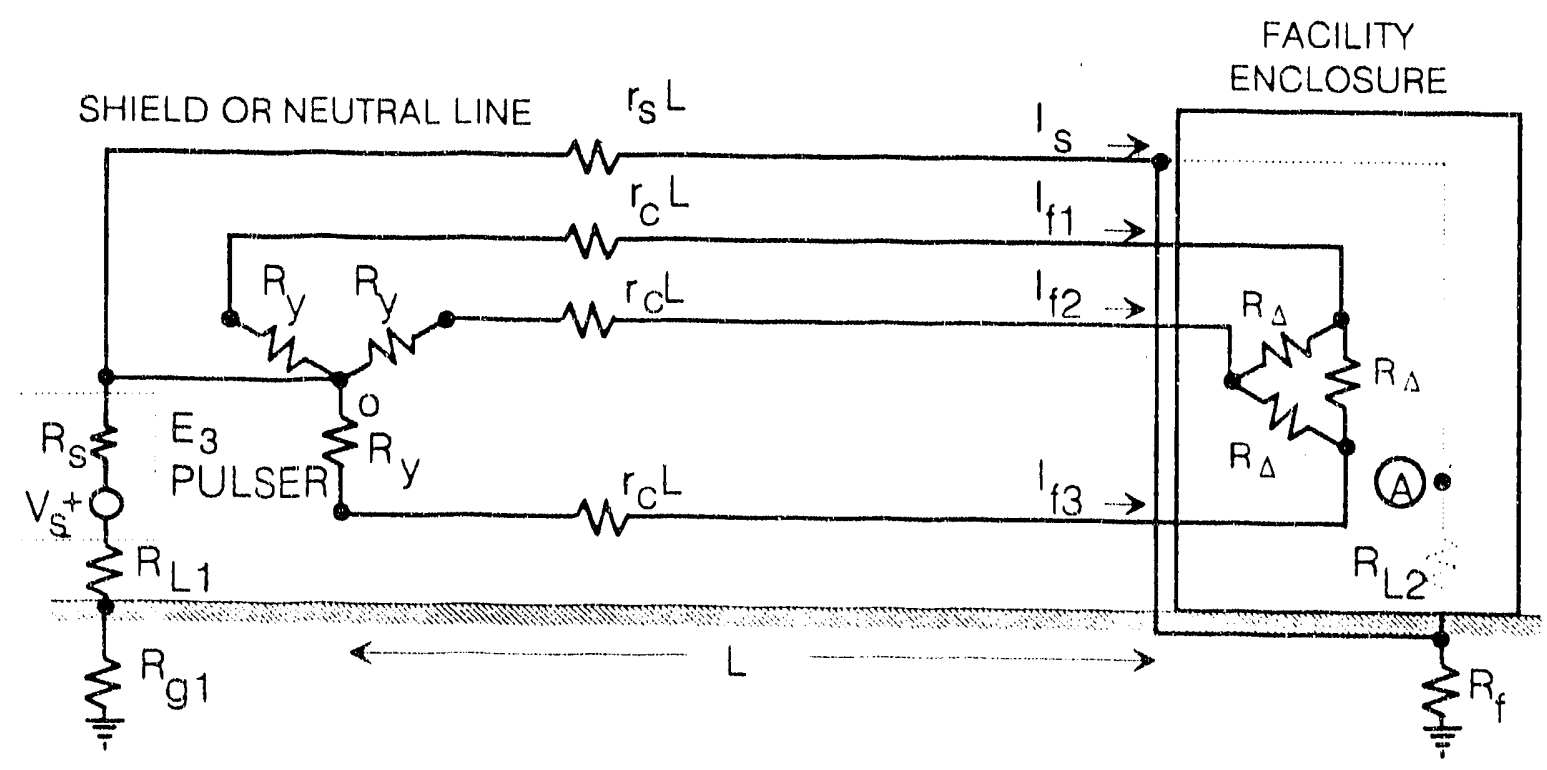

(b)

Fig. A.15. E $E_{3}$ simulation for Fig. A.14. (a) Use of a Thevenin equivalent circuit at the facility, (b) alternate $E_{3}$ simulation at the far end of the line. 
Of course, the simulation scheme in Fig. A.15a does not easily provide for the normal operational power for the facility. Fig. A.15b illustrates a possible the $E_{3}$ simulation configuration for this case. The pulser is located in the neutral earth connection of the transformer secondary at the far end of the line, and has the parameters

$$
V_{s}=E_{0} L
$$

and

$$
R_{\mathrm{s}} \ll\left(R_{L 1}+R_{\mathrm{g} 1}+r_{\mathrm{s}} L\right)
$$

One might be tempted to locate the pulser at point $\mathrm{A}$ within the facility as was done for the simple case of a single conductor penetration. This is not possible, however, due to the presence of the external ground connection.

Fig. A.16a illustrates a facility load having a grounded wye configuration. In this case, the neutral connection is made at the center point of each of the wyes. The MHD-EMP current can flow through the transformer secondary and create $60-\mathrm{Hz}$ harmonics. If the load consists of a three-phase transformer, harmonics can also be generated inside the facility. For the $E_{3}$ simulation, a four conductor Thevenin equivalent circuit, similar to that in Fig. A.11 could be envisioned, although the provision of the normal $60-\mathrm{Hz}$ power and the simulation of the harmonic generation in the source transformer will be difficult to achieve. A more suitable simulation configuration is shown in Fig. 16b, with the $E_{3}$ pulser again located in the ground connection of the source transformer neutral. As in Fig. A.15b, the location A in the facility is not suitable for the pulser.

Note that for this relatively complex interconnection of conductors, only a single pulser is required. As in the previous case, the required pulser voltage is given by Eq.(A15a) and the source resistance must be such that $R_{\mathrm{S}} \ll \mathrm{R}_{\mathrm{L} 1}+\mathrm{R}_{\mathrm{g} 1}$.

Figure. A.17a shows another grounding configuration for the three-phase line. The power circuit and the neutral circuit have different grounding resistances. Because these two circuits are not connected at the far end of the line, two $E_{3}$ pulsers are required for MHD-EMP simulation, as indicated in Fig. A.17b. Equation (A15a) defines the pulser voltage requirements and the pulser source resistances must be small compared with all of the other line and rounding resistances. 


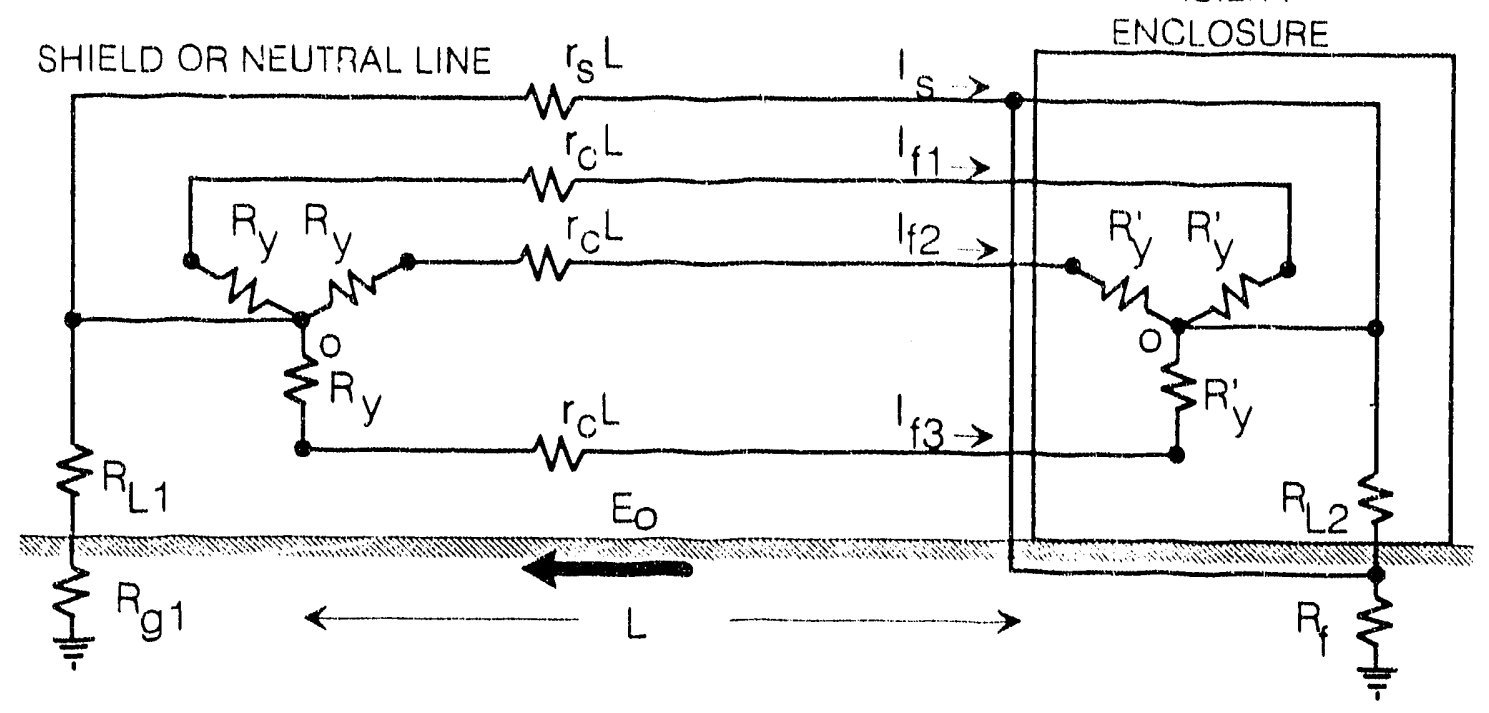

(a)

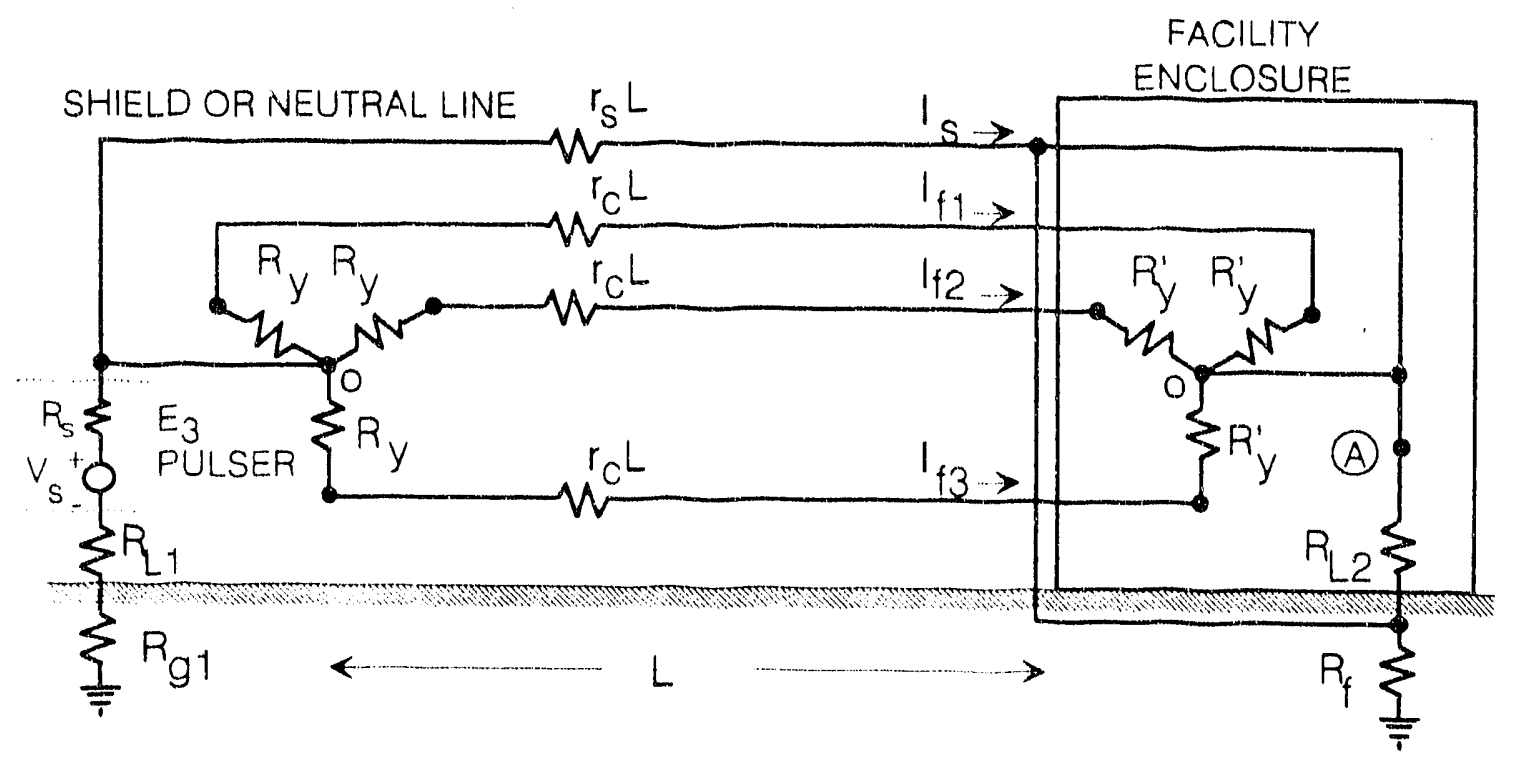

(b)

Fig. A.16. Three-phase line with grounded load and neutral conductor. (a) Physical configuration, (b) $E_{3}$ simulation. 


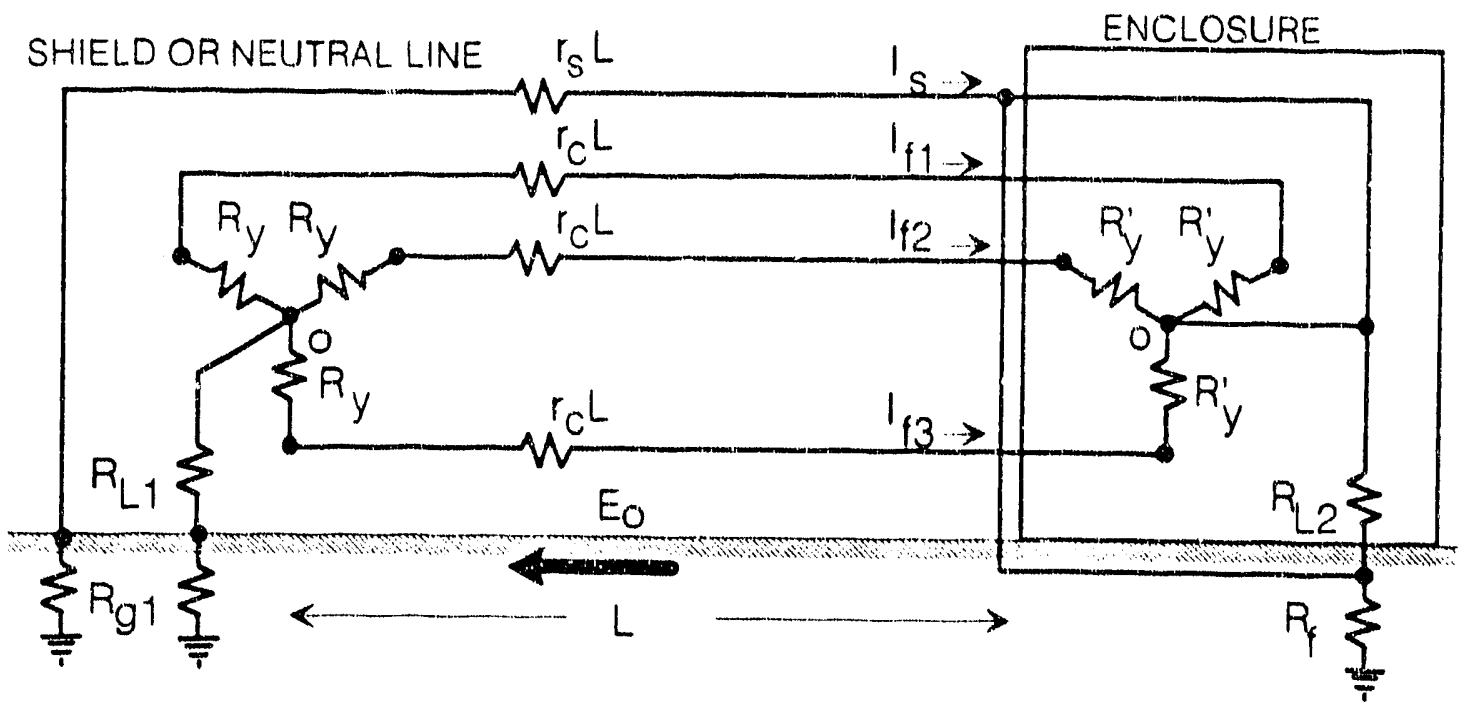

(a)

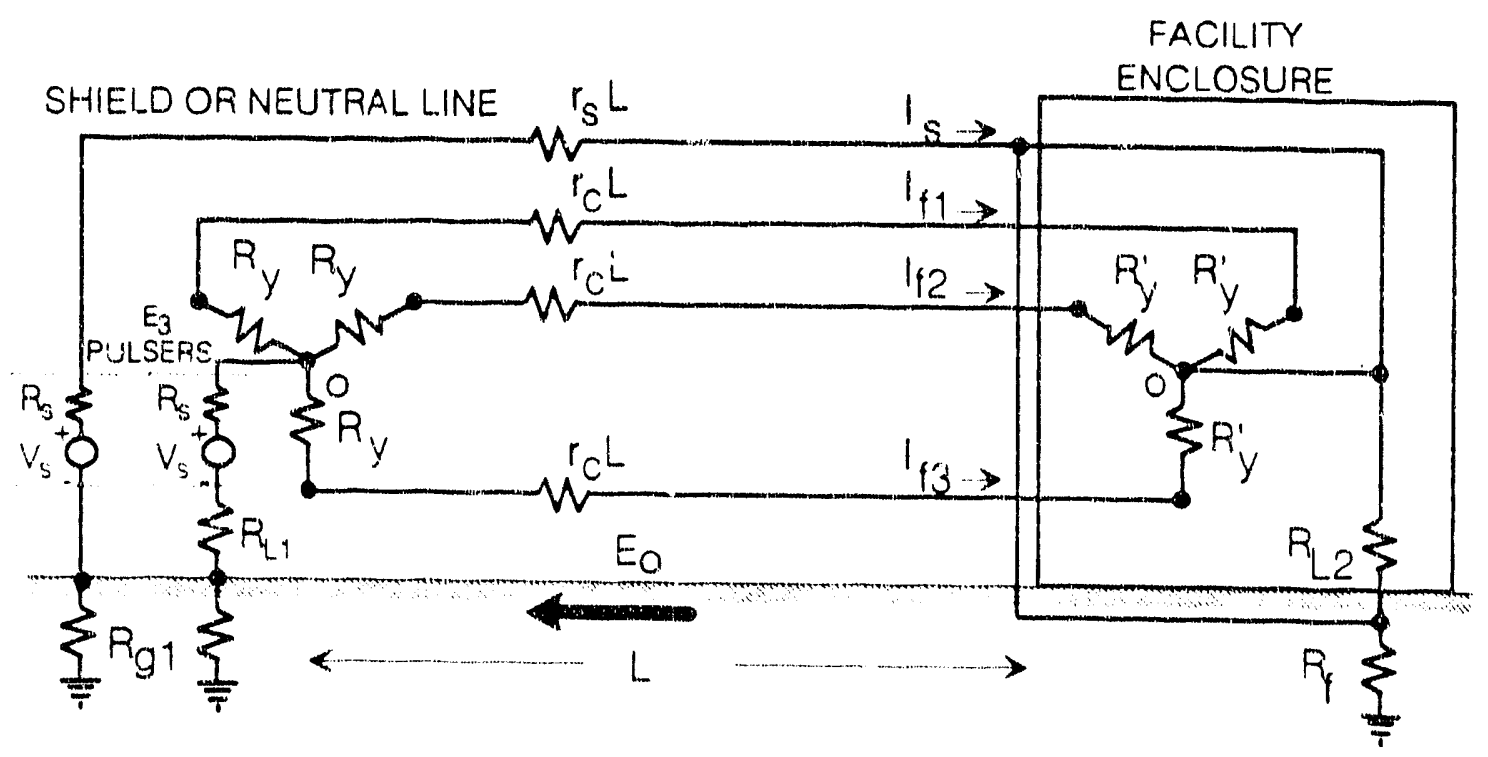

(b)

Fig. A.17. Alternate configuration of three-phase line with grounded load and neutral conductor. (a) Physical configuration, (b) $E_{3}$ simulation. 


\section{A.3.1.3 Three-phase line with periodically grounded neutral}

Another contiguration commonly found in three-phase power lines is shown in Fig. A.18a. In this line, the neutral conductor is supported by periodic towers and is electrically connected to the earth at each tower. The tower footing resistances are denoted by $R_{t}$. In this configuration, the MHD-EMP excitation induces equal quasi-dc currents in each of the phase conductors, with a different current in the neutral. Because of the periodic grounding of the neutral to the earth, it has been noted in ref. A2 that the overall MHD-EMP excitation of the facility is less in this case than it would be if the neutral line were ungrounded.

The $E_{3}$ simulation for this configuration is more complex than in the previous cases. One again could envision locating a generalized four-conductor Thevenin pulser at the facility enclosure in an attempt to simulate exactly all four open-circuit voltages exciting the facility penetrations. This approach, however, is not recommended. In its place, the approximate sinulation shown in Fig. A.18b is possible. In this case, the $E_{3}$ pulser is located in the transformer neutral conductor at the far end of the line or $a^{t}$ the neutral connection of the wye load within the facility. The required open-circuit voltage for the pulser has been calculated in ref. A.2 and is shown in Fig. A.19 in normalized form as a function of the number of tower section $(\mathrm{N})$. These data are shown as a family of different curves for the dimensionless parameter $r_{s} L / R_{t}$, where $r_{s}$ is the per-unit-length resistarice of the neutral conductor. This analysis assumes that the grounding resistances of $R_{g 1}$ and $R_{f}$ are both equal to the tower footing resistance $\left(R_{t}\right)$, and that $R_{L 1}=0$. The value of $R_{L 2}$ is not important in this analysis.

This simulation provides the correct MHD-EMP current flowing in the power phase conductors. Consequently, the transformer and possible load harmonics are generated faithfully. However, the simulation of the neutral currerit $\left(I_{s}\right)$ in not done correctly. If desired, another pulser could be located in series with the neutral conductor, just prior to its branching to enter the facility, to correct the simulation. Its value would need to be adjusted along with that of the original pulser un the transformer neutral to provide correct values for all of the currents. However, the phase conductor currents are the most important in dictating overall system behavior to the $\mathrm{E}_{3}$ environment; and consequently, this two-pulser simulation has not been explored further for this type of facility load. 


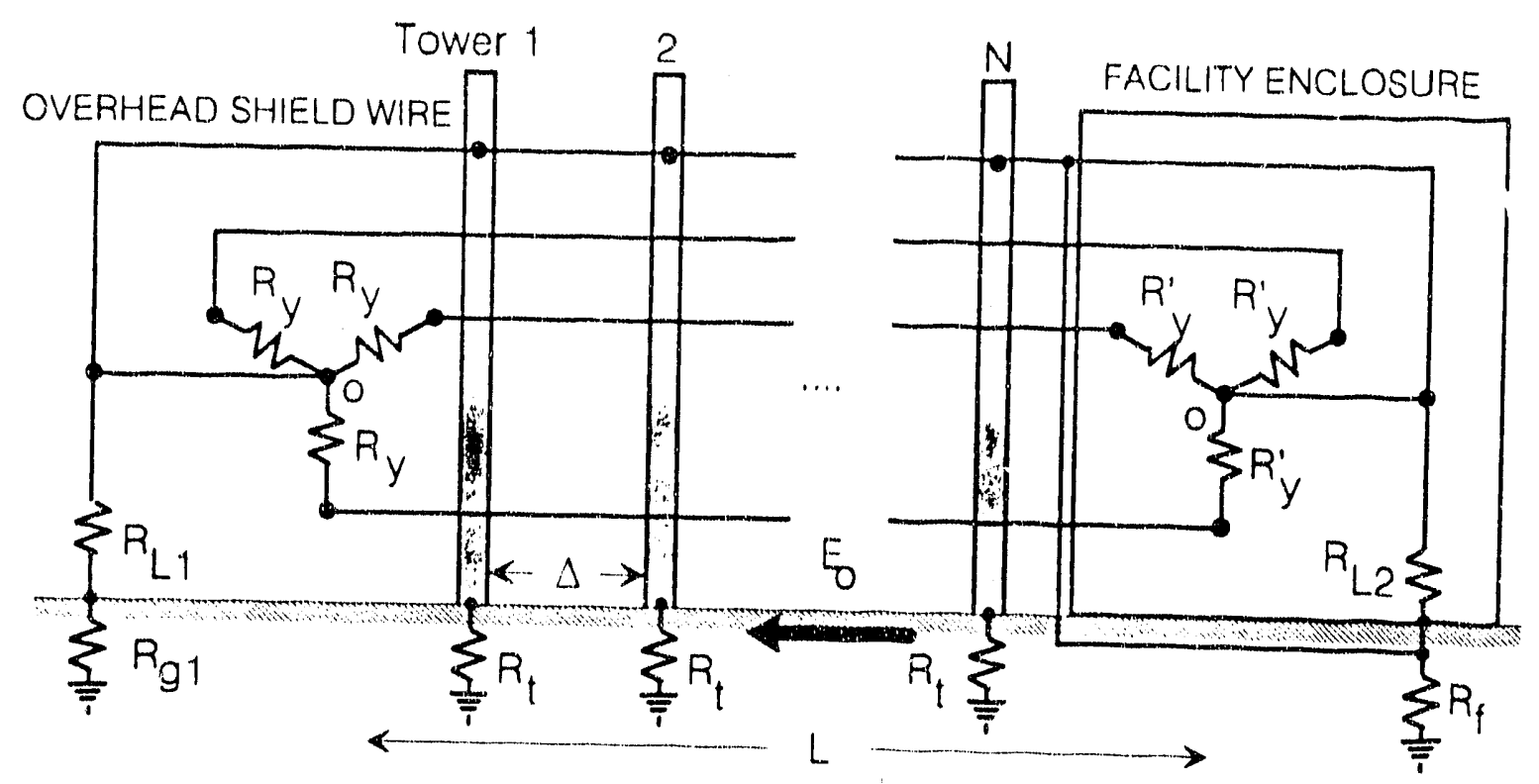

(a)

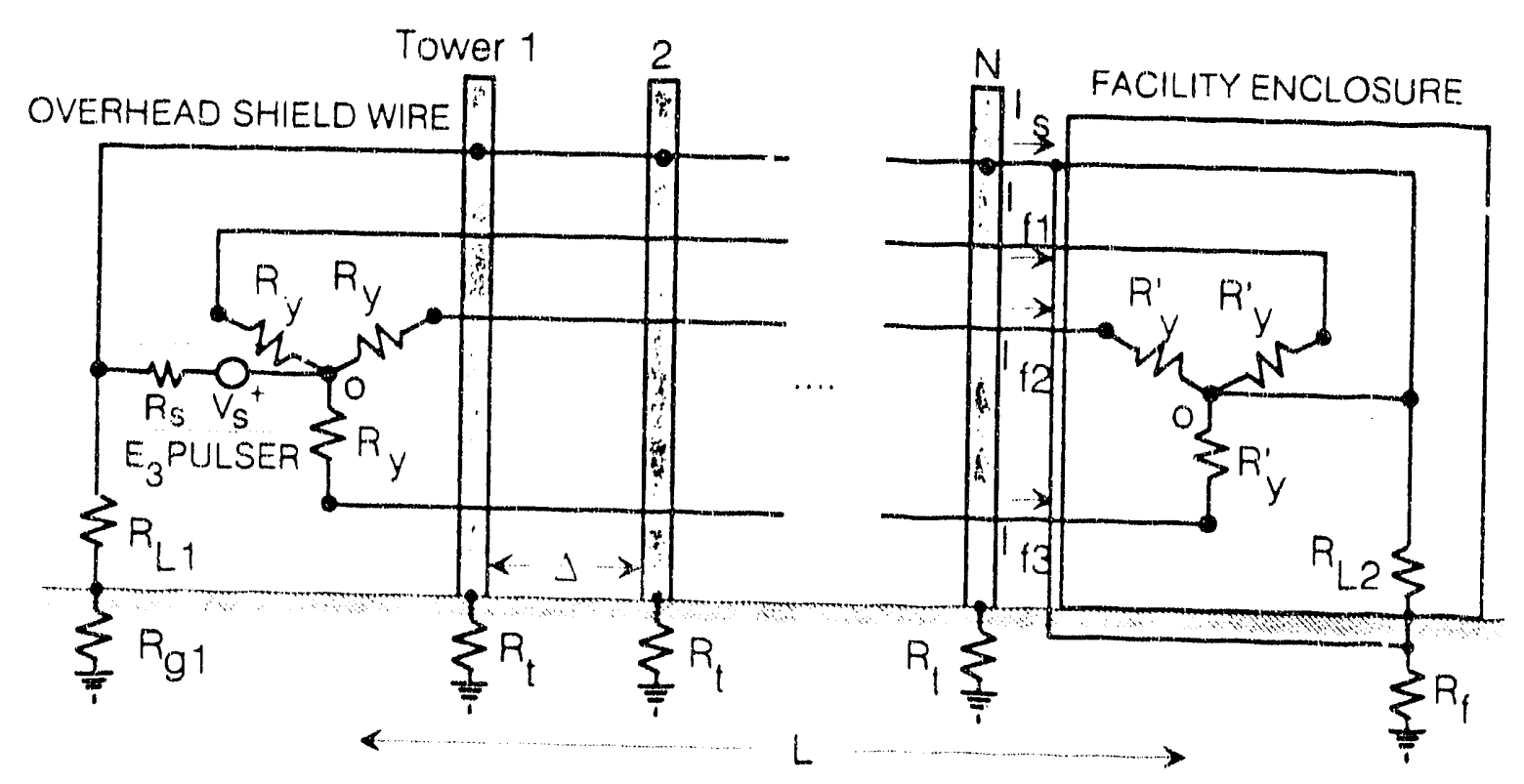

(b)

Fig. A.18. Three-phase power line with periodically-grounded neutral. (a) Physical configuration, (b) $E_{3}$ simulation. 


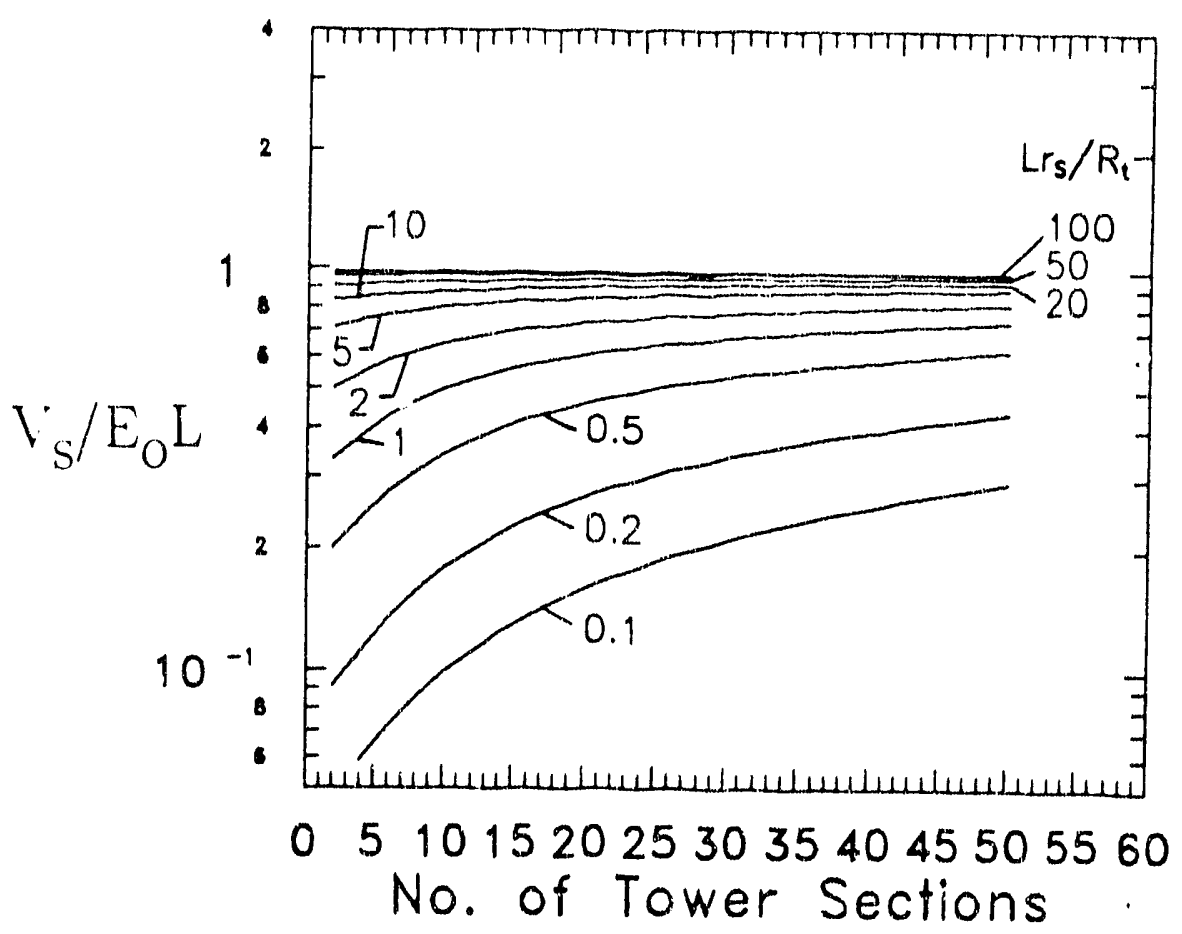

Fig. A. 19. Normalized $E_{3}$ pulser voltage for the simulation configuration in Fig. A.18.

There is, however, a case in which the neutral current entering the facility can be important. Fig. A.20 shows the periodically grounded neutral, three-phase line with an ungrounded delta load configuration at the facility. There will be no $E_{3}$ current flowing on the phase conductors due to the open circuit condition at the line's end, and the only excitation current will be that on the neutral conductor. In this case, the pulser placement shown in the figure is desired, and the proper pulser voltage is given in Fig. A.8. A.ternatively, a pulser on the neutral conductor just prior to its branching at the facility is possible, with its source strength presented in Fig. A.6.

\section{A.3.2 Unbalanced Three-Phase Conductors}

The final line configuration to be discussed here is the unbalanced, three-phase line shown in Fig. A.21. This line consists of the grounded three-phase transformer feeding the line, and the grounded three-phase load within the facility, as treated in previous cases. A neutral conductor is also periodically grounded at the support towers. The neutral connections of the source transformer and the load are connected to the neutral conductor system at points $A$ and $A^{\prime}$, respectively. In addition to these connections, periodic service loads are located randomly along the length of the line between one of the phases and the neutral conductor. These are connected to the grou ded neutral system at points $\mathrm{p} 1, \mathrm{p} 2$, etc. This configuration corresponds to a 
rural power distribution system, and the term "the Farmer Brown configuration" has been coined to describe this situation.

Imbalances in the effective resistive loads will cause corresponding imbalances in the $\mathrm{dc}$ currents entering the facility. This will cause the three-phase power transformer to generate harmonics differently from the balanced line. Furthermore, the dc flowing through the smaller single-phase transformers also may generate harmonics. The detailed simulation of these effects is impossible to do by simply removing the line at the facility and driving it with a Thevenin pulser. The distributed nature of the resistive loads along the line, along with the many potential nonlinear magnetic transformer cores within the system, make the accurate simulation of these effects very difficult. However, it is possible simulate the MHD-EMP response of this system using several properly placed pulsers having suitably tailored voltage relationships.

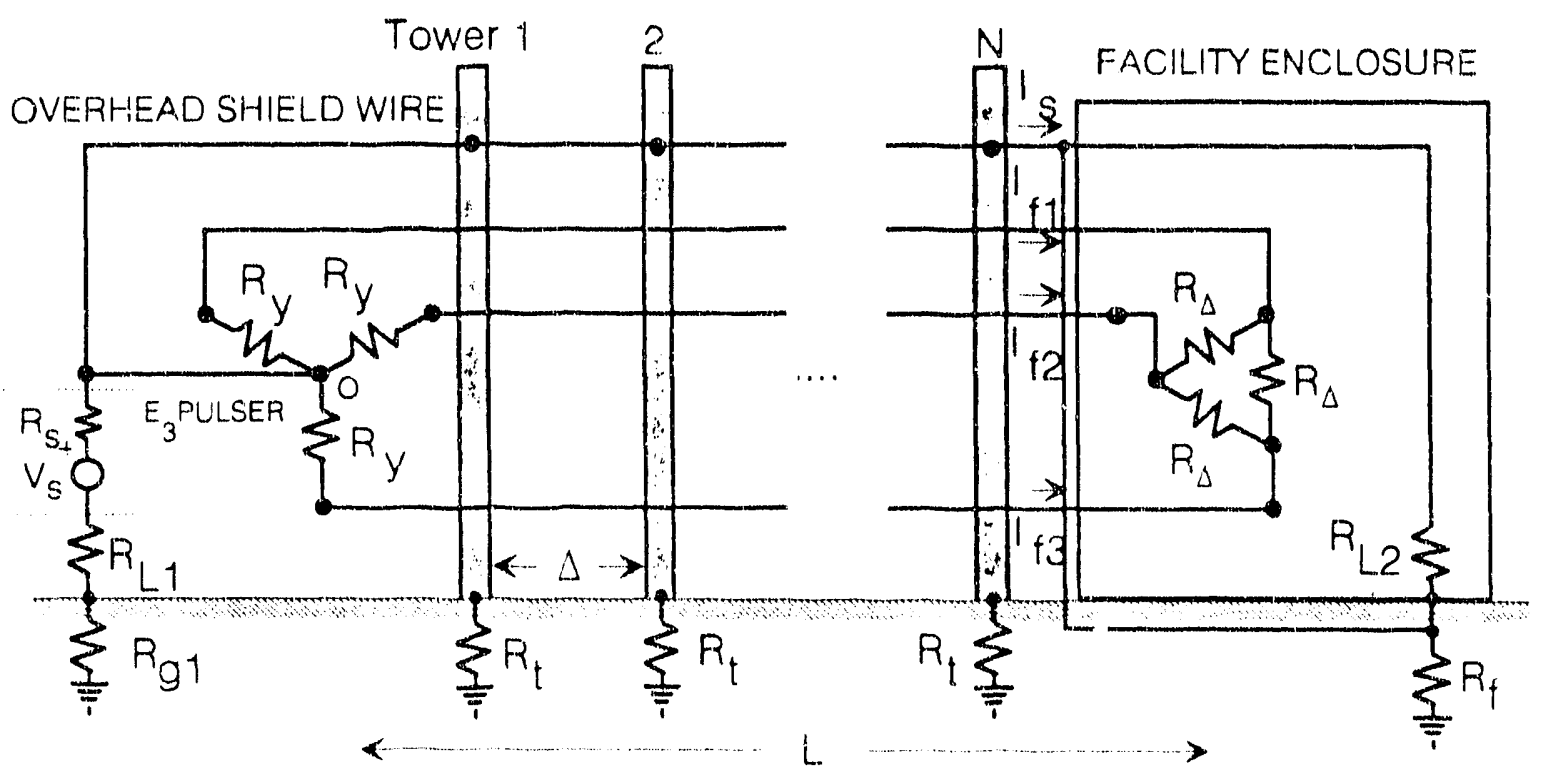

Fig. A.20. Three-phase power line with periodically-grounded neutral and a delta load. 


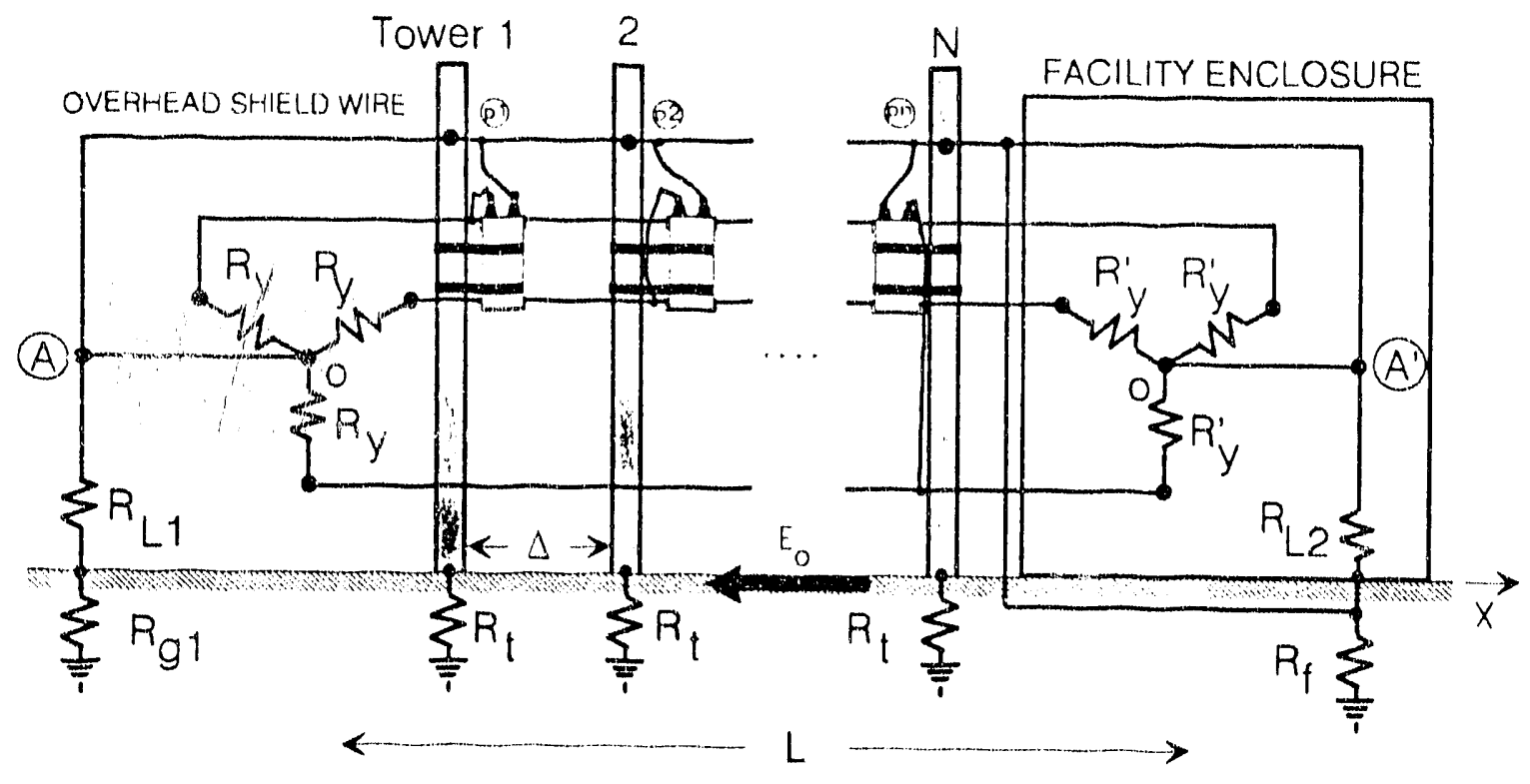

Fig. A.21. Three-phase line with grounded neutral and periodic phase-ground loads.

To illustrate the simulation configuration for this case, the grounded-neutral and tower conductors can be isolated from the three-phase power system conductors, as shown in Fig. A.22a. This is done by cutting all the connections of the grounding system, at points A, p1, p2, $\ldots$ pn, and $A^{\prime}$. At these points, if the grounding circuit is replaced by its generailized Thevenin equivalent, as shown in Fig. A.22b, the resulting behavior of the power system components will be identical to that encountered in the $E_{3}$ excitation. In this figure, the equivalent voltage sources are all calculated relative to the reference conductor at location $A^{\prime}$. Note that all nonlinearities in the system occur in the power system portion of this portioned circuit and the Thevenin-equivalent circuit is completely linear.

The values of the Thevenin voltage sources $\left(V_{s}\right)$ in Fig. A.22b can be determined using the continuously grounded neutral model developed in ref. A2. This neutral line has a per-unitlength resistance of $r_{S} \Omega / \mathrm{km}$, and a per-unit-length conductance due to the towers of

$$
g_{\mathrm{l}}=\frac{\mathrm{N}}{\mathrm{LR}}(\mathrm{mhos} / \mathrm{km})
$$




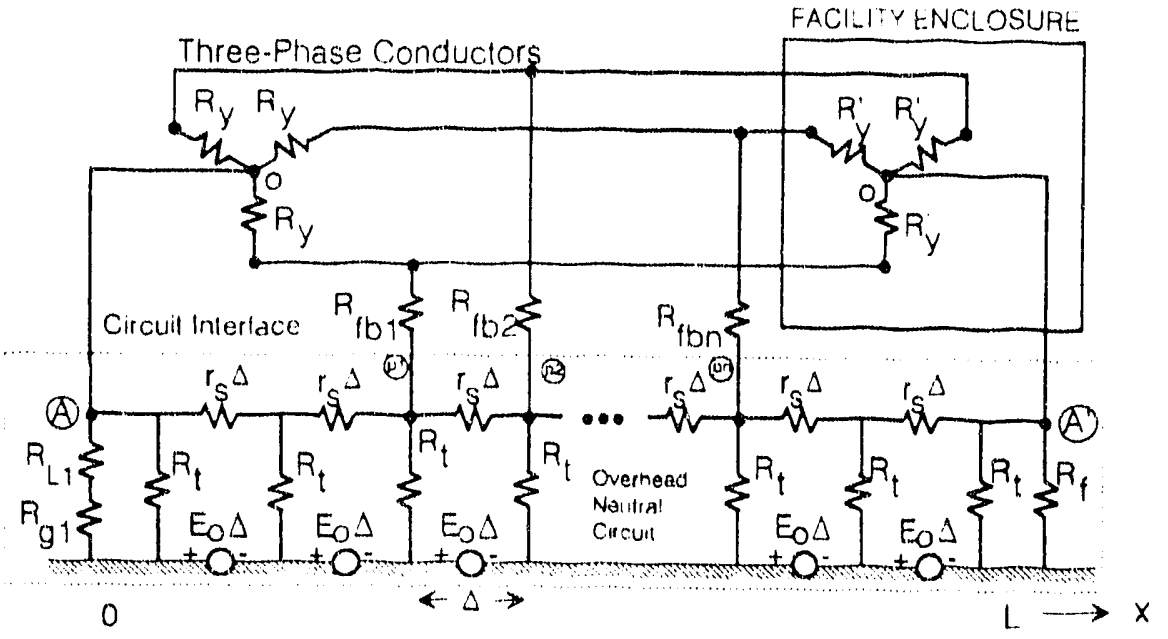

(a)

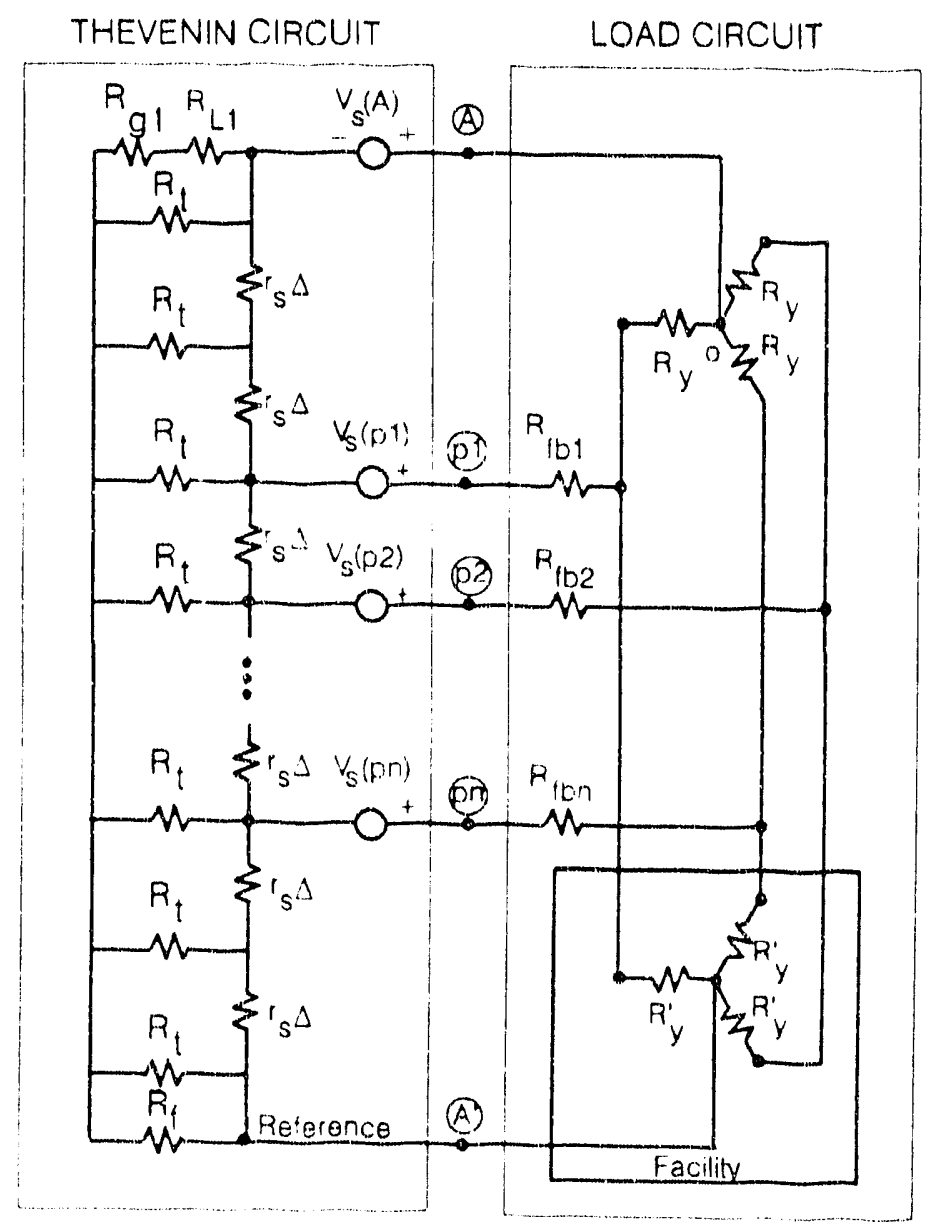

(b)

Fig. A.22. Representation of the three-phase line in Fig. A.21. (a) Separation of the phase and grounded neutral circuits, (b) Thevenin equivalent circuit representation. 
In Eq. (A16), $\mathrm{N}$ is the total number of towers in the line length (L), each of which has a footing resistance of $R_{t} \Omega$. This grounded neutral line is considered to have additional resistances $\left(R_{L 1}\right.$ and $R_{g 1}$ ) at the far end of the line, and $R_{f}$ is the footing resistance of the facility ground. These are all indicated in Fig. A.22a.

The open circuit voltage sources in Fig. A.22b can be thought of as a voltage tapped off of this continuous line model at an arbitrary location $(x)$ with the zero voltage reference being at the $x=L$ end of the line (Fig. A.23). The determination of this voltage proceeds by first determining a solution for the line-earth voltage $\mathrm{V}_{l}(\mathrm{x})$ using the general solutions to the differential equations for the line voltage and current developed in ref. 2, which are similar in form to the telegrapher's equations on a transmission line. In this case, however, there is no propagation of signals along the line, as only a static problem is being considered. Nevertheless, the forms of the solutions to the problems here are similar to those for waves on a transmission line.

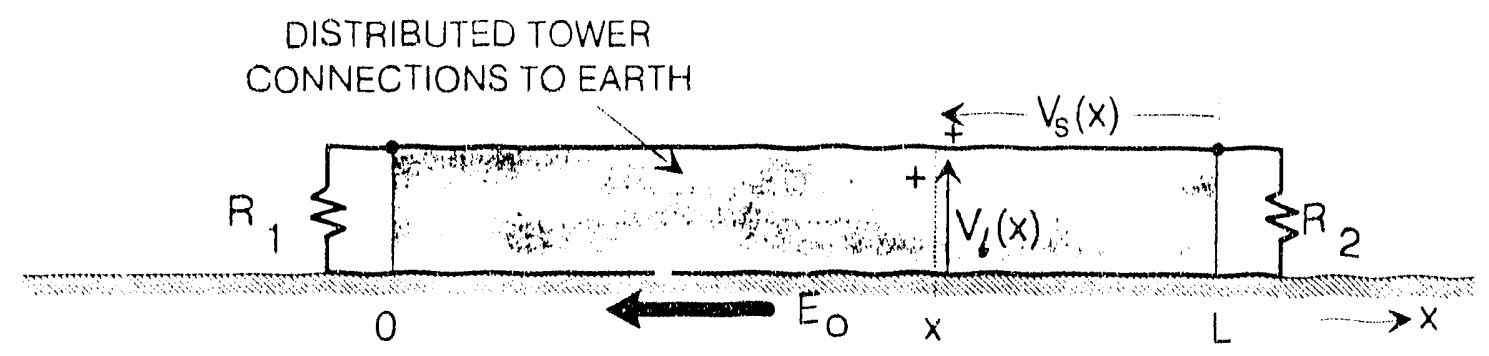

Fig. A.23. Model of the continuously loaded neutral line.

The line representing the grounded neutral circuit has characteristic resistance and attenuation functions ( $\Re$ and $\alpha$ ), given in terms of $r_{S}$ and $g_{t}$ by Eqs. (Alla) and ( $A \mid l b$ ). In an analogy to transmission line theory, a reflection coefficient $\rho$ may be defined as

$$
\rho_{i}=\frac{R_{i}-\Re}{R_{i}+\Re}
$$

where $\mathrm{R}_{\mathrm{i}}$ is the total load resistance, consisting of the sum of the load and grounding resistances, and $i=1$ or 2 , depending on which load resistance is being considered. The line-earth voltage at an arbitrary location induced by the $E_{3}$ electric field may be expressed as 


$$
\begin{gathered}
V_{\ell}(x)=\frac{E_{0} L}{2 \alpha L} \frac{1}{\left(1-\rho_{1} \rho_{2} e^{-2 \alpha L}\right)} \times \\
\left\{\left[\left(1+\rho_{2} e^{-2 \alpha(L-x)}\right)\left(1-\rho_{1} e^{-\alpha x}\right)\left(1-e^{-\alpha x}\right)\right]-\left[\left(1+\rho_{1} e^{-2 \alpha x}\right)\left(1-\rho_{2} e^{-\alpha(L-x)}\right)\left(1-e^{-\alpha(L-x)}\right)\right]\right\}
\end{gathered}
$$

Applying Kirchoff's voltage law for the loop between $x$ and $L$ shown in Fig. A.23, and taking into account the contribution of the earth-induced E-field, the source voltage $V_{s}(x)$ may be expressed as

$$
V_{s}(x)=E_{0}(L-x)+V_{l}(x)-V_{l}(L)
$$

or

$$
V_{s}(x)=\frac{E_{0} L}{\alpha L}\left\{\begin{array}{c}
\alpha(L-x)+\frac{1}{2\left(1-\rho_{1} \rho_{2} e^{-2 \alpha L}\right)} x \\
\left\{\left[\left(1+\rho_{2} e^{-2 \alpha(L-x)}\right)\left(1-\rho_{1} e^{-\alpha x}\right)\left(1-e^{-\alpha x}\right)\right]-\left[\left(1+\rho_{1} e^{-2 \alpha x}\right)\left(1-\rho_{2} e^{-\alpha(L-x)}\right)\left(1-e^{-\alpha(L-x)}\right)\right]\right\}
\end{array}\right\}
$$

With the definition of the voltage sources above, the physical configuration for this simulation is shown in Fig. A.24, where the proper voltage source $\left(V_{s}(x)\right)$ is located in each neutral connection of the individual load transformers, as well as in the neutral of the three-phase transformer. These sources, along with the power system equipment, will produce the proper harmonic responses and other $E_{3}$-induced responses in the system.

For the case of many unbalanced loads on the line, however, this simulation solution may not be practical, due to the requirement that each load be excited. As a result, compromises in the quality of the simulation must be accepted. Fig. A.25 suggests a simple alternative using a single $E_{3}$ pulser in the neutral line of the load within the facility. The voltage source $\left(V_{S}\right)$ should be chosen so that the same quasi-dc current flows through the load neutral as in the case of the $E_{3}$ excitation. Here, the unbalancing effects of the loads are still present, and this will create unbalancing in the dc current flolving along the three phases of the power rircuitry. However, the interaction of these phase-ground loads with the earth-induced E-field is not taken into account. 
Unfortunately, there are so many different parameters in the modeling of this configuration - such as the details of unbalanced load connections, the tower grounding resistances, the line resistances, etc., - that it is impossible to evaluate the errors in the simulation shown in this figure without performing a detailed, site-specific calculation. This may be done by computing the expected responses of currents flowing at selected points in the system and then comparing them to those calculated using the distributed model of Fig. A.22. Part of any $E_{3}$ simulation test program involving this type of unbalanced power system should include pre-test design calculations to assess in detail the errors involved in this simulation concept.

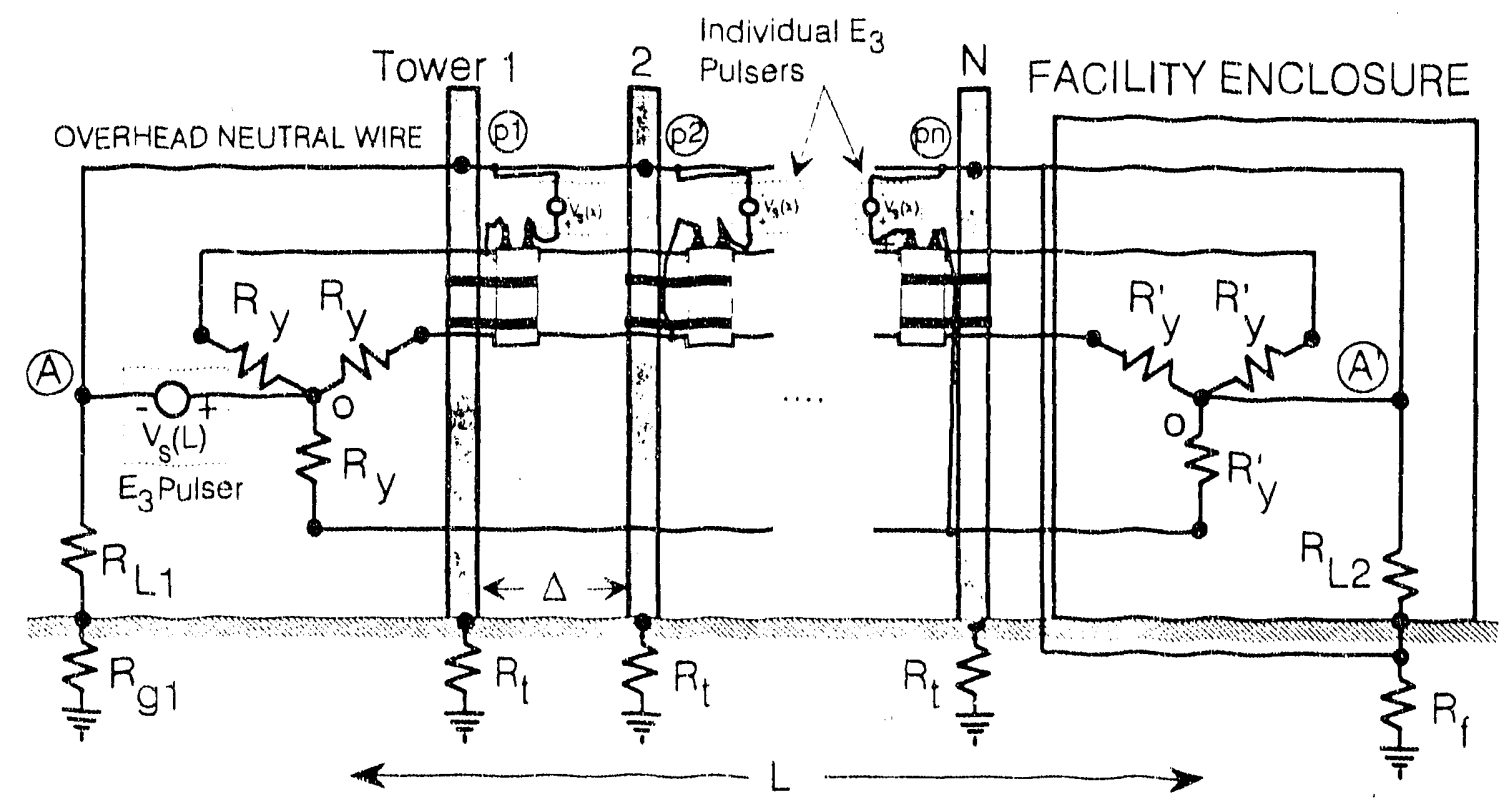

Fig. A.24. Physical configuration for $E_{3}$ simulation on the unbalanced line. 


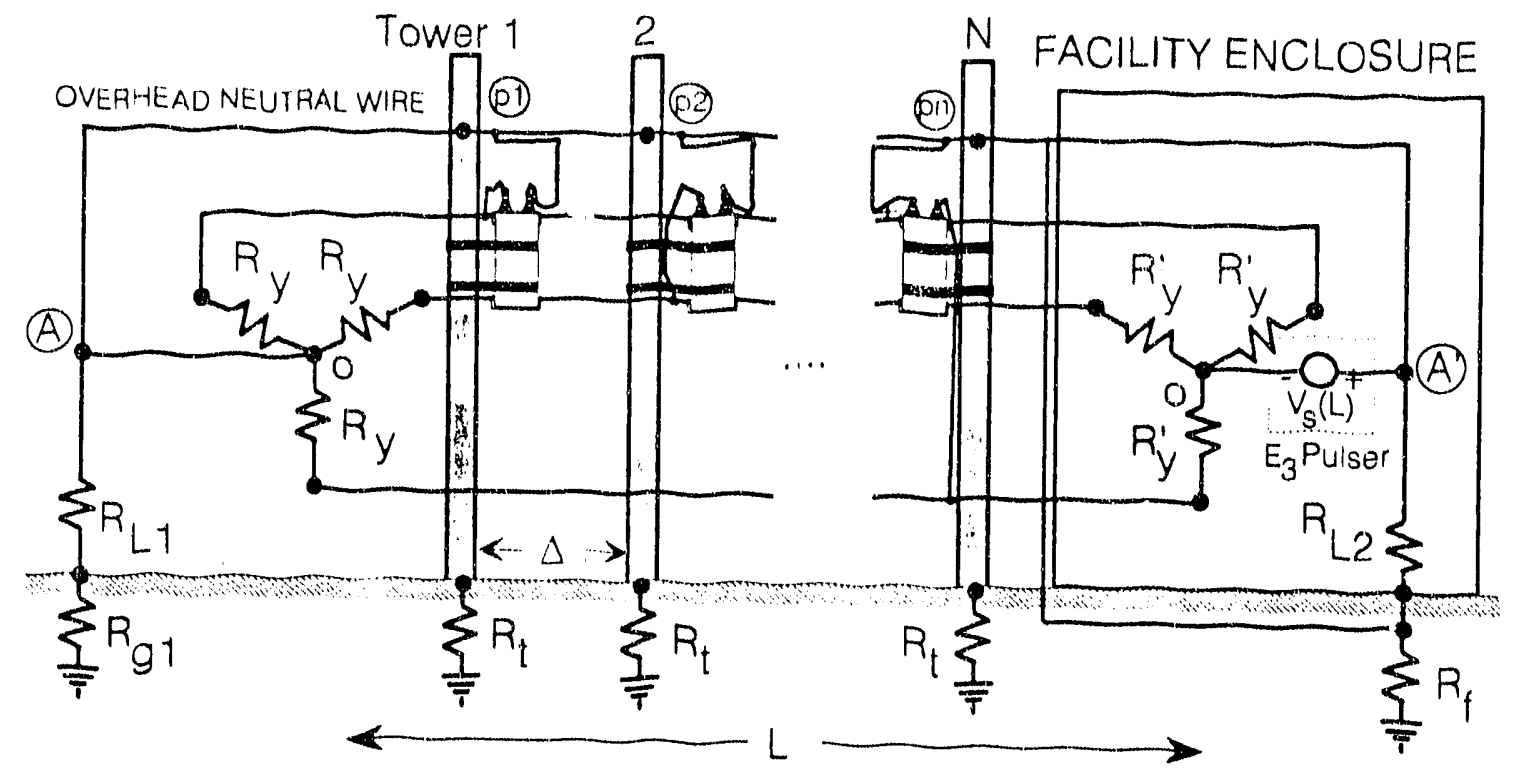

Fig. A.25. Alternate configuration for $E_{3}$ simulation on the unbalanced line.

\section{REFERENCES}

A1. High-Alitude Electromagnetic Pulse (HEMP) Protection for Ground-Based $C^{4}$ Facilities Performing Critical, Time-Urgent Missions, MIL-STD-188-125, U.S. Department of Defense, June 26, 1990.

A2. P.R. Barnes, et. al., MHD-EMP Interaction with Power Transmission and Distribution Systems, ORNL/Sub-90/SG828/1, Martin Marietta Energy Systems, Inc., Oak Ridge Natl.
Lab., February 1992.

A3. W.D. Stevenson, Jr., Elements of Power System Analysis, McGraw-Hill Book Co., New York, 1962. 
ORNL-6709

\section{INTERNAL DISTRIBUTION}

1-10. P. R. Barnes

11. G. E. Courville

12. P. S. Gillis

13. M. A. Kuliasha

14. B. W. McConnell

15. D. T. Rizy

16. R. B. Shelton

17. J. N. Stone
18. T. A. Stone

19. J. P. Stovall

20. ORNL Patent Office

21. Central Research Library

22. Document Reference Section

23-25. Laboratory Records

26. Laboratory Records-RC

\section{EXTERNAL DISTRIBUTION}

\section{ORNL LIST}

27. V. D. Albertson, Dept. of Electrical Engineering, University Of Minnesota, 123 Church Street, S.W., Minneapolis, MN 55455.

28. J. C. Allen, Southwestern Electric Power co., P. O. Box 21106, Shreveport, LA 71156.

29. R. W. Allen, New England Power Service Co., 25 Research Drive, Westboro, MA 01582 .

30. G. Applegren, Main Coordination Center, 1n301 Swift Road, P.O. Box 278, Lombard, Illinois 60148.

31. M. R. Apprill, Engineering \& System Operations, Missouri Public Service, 10700 East 350 Highway, Kansas City, MO 64138.

32. G. H. Baker, HQ DNA/RAEE, 6801 Telegraph Road, Alexandria, VA 22310-3398.

33. P. Balma, Public Service Electric, 80) Park Plaza, Newark, NH 07101.

34. D. L. Bartel, Wisconsin Power \& Light Co., 222 West Washington Ave., P. O. Box 192, Madison, WI 537(01-()192.

35. J. E. Benning, Power System Enginecring/Operations, PSI Energy, 1000) East Main Street, Plainficld, IN 46168.

36. Robert E. Benson, Chief Electrical Engineer, New York State Electric \& Gas Corp., 4500 Vestal Parkway East, Binghamton, NY 13903. 
37. G. D. Birney, Western Area Power Administration, P. O. Box 3402, Golden, CO 80401 .

38. P. D. Blair, Energy and Materials Program, Congress of the United States, Office of Technology Assessment, Washington, DC 20510.

39. Ellery Block, SAIC, 6725 Odyssey, Huntsville, AL 35806-3301.

40. W. T. Boston, Tennessee Valley Authority, 6N 31B Signal Place, 1101 Market Street, Chattanooga, TN 37402-2801.

41. Larry Bressler, Western Area Power Administration, P. O. Box 3402, Golden, C. 80401.

42. B. G. Buchanan, Computer Science Department, University of Pittsburgh, 206 Mineral Industries Building, Pittsburgh, Pennsylvania 15260.

43. W. J. Budney, Distribution Systems, Public Service Electric \& Gas Co., 80 Park Plaza, Newark, NJ 07101.

44. C. K. Bush, Atlanta Electric, P.O. Box 1264, Plcasantville, NJ 08232.

45. R. F. Campbell, Transmission \& Electrical Projects, Tennessee Valley Authority, 3N 53A Missionary Ridge Place, Chattanooga, TN 37402-2801.

46. H. S. Cabayan, Lawrence Livermore National Laboratory, P.O. Box 5504, L-81, Livermore, CA 94550.

47. J. Chadwick, 902 Glamis Circle, Signal Mountain, TN 37377.

48. D. J. Christofersen, Manager, Electrical Engineering Division, United Power Association, P. O. Box 800, Elk River, MN 55330-0800.

49. P. Chrzanowski, Evaluation \& Planning Program, Lawrence Livermore National Lab, P.O. Box 808, L-81, Livermore, CA 94550.

50. R. F. Chu, Research Engineer, Philadelphia Electric Co., Research Division (S10)-1), 2301 Market Strect, Philadelphia, PA 19101.

51. Lynn Coles, Principal Policy Advisor, SERI, 1617 Cole Boulevard, Golden, CO 80401.

52. O. R. Compton, Richmond Plazit, P. O. Box 26666, Richmond, Virginia 23261.

53. T. B. Cook, 80 Castlewood Dr., Pleasanton, CA 94566.

54. G. H. Coplon, U.S. Department Of Energy, Rm. 8F(089, 1000) Independence Avenue, S.W., Washington, DC 20585. 
55. J. J. Cuttica, Research and Development, Gas Research Institute, 8600 W. Bryn Mawr Avenue, Chicago, Illinois 60631.

56. G. Dahlen, Royal Institute of Technology, Tds, P.O. Box 70043, S-10044, Stockholm, Sweden.

57. S. J. Dale, Manager Transmission Technology Institute, ABB Power T\&D Company Inc., Centonnial Campus, 1021 Main Campus Drive, Raleigh, NC.

58. L. W. DeJong, Iowa Public Service Co., P. O. Box 778, Sioux City, IA 51102.

59. A. R. Donnell, Northwestern Public Service Co., 3rd St. \& Dakota Ave., S.E., Huron, SD 57350 .

60. Raymond Dunlop, Director of Research, New England Power Scrvice Co., 2.5 Research Drive, Westborough, MA 01582.

61. H. Elbadaly, Underground T\&D Research Manager, Consolidated Edison Company, 4 Irving Place, New York, NY 10003.

62. D. Fagnan, Philadelphia Electric Co., 2301 Market Street, Philadelphia, PA 19101.

63. W. E. Ferro, Electric Research and Management, Inc., P.O. Box 165, State College, PA 16804.

64. R. Gates, EMP Program Manager, FEMA, RM 606, 500 C Street, S.W., Washington, DC 20472.

65. P. R. Gattens, Allegheny Power, 800 Cabin Hill Dr., Greensburg, PA 15601.

66. M. R. Gent, President, North American Electric Reliability Council, 101 College Road East, Princeton, New Jersey $0854(0-8060$.

67. J. D. Gregory, Southern Company Services, Inc., P. O. Box 2625, Birmingham, AL $35202-2625$.

68. V. Guten, National Security Agency (M-352), Fort Mead, MD 20755.

69. I. Gyuk, Program Manager, U.S. Department of Energy, 1000 Independence Ave., S.W., Washington, DC 20585.

70. Wayne Hilson, Manager, Transmission and Electrical Systems Department, Missionary Ridge, 3 North 41, 1101 Market Street, Chattanooga, TN 37402-2801, .

71. E. R. Holcomb, Texas Utilities Electric Co., 1506 Commerce Street, Dallas, TX 75201. 
72. M. B. Hunter, Puget Sound Power \& Light Co., 13635 N.E. 80th Streer, Redmond, WA $98052-4098$.

73. Joe lannucci, Pacific Gas \& Electric, 3400 Crow Canyon, San Ramon, CA 94583.

74. J. Kappenman, Minnesota Power, 30 W. Superior St., Duluth, Minnesota 55802.

75. S. Kashyap. Defense Research Establishment - Ottawa, Electronics Division, 3701 Carling Ave., Otlawa, Ontario KIA(1Z4, Canada.

76. J. L. King. System Executive Operations, Entergy Corporation, P. O. Box 61005, 225 Baronne St. New Orleans, LA 70161.

77. J. L. Koepfinger, Director, Systems Studies and Research, Duquesne Light Company, One Oxford Center, 301 Grant Street (19-5), Pitusburgh, PA 15279.

78. R. A. Kramer, Northern Indiana Public Service Co., 5265 Hohman Avenue, Hammond, IN 46320.

79. E. Larsen, General Electric, ESDS Bldg. 2, Rm 642, One River Road, Schenectady, NY 12345 .

80. Major Robert Launstein, Defense Nuclear Agency, DNA/RAEE, 6801 Telegraph Rd., Alexandria. VA, 22310.

81. J. L. Layton, Systens Operation, Carroll Electric Membership Corp., 15 j Temple Road, Carrollton. GA 30117.

82. G. R. Leidich, System Planning Engineering Dept., Centerior Energy, 6200) Oak Tree Boulevard, Independene, OH 44131.

83. R. C. Lichentritt, Omaha Public Power District, 444 South 16th Street Mall, Omaha, NE $68102-2247$.

84. R. C. Limatainen. Commiltee on Science, Space and Technology, 374 Razyburn House Oflice Bldg. Rm. B., Washington, DC 20515.

85. J. Lloyd, CEHND-ED-SY, U.S. Army, Enginecring Division Huntsvile, P.O. Box 16(0), Huntsville. AL 35807 .

86. C. L. Longmire, Mission Research Corporation, P.O. Drawer 719. Santa Barbara, CA 9.3102.

87. D. J. Lerden, New England Power Service, 25 Rescarch Drive, Westborough, MA 01582 . 
ORNL- $1 Y 09$

88. David Mayhall, Lawrence Livermore National Laboratory, P.O. Box 808, L-156. Livermore, CA 94550.

89. A. P. Meliopoulos, Georgia Tech, School of Electrical Engineering, Atlanta, GA 303.32 .

90. S. R. Mendoza, Salt River Project, P.O. Box 52025, Phoenix, AZ 85072-2025.

91. N. V. Mesland, Tot Keuring Van Elektrotechnische, Materialen, 6800 ET Arnhem. P.O. Box 9035. The Netherlands.

92. Walter E. Myers, R\&D Manager. Bonneville Power Administration, P. O. Box 3621 , Portland, OR 97208.

93. D. L. Nickel, Manager, ABB Power Systems, Inc, 777 Penn Center Blvd., Pittsburgh, PA 15235-5927.

94. S. Nilsson, Program Manager, Electric Power Research Institute, Electrical Systems Division, 3412 Hillview Avenue, P.O. Box 10412, Palo Alto, CA 94303.

95. B. M. Pasternack, American Electric Power Service Corp., 1 Riverside Plaza, P.O. Box 16631, Columbus, OH 43216-6631.

96. J. Z. Ponder, PJM Interconnection, 955 Jefferson Ave., Norristown, PA 19426.

97. J. W. Porter, Electric Power Research Institute, Suite 100, 1019 Nineteenth St. N.W., Washingen, DC 20036.

98. M. Rabinowitz, Electric Power Research Institute, 3412 Hillview Avenue, P.O. Box 10412, Palo Alto, CA 94303.

49. J. J. Ray, Division of Syst. Planning, BPA, P.O. Box 3621, Portland, OR 97208.

100. T. W. Reddock. Electrotek Concepts, Inc., 10305 Dutchtown Rd., Suite 103, Knoxville, TN 379.32.

101. J. R. Rempel, Physicist, Defense Intelligence Agency, Washington, DC 2034()-6761.

102. H. I. Robidoux, Metropolitan Edison Company, 2800 Pottsville Pike, P. O. Box 16001, Reading, PA 19640-0001.

103. Dictrich J. Rocsler, U.S. Department of Energy, CE-141, 1000 Independence Avenue SW. Washingion, DC 20585.

104. F. Rosa. Division of System Intg. Nuclear Regulatory Commission, MS P1030, Washington, DC 20555. 
205. V. G. Rose, Pacific Gas \& Electric Co., 123 Mission Street, San Francisco, CA 94106.

106. C. H. Rish, Construction Department, Philadelphia Electric Co., 2301 Market St. (S25-1), Philadelphia, PA 19101.

107. J. E. Scalf, Florida Power \& Light Company, P. O. Box 14000, 700 Universe Blvd., Juno Beach, FL 3.3408.

108. Virgil Schafer, Engineering Division Manager, Tri-State Generation and Trans. Assoc., 12076 Grant Street, Denver, CO 80233.

109. W. G. Schiffmacher, Long Island Lighting Company, Office of Engineering \& Constr., 1660 Walt Whitman Road, Melville, NY 11747.

110. W. J. Scott, Hq DNA/RAEE, 6801 Telegraph Road, Alexandria, VA 22310-3398.

111. Joe Sefcik, Nuclear Design, Lawrence Livermore National Lab, P.O. Box 808, L-22, Livermore, CA 94550.

112. C. H. Shih, Manager, Electrical Research, American Electric Power Service Corp., 1 Riverside Plaza, Columbus, OH 43215.

113. M. L. Sloan, Austin Research Associate, 1101 Capital of Texas Highway S., Building B. Suite 210, Austın, TX 78746.

114. R. B. Spence. Bonneville Power Administration, P.O. Box \#3621 - MOEA, Portland, OR 97208.

115. G. I. Stillman, Research \& Development, New York Power Authority, 1633 Broadway, New York. NY 10019.

116. P. Sullivan, Philadelphia Electric Co., 2301 Market Street (S10-1), Philadelphia, PA 19101.

117. R. L. Taylor, Director - Power Supply, Florida Power \& Light Co., 9250 W. Flagler, Miami, FL 33102.

118. L. L. Taylor, Northern States Power Company, 414 Nicollet Mall, Minneapolis, MN 55401.

119. E. R. Taylor, ABB Power Systems, Inc. , 777 Penn Center Blvd., Pittsburgh, PA $15235-5927$.

120. A. N. Terreri, Electrical Operations, Green Mountain Power Corp., P. O. Box 850, South Burlington, VT 05402.

121. F. M. Tesche, Consulting Scientist, 6921 Spanky Branch Dr., Dallas, TX 75248. 
ORNL-6709

122. M. V. Thaden, Potomac Electric Power Co., 1900 Pennsylvania Ave., NW, R.m. 311 , Washirigton, DC 20068.

123. G. F. Thompson, Northeast Utilities Service Co., P. O. Box 270, Hartford, CT 061410270 .

124. J. Towle, 3906 Bagley Ave. N., Suite 100, Seattle, WA 98103.

125. E. F. Vance, 6885 HWY 1187, Fort Worth, TX 76140.

126. D. R. Volzka, Senior Project Engineer, Wisconsin Electric Power Company, 333 West Everctt Sireet, Milwaukee, WI 53201.

127. Jan Wagers, Power Systems Planning, City of Colorado Springs, Department of Utilities, 30 South Nevado, Colorado Springs, CO 80903.

128. C. L. Wagner, 4933 Simmons Dr., Export, PA 15632.

129. R. Walling, General Electric Company, Building 2, Rm 507, One River Road, Schenectady, NY 12345.

130. R. C. Webb, Defense Nuclear Agency, RAEE, 6801 Telegraph Road, Alexandria, VA 22310 .

131. L. B. Wideman, Houston Lighting \& Power Co., P. O. Box 1700, Houston, TX 77001.

132. E. P. Wigner, Consultant, 8 Ober Road, Princeton, NJ 08540.

133. M. W. Wik, Forsvarets Materielverk, Stockholm, S-11588, Sweden.

134. D. Woodford, Suite 400, 1619 Pembina Ave., Winnipeg, Manitoba, R-3T-2G5, Canada.

135. S. E. Wright, Electric Power Research Institute, 3412 Hillview Ave., P.D. Box 10412, Palo Alto, CA 94303.

136. F. S. Young. Director, Electrical Systems Division, Electric Power Research Institute, P.O. Box 10412, Palo Allo, CA 94303.

137. R. M. Youngs, Seattle City Light. 1015 Third Avenue, Seattle, WA 98104.

138. R. W. Zwickl, Space Environment Laboratory, Moil Stop R/E/SE, Boulder, CO 800303.

139. J. A. Zychinski, Union Electric Company, P. O. Box 149, M/C (6)1, st. Louis, MO 63166

140. Olfice of Assistant Manager for Energy, Research and Development, DOE-ORO, P.O. Box 2001. 
141-152. OSTI, U.S. Department of Energy, P.O. Box 62, Oak Ridge, TN 37831.

\section{DNA LIST}

153. Air Force Space Command. Headquarters, DEES/D C DE MIO, Petırsor AFB, CO $80914-5001$.

154. Atomic Energy, The Penatogon, Assistant to the Secretary of Defense, Executive Assistant, Washington, DC 20301-3050.

155. BDM International Inc., Library, P.O. Box 9274, Albuquerque International, Albuquerque, NM 87119.

156. BDM International Inc., E. Dorchak, 7915 Jones Branch Drive, McLean, VA 221023396 .

157. Booz-Allen \& Hamilton, Inc., Technical Library, 4330 East West Highway, Bethesda, MD 20814-4455.

158. Central Intelligence Agency, OSWR/STD/MTB, Washington, DC 20505.

159. Central Intelligence Agency, OSWR/NED, Washington, DC 20505.

160. Defense Communications Engineer Center, Code R410, 1860 Wiehle Avenue, Reston, VA $22(199)-5285$.

161. Defense Intelligenc: Agency, Director, RTS-2B, Washington, DC 20340.

162. Defense Intelligence Agency, Director, VP-TPO, Washington, DC 20340.

163. Defense Nuclear Agency, RAEV, 6801 Telegraph Road, Alexandria, VA 22310.

164-173. Delense Nuclear Agency, RAEE, 6801 Telegraph Road, Alexandria, VA 22310.

174-175. Defense Nuclear Agency, TITL, 6801 Telegraph Road, Alexandria, VA 22310.

176. Defense Nuclear Agency, RAAE, 6801 Telegraph Road, Alexaridria, VA 22310.

177. Defense Research Establishment Otlawa, S. Kashyap, Ottawa, Ontario, Canada K1AIIZ4.

178. Defense Technical Information Center. DTIC/FDAB, Cameron Station, Alexandria, VA $223(14-6145$. 
ORNL-6709

179. Department of the Navy, Command \& Control Programs, OP 941, Washington, DC 20350 .

180. Department of Commerce, NOAA/MASC Security Office, MC43, G. Reeve, 325 Broadway, Boulder, $\mathrm{CO} 80303$.

181. Department of Commerce, NOAA/MASC Security Office, MC43, W. Utlaut, 325 Broadway, Boulder, CO 80303 .

182. Department of Commerce, NOAA/MASC Security Office, MC43, D. Peach, 325 Broadway, Boulder, CO 80303.

183. Department of the Air Force, Air Foree CTR For Studies \& Analysis, AFCSA/SAMI (R. Griffin), Washington, DC 20330-5420.

184. E-Systems, Inc., ECI Division, Mail Stop 3, Tech Info CTR, P.O. Box 12248, St. Petersburg, FL 33733.

185. EG\&G Special Projects Inc., J. Giles, Albuquerque Operations, 2450 Alamo Avenue, SE, Albuquerque, NM 87106.

186. Electro-Magnetic Applications, Inc., D. Merewether, P.O. Box 8482, Albuquerque, NM 87198-8482.

187. General Research Corp., W. Naumann, P.O. Box 6770, Santa Barbara, CA 931606770 .

188. Harry Diamond Laboratories, Director, SLCHD-NW'TN (G MERKEL), 2800 Powder Mill Road, Adelphi, MD 20783-1197.

189. Harry Diamond Laboratorias, Director, SLCHD-NW-EP (21100), 2800) Powder Mill Road, Adelphi, MD 20783-1197.

190. Harry Diamond Laboratories, Director, W. Patterson, 2800 Powder Mill Road, Adelphi, MD 20783-1197.

191. Harry Diamond Laboratories, Director, SLCIS-IM-TL (81100), 2800) Powder Mill Road, Adelphi, MD 20783-1197.

192. IIT Research Instilute. I. Mindel, 10 W. 35th Street, Chicago, IL 60616-370)3.

193. Institute for Defense Analyses, Tech Info Services, 1801 N. Beauregard Street, Alexandria, VA 22311-1772.

194. Jaycor, R. Poll, P.O. Box 1577, Santa Monica, CA 904()6-1577.

195. Jaycor, E. Wenaas, P.O. Box 85154. San Diego, CA 92186-5154. 
196. Jaycor, M. Schultz, Jr., 1608 Spring Hill Road, Vienna, VA 22182-2270.

197. Joint Strategic Target Planning Staff. The Joint Staff, JLWT (Threat Analysis), Offutt $\mathrm{AFB}, \mathrm{NE} 68113-50001$.

198. Joint Strategic Target Planning Staff, The Joint Staff, JKC (DNA REP), Offutt AFB, NE 68113-50001.

199. Kaman Sciences Corporation, DASIAC, Santa Barbara Operations, P.O. Box 1479 , Santa Barbara, CA 93102-1479.

200. Kaman Sciences Corp., Library/B. Kinslow, P.O. Box 7463, Colorado Springs, CO 80933-746.3.

201. Kaman Sciences Corp., Washington Operations Division, DASIAC, 2560 Huntington Ave., Suite 200, Alexandria, VA 22303.

202. Kamana Sciences Corporation, Technical Library, Dikewood Division, 6400) Uptown Blvd., N.E. Suite 300E, Albuquerque, NM 87110.

203. Metatech Corporation, W. Radasky, P.O. Box 1450, Goleta, CA 93116-1450.

204. Mission Research Corp., J. Lubell, 4935 North 30th Strect, Colorado Springs, CO $80919-4199$.

205. Mission Research Corp., A. Chodorow, 1720 Randolph Rd., SE, Albuquerque, NM $87106-4245$.

206. Mission Research Corp., Tech Info Center, P.O. Drawer 719, Santa Barbara, CA 9.3102-(0719.

207. National Security Agency, Director, R-54, Fort George G Meade, MD 20755-6000).

208. Naval Research Laboratory, Commanding Officer, Code 2627 (TECH LIB), Washington, DC 20375-50)(\%).

209. Office of the Sec of Defense. Dircetor, Document Control, Net Assessment, Room 3A930, The Pentagon, Washington, DC 20301.

210. Office Secretrary Delense, U S Nuclear Command \& Central Sys Support Staft, SAB H Sequine, Pentagon, Room 3E 172, Washington, DC 2(0301-3040.

211. Pacilic-Sierra Research Corp.. H. Brode, 12340 Santa Monica Blvd, Los Angeles, CA 90)(125-2587.

212. R \& D Associates, Document Control, P.O. Box 92500). Los Angcies, CA 900099. 
ORNL-6709

213. R \& D Associates, J P Castillo, P.O. Box 9377, Albuquerque, NM 87119-9377.

214. Rockwell International Corp., G. Smith, P.O. Box 3105, Anaheim, CA 92803-3105.

215. S-Cubed, J. Knighten, A Division of Maxwell Laabs, Inc., P.O. Box 1620, La Jolla, CA. 92038-1620.

216. Science \& Engrg Associates, Inc., Robert L. Charters, P.O. Box 3348, Seattle, WA 98009-3348.

217. Science Applications Intl. Corp., P.J. Dowling, 2860 S Circle Dr., St. 2400, Colorado Springs, CO 80906.

218. Science Applications Intl. Corp., W. Chadsey, P.O. Box 1303, McLean, VA 22102 1303 .

219. Space \& Naval Warfare Systems CMD, Commander, Technical Library, Department of the Navy, Washington, DC 20363-0001.

220. SRI International, J. Prewitt, 333 Ravenswood Ave., Menlo Park, CA 94025-3434.

221. Strategic Air Command/XRFS, Headquarter, XRFS, Department of the Air Force, Offutt AFB, NE 68113-5001.

222. The Joint Staff, J-3/Nuc. Operations Br., Strat. Operations Br., Washington, DC 20318 .

223. The Joint Staff, C3S (ER) Analysis Div, Washington, DC 20318.

224. The Joint Staff, J-6F D Butts, Washington, DC 20318.

225. TRW Inc., DH4/2461, G.E. Morgan, TRW Space \& Defense, One Space Park, Redondo Beach, CA 90278-1071.

226. U S Army Engineer Div Huntsville, Division Engineer, CEHND-SY J LOYD, P.O. Box 1600, West Station, Huntsville, AL 35807-4301.

227. U S Army Strategic Defense Command, CSSD-SL, P.O. Box 1500, Huntsville, AL 35807.

228. U S Army Nuclear \& Chemical Agency, Commander, MONA-NU (D. Bash), 7500) Backlick Rd., Bldg. 2073, Springfield, VA 22150-3198.

229. Under Secretary of Defense, Director, Strai \& Theater NUC Forces, The Pentagon, RM 3E 129, Strat \& Theater NUC Forces (O\&SS), Washington, DC 20301-3090). 
230. USA Survivability Management Office, Director, SLCSM-SE J BRAND, 2800 Powder Mill Road, Adelphi, MD 20783-1145.

231. USAF/LEEEU, HQ, LEEE, Washington, DC 203.30.

232. Weapons Laboratory, NTN, Kirtland AFB, NM 87117-6008.

233. Weapons Laboratory, NTAA, Kirtland AFB, NM 87117-6008.

234. Weapons Laboratory, WL SUL, Kirtland AFB, NM 87117-60108. 

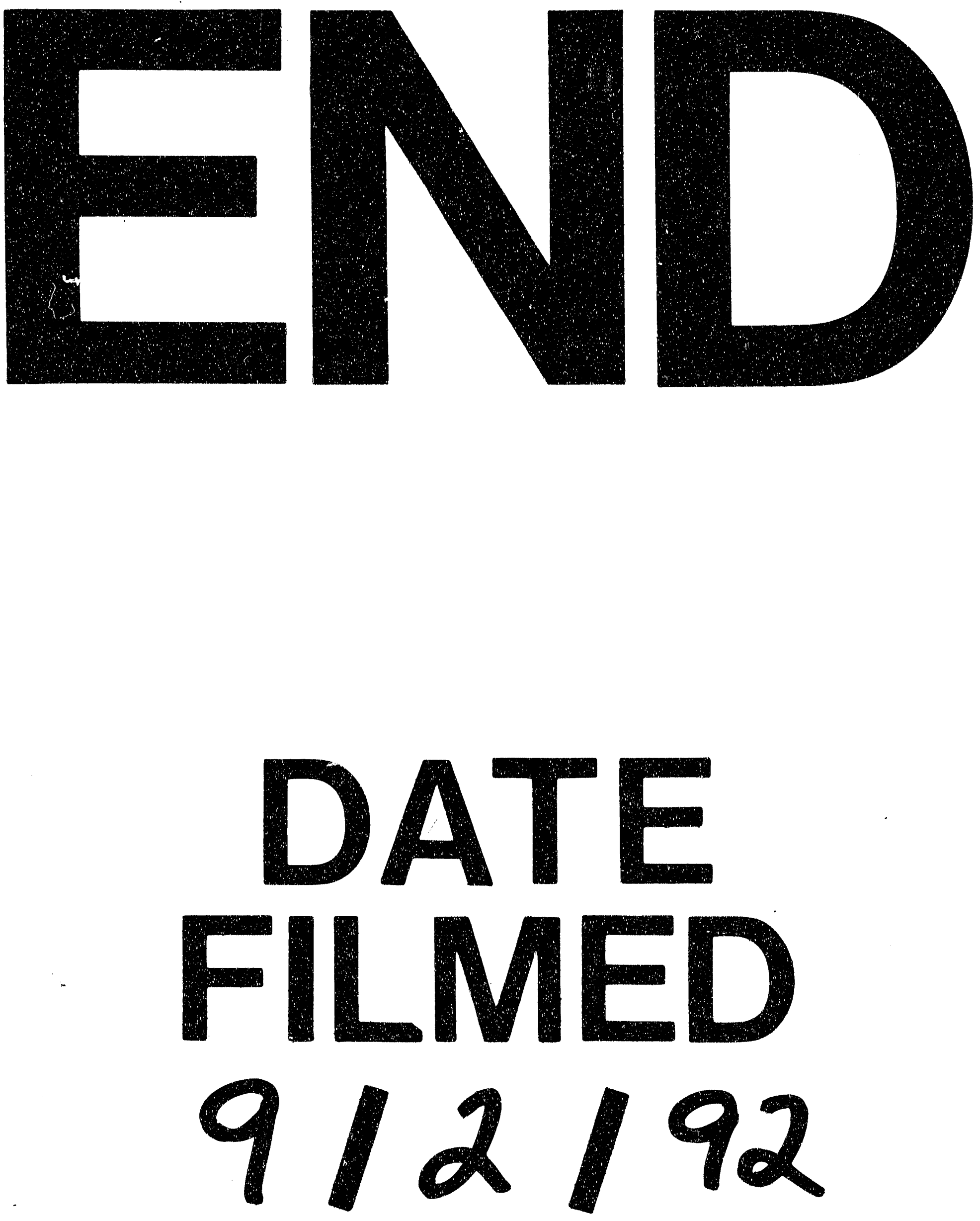
